OPEN ACCESS

Edited by:

Yu-Chih Lin,

Hussman Institute for Autism, United States

Reviewed by: Mark H. Lewis,

University of Florida, United States Christina Gross,

Cincinnati Children's Hospital Medical Center, United States

*Correspondence: Tanya Gandhi tgandh1@lsu.edu

Specialty section:

This article was submitted to Cellular Neuropathology, a section of the journal Frontiers in Cellular Neuroscience

Received: 07 August 2020 Accepted: 09 December 2020 Published: 14 January 2021

Citation: Gandhi T and Lee CC (2021) Neural Mechanisms Underlying Repetitive Behaviors in Rodent Models of

Autism Spectrum Disorders. Front. Cell. Neurosci. 14:592710. doi: 10.3389/fncel.2020.592710

\section{Neural Mechanisms Underlying Repetitive Behaviors in Rodent Models of Autism Spectrum Disorders}

\author{
Tanya Gandhi* and Charles C. Lee \\ Department of Comparative Biomedical Sciences, Louisiana State University School of Veterinary Medicine, Baton Rouge, \\ LA, United States
}

Autism spectrum disorder (ASD) is comprised of several conditions characterized by alterations in social interaction, communication, and repetitive behaviors. Genetic and environmental factors contribute to the heterogeneous development of ASD behaviors. Several rodent models display ASD-like phenotypes, including repetitive behaviors. In this review article, we discuss the potential neural mechanisms involved in repetitive behaviors in rodent models of ASD and related neuropsychiatric disorders. We review signaling pathways, neural circuits, and anatomical alterations in rodent models that display robust stereotypic behaviors. Understanding the mechanisms and circuit alterations underlying repetitive behaviors in rodent models of ASD will inform translational research and provide useful insight into therapeutic strategies for the treatment of repetitive behaviors in ASD and other neuropsychiatric disorders.

Keywords: autism models, repetitive behavior, neural mechanisms, signaling, circuitry, neuroanatomical alterations

\section{INTRODUCTION}

Autism spectrum disorder (ASD) consists of a group of neurodevelopmental disorders with shared, yet heterogeneous, behaviors. With the introduction of improved diagnostic criteria, there has been a substantial rise in the prevalence of autistic cases in the last few decades, reported between three and six children per 1,000 worldwide (Kassim and Mohamed, 2019; Lord et al., 2020) and 1 in 54 children in the US (Zablotsky et al., 2019; Maenner et al., 2020). The variability in global prevalence is largely due to differences in methodological assessment and environmental and/or geographical factors (Chiarotti and Venerosi, 2020; Lord et al., 2020). Both genetic and environmental factors influence the development of ASD and may converge on similar neural outcomes, such as altered connectivity, excitation/inhibition imbalance, and signaling system alterations (Muhle et al., 2004; Satterstrom et al., 2020). Several candidate genes have been associated with the development of ASD (Levitt and Campbell, 2009; Yuen et al., 2017; Feliciano et al., 2019; Grove et al., 2019; Guo et al., 2019); siblings born in families with ASD are particularly high risk indicating a strong genetic basis (Stubbs et al., 2016). Environmental factors involved in the development of ASD include prenatal and postnatal complications, viral infections and nutrient deficiencies (Grabrucker, 2013; Sealey et al., 2016; Karimi et al., 2017; Modabbernia et al., 2017). Understanding these environmental and genetic interactions in autism risk will help guide treatment strategies for ASD (Chaste and Leboyer, 2012; LaSalle, 2013; Tordjman et al., 2014; Kim and Leventhal, 2015; Nardone and Elliott, 2016). 
Children with ASD are characterized by social and communication challenges and restricted, repetitive behaviors (Baranek, 1999; Lord et al., 2000). These core behaviors are often accompanied by comorbidities such as epilepsy, anxiety, hyperactivity, and aggression (Richler et al., 2007; King et al., 2009). The restricted, repetitive behaviors (RRBs) in ASD are clustered into two categories. The repetitive behaviors include stereotypic motor movements, repetitive use of objects, self-injurious behaviors, and the circumscribed behaviors include compulsions, desire for sameness, rituals, and restricted interests (Zandt et al., 2007; Whitehouse and Lewis, 2015). The restricted, repetitive behaviors in ASD share similarities with obsessivecompulsive disorder (OCD) and other neuropsychiatric and neurodevelopmental disorders (Scahill and Challa, 2016; Jiujias et al., 2017; Gulisano et al., 2020). Currently, behavioral and pharmacological interventions target specific symptoms and/or associated comorbidities, which are personalized according to individual needs (Eissa et al., 2018; Chahin et al., 2020). Yet, more robust therapeutic interventions have been required that target the underlying neural mechanisms that govern these core autistic symptoms.

Behavioral approaches are typically used to treat repetitive behaviors in ASD and related neurodevelopmental disorders. Behavioral approaches usually employ reinforcement procedures, altering the environment, and promoting variability and flexibility in behavior (Boyd et al., 2012). Pharmacological interventions for irritability and some forms of repetitive behavior, such as self-injurious behavior include selective serotonin reuptake inhibitors (SSRIs) like Fluoxetine and antipsychotics such as haloperidol (typical) and Risperidone (atypical) (Gencer et al., 2008; Miral et al., 2008; Malone and Waheed, 2009; Doyle and McDougle, 2012; DeFilippis and Wagner, 2016; Masi et al., 2017; Maneeton et al., 2018). Risperidone is a second-generation antipsychotic medication that has been FDA approved for the treatment of irritability in children and adolescents (McDougle et al., 2005, 2008; Scahill et al., 2007, 2012; Aman et al., 2009). It is an antagonist at the serotonin 2A and dopamine D2 receptors and is useful in alleviating irritability, aggression, and self-injurious behavior in young ASD subjects (McCracken et al., 2002; Shea et al., 2004; Chavez et al., 2006; Kent et al., 2013; Fung et al., 2016; Maneeton et al., 2018). Besides, in controlled clinical trials, some of these pharmacological medications also reduce repetitive behaviors, but with potential side-effects that limit the widespread usage of these drugs in the treatment of ASD and as such is not approved by the FDA for repetitive disorders (McPheeters et al., 2011; Sharma and Shaw, 2012; Whitehouse and Lewis, 2015). Additionally, the benefits of pharmacological medications in improving ASD behavior are highly variable across studies and clinical populations. There is also a paucity of long-term clinical trials with a large sample size on pharmacological interventions against restricted/repetitive behavior in ASD (Yu et al., 2020; Zhou et al., 2020). Furthermore, there is a lack of evidencebased treatment strategies targeting diverse repetitive/restricted behaviors in ASD. Hence, novel treatment strategies are required that target core autistic deficits, while limiting the detrimental side effects of such medications. In this review article, we have discussed preclinical studies demonstrating the efficacy of the pharmacological treatments on restricted/repetitive behaviors, which are still under development for targeting repetitive/restricted behaviors in a clinical population. Besides, we have also reviewed studies pointing in the direction of circuitbased strategies for targeting repetitive/restricted behaviors in rodent models of ASD.

As an approach to developing new therapeutics, several rodent models of ASD have been generated with good construct validity that recapitulates many of the behavioral phenotypes observed in autistic individuals. The behavioral tasks assessing repetitive behaviors are more developed than behavioral tasks assaying resistance to change or restricted behaviors (Lewis et al., 2007). The studies we will review mainly discuss rodent models primarily displaying lower-order stereotyped motor behaviors, which are generally better characterized and easier to model than models of insistence on sameness or restricted behaviors (higher-order). Nevertheless, in this review article, we have also discussed a few rodent models that show both the repetitive and restricted behavioral phenotypes. The repetitive behaviors observed in rodent models of autism are complex and diverse, including self-grooming, jumping, circling, marble burying, hanging, rearing, and forelimb movements and involve several molecular and neural pathways (Whitehouse and Lewis, 2015; Kim et al., 2016). Also, complex restricted behaviors such as resistance to change and narrow interests represent cognitive rigidity to routines and obsessions that correspond with executive function deficits (Lopez et al., 2005). Behavioral assays for resistance to change or cognitive inflexibility in rodents include response extinction, reversal learning, and set-shifting tasks, assessing the inability to change the developed spatial habit (Colacicco et al., 2002; Roullet and Crawley, 2011). Understanding of the complex neural mechanisms underlying repetitive behaviors in these models is expected to boost translational research and provide valuable insight into potential treatments for repetitive behaviors observed in ASD. Therefore, in this review article, we will discuss the underlying mechanisms that mediate the complex motor activities and consequent repetitive behavioral repertoire in different rodent models of ASD.

\section{RODENT MODELS OF AUTISM: GENETIC MUTATIONS, ENVIRONMENTAL RISK FACTORS, AND SOME INBRED STRAINS DISPLAYING REPETITIVE/RESTRICTED BEHAVIORS}

Genetic mutations account for a significant proportion of ASD risk (Ronemus et al., 2014). Genetic mutations in ASD are complex and diverse depending on structure type [i.e., large-scale chromosome abnormalities, small scale insertions, deletions, substitutions, copy number variation $(\mathrm{CNV})$ and single nucleotide variation $(\mathrm{SNV})]$, inheritance type [i.e., germline, somatic, de novo mutation (non-inherited)], frequencies (i.e., common, rare and very rare) and protein sequence affected (i.e., frameshift 
mutation, point substitution (De Rubeis and Buxbaum, 2015; De La Torre-Ubieta et al., 2016; Ramaswami and Geschwind, 2018). Over the last decade, with the advancement of sequencing technology, many genes have been implicated in autism pathogenesis (Geschwind and State, 2015). This review covers many of the most common of these factors, which underscores the range of molecular and cellular factors implicated in ASD. Such diversity of neurobiological factors in ASD further highlights the challenges of treatment development, where seemingly divergent neural factors may converge on similar behavioral outcomes, i.e., restrictive and repetitive behaviors. When possible, we have attempted to highlight some of these similarities and differences in risk factors (Figure 1), which remains a major challenge for the field to define and address.

Many genes are linked to syndromic ASD, in which monogenic syndromes exhibit phenotypic overlap with ASDs (i.e., ASD is secondary to a known genetic cause and disorder with clinically defined presentation) (Walsh et al., 2008; Schaefer and Mendelsohn, 2013; Ramaswami and Geschwind, 2018). Monogenic disorders accounted for in ASD include Fragile X

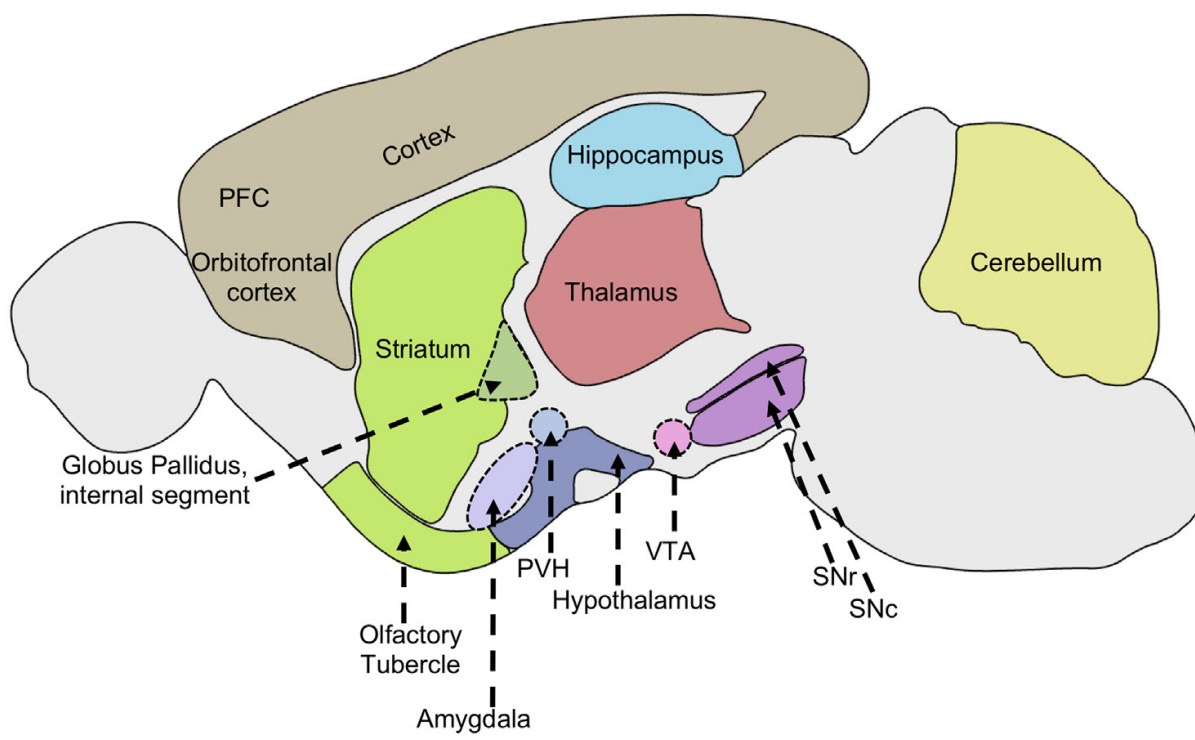

BTBR, Cntnap2 ${ }^{-/-}$, Deer, FMR1 ${ }^{-/-}$, Hoxb8, KCNQ2 ${ }^{+/-}$, MeCP2, Ninj1, NL2, NL3 ${ }^{\text {R451C }}$, Pak2 $^{+/-}$, PV $^{-/-}$ , Scn1 $\mathrm{a}^{+/-}, \mathrm{VPA}, 16 \mathrm{p} 11^{+/-}$

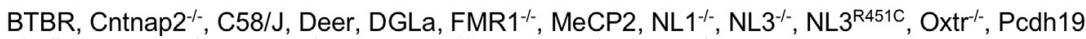

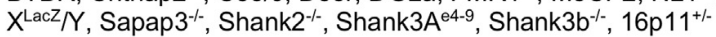

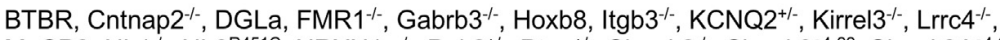

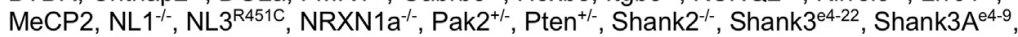
Shank3b $\mathrm{b}^{-1-}$, Sh3rf2 $2^{+-}$, Ube3A $\mathrm{A}^{\mathrm{m}-\mathrm{p}^{+}}$, VPA, 5Ko

BTBR, FMR1 $1^{-1-}$, Gabrb3 ${ }^{-1-}$, Itgb3 ${ }^{-1-}$, MeCP2, PV ${ }^{-1-}$, Tsc2f/-;Cre, Ube3A,

BTBR, Cntnap2 ${ }^{-1-}$, MeCP2, Ninj1

$\operatorname{ltgb} 3^{-1 /}, N L 3^{R 451 C}$

$16 \mathrm{p} 11^{+/-}$

FIGURE 1 | Implicated brain regions in mouse models of autism. Different mouse models of autism exhibit alterations in various brain areas such as the striatum, cortex, thalamus, hippocampus, cerebellum, hypothalamus, and amygdala. These brain regions are involved in cortico-striatal and limbic circuitry. Molecular and/or neuroanatomical changes in these structures are correlated with the pathophysiology of repetitive behaviors. Some mice models implicate multiple brain regions in the pathology of restricted/repetitive behaviors. PFC, prefrontal cortex; VTA, ventral tegmental area; SNc, substantia nigra pars compacta; SNr, substantia nigra pars reticulata; PVH, paraventricular nucleus of hypothalamus; Cntnap2, Contactin Associated Protein-like 2 gene; FMR1, Fragile X mental retardation 1; Gabrb3, Gamma-aminobutyric acid receptor subunit beta-3; Hoxb8, Homeobox protein; Itgb3, Integrin beta-3; KCNQ, Potassium voltage-gated channel subfamily; Kirrel3, Kin of Irregular Chiasm-like 3; Lrrc4, Leucine-rich repeat-containing 4; MeCP2, Methyl CpG binding protein 2; Ninj1, Nerve injury-induced protein-1; NL, Neuroligin; NRXN1a, Neurexin 1a; Oxtr, Oxytocin receptor; Pcdh19, Protocadherin-19; PV, Parvalbumin; Pak2, p21 activated kinase 2; Pten, Phosphatase and tensin homolog; Sapap3, Synapse-associated protein 90/postsynaptic density protein 95 associated protein 3; Shank, SH3 and multiple ankyrin repeat domains 3; Sh3rf2, SH3 Domain Containing Ring Finger 2; Scn1, Sodium Voltage-Gated Channel Alpha Subunit 1; Tsc2, Tuberous Sclerosis Complex 2; Ube3A, Ubiquitin Protein Ligase E3A; VPA, Valproic acid; 5Ko, 5 kainate receptor subunit. 
Syndrome (FMR1), Tuberous Sclerosis (TSC1, TSC2), Angelman and Prader-Willi Syndromes (15q11-q13 deletion/UBE3A and GABRB3 deletion), Rett Syndrome (MECP2), Phelan-McDermid syndrome (PMS; 22q13.3 deletion/SHANK3 mutation), SmithLemli-Opitz Syndrome (DHCR7), Neurofibromatosis (NF1), Timothy Syndrome (CACNA1C), et cetera (Muhle et al., 2004; Moss and Howlin, 2009; Geschwind, 2011; Ramaswami and Geschwind, 2018). Whereas in idiopathic autism, the cause is unknown.

Susceptibility genes linked with non-syndromic autism involve multiple common and rare variants (CNVs), and de novo mutations. This genetic heterogeneity is associated with idiopathic ASD and accounts for a substantial fraction of autism risk, indicating the involvement of multiple genetic pathways in its etiology (Swanwick et al., 2011; Devlin and Scherer, 2012). Multiple genes with different functions implicated in ASD include SHANK1, 2, CNTNAP2, NLGN, NRXN, 16p11.2 microdeletion/microduplication, SCN1A, et cetera (Cook and Scherer, 2008; Geschwind and State, 2015; Ramaswami and Geschwind, 2018; Sultana et al., 2018). Most ASD related genes affect neural circuit structure and function, with defects in either a single neural circuit component (localized) or multiple neural systems (distributed) impacting overall network activity (Figure 1) (Rubenstein, 2010). These neurodevelopmental defects can lead to abnormal neural structure and connectivity, as well as alterations to neurotransmitter systems and their receptors.

Animal models of repetitive and restricted behaviors are classified into different categories by causal factors. The categories of models of repetitive and restricted behavior include: (1) after CNS insult (e.g., specific genetic mutations, lesions or environmental factors); (2) caused by pharmacological agents [e.g., apomorphine (dopamine agonist), amphetamine, cocaine, NMDA (glutamate receptor ligand)]; (3) resulting from restricted housing (e.g., laboratory cage, social deprivation); and (4) linked with particular inbred rodent strains (BTBR, C58) (Lewis et al., 2007; Bechard and Lewis, 2012).

Many of the genetic and environmental factors implicated in the etiology of autism have been modeled using rodents. However, not all rodent models of ASD manifest repetitive behavior. For example, mice with knockout of neuroligin-2 and -4 genes or mutations of the $\operatorname{Scn} 2 \mathrm{a}\left(\mathrm{Scn} 2 \mathrm{a}^{+/-}\right)$gene do not exhibit alterations in intensity or frequency of repetitive behavior (El-Kordi et al., 2013; Wöhr et al., 2013; Shin et al., 2019; Cao et al., 2020). Hence, we will review preclinical studies with particular emphasis on rodent models displaying robust stereotypic behavior (Table 1), as discussed below.

Fragile X syndrome (FXS) is caused by an expansion of a single trinucleotide sequence (CGG) resulting in silencing of FMR1, an X-linked gene coding for fragile X mental retardation protein (FMRP). FMR-1 protein, an RNA binding protein plays an important role in regulating synaptic proteins via mRNA translation and the development of neural synapses. In addition to mRNA binding, FMRP protein has diverse functions including protein-protein interactions, DNA damage repair via chromatin binding, regulation of $\mathrm{Ca}^{2+}$ signaling, and neuronal excitation/inhibition balance (Brown et al., 2010; Alpatov et al.,
2014; Davis and Broadie, 2017; Filippini et al., 2017; Zhou et al., 2017). Hence, failure to express the FMR-1 protein results in the development of autistic symptoms such as repetitive and restricted behavior (Turner et al., 1996; Mazzocco et al., 1998; Spencer et al., 2005). Fragile X mutant models exhibit increased marble burying (Thomas et al., 2012; Gandhi et al., 2014), resistance to change in an operant task (Moon et al., 2006), learning deficits on water maze task, hyperactivity, anxiety, and inadequate pre-pulse inhibition of acoustic startle (D'Hooge et al., 1997; Peier et al., 2000; Spencer et al., 2005; Lauterborn et al., 2007; Errijgers et al., 2008). Fmr-1 null mice exhibit altered spine density and morphology on apical dendrites of occipital cortical layer 5 pyramidal cells (Comery et al., 1997; Beckel-Mitchener and Greenough, 2004). Also, Fmr1 knockout mice exhibit dysfunctional cortico-striatal circuitry, reduced long-term potentiation (LTP), and decrease in levels of synaptic proteins like NMDAR subunits NR1, NR2A, and NR2B in the medial prefrontal cortex (Lauterborn et al., 2007; Krueger et al., 2011; Zerbi et al., 2018). Gene therapy using human FRM1 alleviates the low pre-pulse inhibition, hyperactivity, and anxiety behaviors in Fmr1-KO mice (Peier et al., 2000; Paylor et al., 2008; Spencer et al., 2008; Gholizadeh et al., 2014). Application of brain-derived neurotrophic factor (BDNF), mGluR5 antagonists, anti-purinergic therapy (suramin), minocycline, phosphodiesterase-4D negative allosteric modulator (BPN14770) and PI3K antagonist [GSK2702926A (GSK6A)] attenuates dendritic spine development aberrations, LTP impairments, and behavioral abnormalities in Fmr1 mutant mice (Dölen et al., 2007; Lauterborn et al., 2007; Dölen and Bear, 2008; Bilousova et al., 2009; Naviaux et al., 2015; Gurney et al., 2017; Yau et al., 2018; Gross et al., 2019).

Angelman syndrome involves chromosome 15 deletions, particularly the q11-13 region, comprising the $\mathrm{GABA}_{\mathrm{A}}$ receptor beta 3 subunit (GABRB3) and ubiquitin ligase (UBE3A) genes. GABRB3 and UBE3A genes play a role in regulating protein synthesis and synaptic plasticity (Weeber et al., 2003; Moy et al., 2006; Mardirossian et al., 2009). Mouse models of GABRB3 and UBE3A deletions exhibit ASD phenotype including developmental delay, hyperactivity, epilepsy, impaired motor function, learning deficits, and anxiety-related behaviors (DeLorey et al., 1998; Jiang et al., 2010; Tanaka et al., 2012). Mice with a mutation in Ube $3 \mathrm{~A}^{\mathrm{m}-/ \mathrm{p}+}$ (maternal null mutation) exhibit deficits in LTP and changes in calcium-dependent CaMKII activity in the hippocampus (Weeber et al., 2003). The Ube $3 \mathrm{~A}^{\mathrm{m}-/ \mathrm{p}+}$ mice show decreased marble burying, rearing behavior, and reversal-learning deficits in the Morris water maze (MWM) (Huang et al., 2013). Additionally, Gabrb3 deletions cause neuronal dysfunction via alterations in protein synthesis and GABA-A receptor-mediated synaptic transmission. The Gabrb3 $^{-/-}$mice also exhibit repetitive circling behavior (Mercer et al., 2016; Orefice et al., 2016).

Another condition, tuberous sclerosis (TSC), involves mutation of either TSC1 and TSC2 genes that codes for proteins hamartin and tuberin, which act as tumor suppressors that regulate cell growth and the mTORC1 complex (Astrinidis and Henske, 2005; Inoki et al., 2005; Curatolo and Bombardieri, 2007). mTOR is a crucial part of signaling pathways involved 
TABLE 1 | Neural alterations underlying repetitive behaviors and rescue of repetitive behaviors in rodent models of autism spectrum disorders (ASDs).

\begin{tabular}{|c|c|c|c|c|}
\hline Model & $\begin{array}{l}\text { Repetitive and related } \\
\text { behaviors }\end{array}$ & Neural alterations & $\begin{array}{l}\text { Rescue of repetitive } \\
\text { behaviors }\end{array}$ & References \\
\hline$B T B R T+t f / J$ & $\begin{array}{l}\text { - Repetitive self-grooming } \\
\text { - Increased marble-burying } \\
\text { behavior } \\
\text { - Reversal learning deficit in } \\
\text { Morris water maze (MWM) }\end{array}$ & $\begin{array}{l}\text { - Reduced GABAergic } \\
\text { inhibitory transmission } \\
\text { - Upregulation of serotonin } \\
5 \mathrm{HT}_{2 \mathrm{~A}} \text { receptor density and } \\
\text { activity } \\
\text { - Increased in glutamatergic } \\
\text { transmission in } \\
\text { cortico-striatal circuitry } \\
\text { - Impaired dopamine } \\
\text { D2 receptor function } \\
\text { - Reduced expression of BDNF } \\
\text { in hippocampus and cortex } \\
\text { - Absence of corpus callosum, } \\
\text { lack of hippocampal } \\
\text { commissure } \\
\text { - Reduced cortical thickness } \\
\text { - Reduced cerebral white and } \\
\text { gray matter } \\
\text { - Impaired cortico-thalamic } \\
\text { function } \\
\text { - Altered volumes of } \\
\text { cerebellum, brainstem, } \\
\text { striatum, and hippocampus }\end{array}$ & $\begin{array}{l}\text { - } \text { mGluR5 receptor antagonist } \\
\text { (MPEP) } \\
\text { - Selective GABA } \mathrm{b}_{\mathrm{b}} \text { receptor } \\
\text { agonist (R-baclofen) } \\
\text { - Dorsomedial striatal injection } \\
\text { of selective } 5 \mathrm{HT}_{2 \mathrm{~A}} \text { receptor } \\
\text { antagonist (M100907) } \\
\text { - Risperidone } \\
\text { - Muscarinic receptor (mAChR) } \\
\text { agonist (Oxotremorine) } \\
\text { - Nicotinic receptor (nAChR) } \\
\text { agonist (nicotine) } \\
\text { - Acetylcholinesterase inhibitor } \\
\text { (AChEl; Donepezil) reduced } \\
\text { behavioral rigidity in water } \\
\text { T-maze task } \\
\text { - Retinoic acid receptor-related } \\
\text { orphan receptor alpha (ROR } \\
\text { a) agonist (SR1078) }\end{array}$ & $\begin{array}{l}\text { Wahlsten et al. (2003), Moy } \\
\text { et al. (2007), McFarlane } \\
\text { et al. (2008), Silverman } \\
\text { et al. (2010, 2012), Gould } \\
\text { et al. (2011), Wöhr et al. } \\
\text { (2011), Amodeo et al. } \\
\text { (2012), Burket et al. (2013), } \\
\text { Dodero et al. (2013); } \\
\text { Ellegood et al. (2013), } \\
\text { Reynolds et al. (2013), Han } \\
\text { et al. (2014), Karvat and } \\
\text { Kimchi (2014), Wang et al. } \\
\text { (2015), Wang Y. et al. } \\
\text { (2016), and Meyza and } \\
\text { Blanchard (2017) }\end{array}$ \\
\hline Cntnap2-/- & $\begin{array}{l}\text { - Repetitive self-grooming and } \\
\text { digging } \\
\text { - Reversal learning deficit } \\
\text { (MWM) } \\
\text { - Hyperactivity } \\
\text { - Seizures }\end{array}$ & $\begin{array}{l}\text { - A decrease in } \\
\text { parvalbumin-positive } \\
\text { interneurons in striatum } \\
\text { resulting in altered activity of } \\
\text { the cortico-striatal-thalamic } \\
\text { pathway } \\
\text { - Cortical migration } \\
\text { abnormalities }\end{array}$ & $\begin{array}{l}\text { - Dopamine D2 receptor } \\
\text { antagonist (Risperidone) }\end{array}$ & $\begin{array}{l}\text { Peñagarikano et al. (2011) } \\
\text { and Lauber et al. (2018) }\end{array}$ \\
\hline C58/J & $\begin{array}{l}\text { - Repetitive self-grooming } \\
\text { - Hind limb jumping } \\
\text { - Backflips } \\
\text { - Decreased exploratory } \\
\text { behavior } \\
\text { - Reversal learning deficit }\end{array}$ & $\begin{array}{l}\text { - Increased mGluR5 signaling } \\
\text { - NMDA receptor } \\
\text { hyperfunction } \\
\text { - Reduced GABAergic } \\
\text { signaling } \\
\text { - Reduced dendritic spines } \\
\text { - Increased dopaminergic } \\
\text { function and cortical } \\
\text { activation } \\
\text { - Aberrant hippocampal and } \\
\text { cortical activity }\end{array}$ & $\begin{array}{l}\text { - mGluR5 negative allosteric } \\
\text { modulator (GRN-529) } \\
\text { - Selective GABA } \text { S receptor } \text { agonist (R-baclofen) } \\
\text { - Environmental enrichment }\end{array}$ & $\begin{array}{l}\text { Moy et al. (2008b), Ryan } \\
\text { et al. (2010), Muehlmann } \\
\text { et al. (2012), Silverman } \\
\text { et al. (2012), and } \\
\text { Whitehouse et al. (2017) }\end{array}$ \\
\hline Deer & $\begin{array}{l}\text { - Repetitive hindlimb jumping } \\
\text { and backflips } \\
\text { - Perseverative behavior in a } \\
\text { reversal-learning task } \\
\text { (T-maze) }\end{array}$ & $\begin{array}{l}\text { - Enhanced Cortico-striatal } \\
\text { glutamatergic projections } \\
\text { - Decrease density of serotonin } \\
\text { transporters in the striatum } \\
\text { - Reduced indirect basal } \\
\text { ganglia pathway activity } \\
\text { - Dorsomedial striatum } \\
\text { alterations }\end{array}$ & $\begin{array}{l}\text { - Striatal injections of NMDA } \\
\text { receptor antagonist (MK-801) } \\
\text { - Dopamine D1 receptor } \\
\text { antagonist (SCH23390) } \\
\text { - Co-administration of } \\
\text { adenosine } \mathrm{A}_{2 \mathrm{~A}} \text { receptor } \\
\text { agonist (CGS21680) and } \mathrm{A}_{1} \\
\text { receptor agonist (CPA) } \\
\text { - Selective SSRI (Escitalopram) } \\
\text { - Triple drug cocktail (D2R } \\
\text { antagonist L-741, 626 + } \\
\text { Adenosine A } 2 \mathrm{AR} \text { agonist } \\
\text { CGS21680 + } \\
\text { mGluR5 positive allosteric } \\
\text { modulator CDPPB) } \\
\text { - Environmental enrichment } \\
\text { (EE) }\end{array}$ & $\begin{array}{l}\text { Presti et al. (2003); } \\
\text { Tanimura Y. et al. (2010), } \\
\text { Tanimura et al. (2008, } \\
\text { 2011), Wolmarans et al. } \\
\text { (2013), Bechard et al. } \\
\text { (2017), and Lewis et al. } \\
\text { (2019) }\end{array}$ \\
\hline
\end{tabular}


TABLE 1 | Continued

\begin{tabular}{|c|c|c|c|c|}
\hline Model & $\begin{array}{l}\text { Repetitive and related } \\
\text { behaviors }\end{array}$ & Neural alterations & $\begin{array}{l}\text { Rescue of repetitive } \\
\text { behaviors }\end{array}$ & References \\
\hline$D G L a^{f|x / f| x}$ & - Repetitive self-grooming & $\begin{array}{l}\text { - Reduced levels of 2-acyl } \\
\text { glycerol in the striatum } \\
\text { - Excessive glutamatergic drive } \\
\text { in direct-pathway MSNs }\end{array}$ & & Shonesy et al. $(2014,2018)$ \\
\hline $\begin{array}{l}\text { EphA2/A3 double } \\
\text { KO }\end{array}$ & $\begin{array}{l}\text { - Stereotypic facial grooming } \\
\text { - Reduced locomotor activity } \\
\text { - Increased pre-pulse inhibition } \\
\text { of acoustic startle }\end{array}$ & $\begin{array}{l}\text { - Sensorimotor gating } \\
\text { abnormalities } \\
\text { - Altered excitability of } \\
\text { forebrain pathways }\end{array}$ & & $\begin{array}{l}\text { Qiu et al. (2012) and } \\
\text { Wurzman et al. (2015) }\end{array}$ \\
\hline$F M R 1^{-/-}$ & $\begin{array}{l}\text { - Repetitive self-grooming } \\
\text { - Increased/decreased } \\
\text { marble-burying } \\
\text { - A deficit in novelty preference } \\
\text { (T-maze spontaneous } \\
\text { alternation) } \\
\text { - Learning task deficits } \\
\text { - Hyperactivity } \\
\text { - Anxiety } \\
\text { - Reduced motor learning } \\
\text { - Olfactory learning deficits }\end{array}$ & $\begin{array}{l}\text { - Increased mGluR-LTD in } \\
\text { hippocampal CA1 and } \\
\text { cerebellum } \\
\text { - Increased endocannabinoid } \\
\text { mediated transmission at } \\
\text { GABAergic synapses of the } \\
\text { hippocampus and dorsal } \\
\text { striatum } \\
\text { - Dysfunctional cortico-striatal } \\
\text { circuitry } \\
\text { - Decrease activity of } \\
\text { fast-spiking interneurons in } \\
\text { cortical areas } \\
\text { (hyperexcitability) } \\
\text { - Abnormal sensorimotor } \\
\text { gating } \\
\text { - Altered dendritic spine } \\
\text { density and morphology } \\
\text { - Impaired long-term } \\
\text { potentiation } \\
\text { - PSD-95 protein deficits } \\
\text { - PI3K/AKT pathway abnormal } \\
\text { activity } \\
\text { - AMPAR and NMDAR } \\
\text { dysfunction } \\
\text { volumergic signaling alteration } \\
\text { - Altered cerebellar and striatal } \\
\text { Polumes }\end{array}$ & 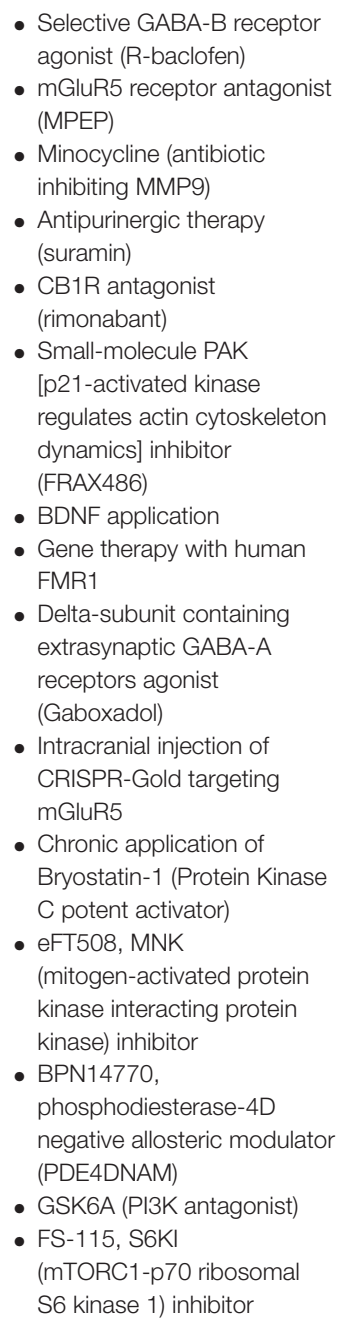 & $\begin{array}{l}\text { Peier et al. (2000), Spencer } \\
\text { et al. (2005, 2008), } \\
\text { Lauterborn et al. (2007), } \\
\text { Dölen and Bear (2008), } \\
\text { Errijgers et al. (2008), } \\
\text { McNaughton et al. (2008), } \\
\text { Paylor et al. (2008), } \\
\text { Bilousova et al. (2009), } \\
\text { Zhang and Alger (2010), } \\
\text { Pietropaolo et al. (2011), } \\
\text { Henderson et al. (2012), } \\
\text { Jung et al. (2012), Thomas } \\
\text { et al. (2012), } \\
\text { Busquets-Garcia et al. } \\
\text { (2013), Dolan et al. (2013), } \\
\text { Berry-Kravis (2014), Gandhi } \\
\text { et al. (2014), Naviaux et al. } \\
\text { (2015), Tang and Alger } \\
\text { (2015), Bhattacharya et al. } \\
\text { (2016), Gurney et al. (2017), } \\
\text { Sinclair et al. (2017), Lee } \\
\text { et al. (2018), Nolan and } \\
\text { Lugo (2018), Yau et al. } \\
\text { (2018), Zerbi et al. (2018), } \\
\text { Cogram et al. (2019, 2020), } \\
\text { Gross et al. (2019), and } \\
\text { Shukla et al. (2020) }\end{array}$ \\
\hline Gabrb3 ${ }^{-/-}$ & $\begin{array}{l}\text { - Repetitive circling } \\
\text { - Hyperactivity }\end{array}$ & $\begin{array}{l}\text { - Cerebellar vermis hypoplasia } \\
\text { - Abnormal GABA-A receptor } \\
\text { function in the hippocampus } \\
\text { - Altered GABA-A } \\
\text { receptor-mediated } \\
\text { neurotransmission }\end{array}$ & & $\begin{array}{l}\text { DeLorey et al. (1998, 2008), } \\
\text { Mercer et al. (2016), and } \\
\text { Orefice et al. (2016) }\end{array}$ \\
\hline $\begin{array}{l}\text { Hoxb8 KO in } \\
\text { microglia }\end{array}$ & $\begin{array}{l}\text { - Increased grooming } \\
\text { - Anxiety-like behavior }\end{array}$ & $\begin{array}{l}\text { - Increased cortical dendritic } \\
\text { spine density } \\
\text { - Increased dendritic spines in } \\
\text { the striatum } \\
\text { - Defects in LTP, miniature } \\
\text { postsynaptic currents }\end{array}$ & - Fluoxetine (SSRI) & $\begin{array}{l}\text { Greer and Capecchi (2002), } \\
\text { Chen et al. (2010), and } \\
\text { Nagarajan et al. (2018) }\end{array}$ \\
\hline
\end{tabular}


TABLE 1 | Continued

\begin{tabular}{|c|c|c|c|c|}
\hline Model & $\begin{array}{l}\text { Repetitive and related } \\
\text { behaviors }\end{array}$ & Neural alterations & $\begin{array}{l}\text { Rescue of repetitive } \\
\text { behaviors }\end{array}$ & References \\
\hline $\operatorname{ltg} 3^{-1-}$ & $\begin{array}{l}\text { - Increased grooming in a } \\
\text { novel environment }\end{array}$ & $\begin{array}{l}\text { - Alterations in axon/dendrite } \\
\text { outgrowth, cell adhesion, and } \\
\text { synapse formation } \\
\text { - The reduced corpus } \\
\text { callosum, hippocampus, } \\
\text { striatum, and cerebellum } \\
\text { - Increased amygdala volume }\end{array}$ & & $\begin{array}{l}\text { De Arcangelis and } \\
\text { Georges-Labouesse } \\
\text { (2000), Clegg et al. (2003), } \\
\text { Carter et al. (2011), and } \\
\text { Ellegood et al. (2012) }\end{array}$ \\
\hline Kirre/3-/- & $\begin{array}{l}\text { - Repetitive rearing behavior } \\
\text { - Increased locomotor activity } \\
\text { - Hypersensitivity to acoustic } \\
\text { startle (acoustic startle test) } \\
\text { - Hyperactivity }\end{array}$ & $\begin{array}{l}\text { - Abnormal hippocampal } \\
\text { mossy fiber synapse } \\
\text { formation } \\
\text { - Increased CA3 neuron } \\
\text { activity during development } \\
\text { - Abnormal neuronal migration }\end{array}$ & & $\begin{array}{l}\text { Gerke et al. (2006), } \\
\text { Serizawa et al. (2006), } \\
\text { Nishida et al. (2011), Prince } \\
\text { et al. (2013), Martin et al. } \\
\text { (2015), Choi et al. (2015), } \\
\text { and Hisaoka et al. (2018) }\end{array}$ \\
\hline $\operatorname{Lrrc4}^{-1-}$ & $\begin{array}{l}\text { - Repetitive self-grooming } \\
\text { - Impaired spatial learning } \\
\text { (MWM) }\end{array}$ & $\begin{array}{l}\text { - Reduced NMDA } \\
\text { receptor-mediated synaptic } \\
\text { plasticity } \\
\text { - Abnormal synaptic } \\
\text { transmission }\end{array}$ & $\begin{array}{l}\text { - NMDA receptor agonist } \\
\text { (D-cycloserine) }\end{array}$ & $\begin{array}{l}\text { DeNardo et al. (2012), Soto } \\
\text { et al. (2013, 2018), and Um } \\
\text { et al. (2018) }\end{array}$ \\
\hline $\mathrm{MeCP} 2$ & $\begin{array}{l}\text { - Repeated forelimb } \\
\text { movements } \\
\text { - Deficits in motor coordination } \\
\text { and motor learning } \\
\text { - Memory deficits }\end{array}$ & $\begin{array}{l}\text { - Decreased levels of } \\
\text { dopamine transporter (DAT) } \\
\text { and tyrosine hydroxylase (TH) } \\
\text { in the striatum } \\
\text { - Altered cortical and cerebellar } \\
\text { volumes } \\
\text { - Cortical LTP deficit } \\
\text { - Decreased cortical BDNF } \\
\text { levels } \\
\text { - Impaired PI3K/AKT/mTOR } \\
\text { pathway } \\
\text { - Upregulated CB1 and } \\
\text { CB2 receptor levels } \\
\text { - Hippocampal circuit } \\
\text { dysfunction }\end{array}$ & & $\begin{array}{l}\text { Shahbazian et al. (2002), } \\
\text { Moretti et al. (2005), Lonetti } \\
\text { et al. (2010), Lu et al. } \\
\text { (2016), Allemang-Grand } \\
\text { et al. (2017), and } \\
\text { Zamberletti et al. (2019) }\end{array}$ \\
\hline Ninj1 & $\begin{array}{l}\text { - Excessive grooming inducing } \\
\text { hair loss and lesions } \\
\text { - Increased anxiety-like } \\
\text { behavior }\end{array}$ & $\begin{array}{l}\text { - Altered synaptic function in } \\
\text { thalamocortical neurons } \\
\text { - Increased expression of } \\
\text { ionotropic glutamate receptor } \\
\text { - The increased amplitude of } \\
\text { miniature EPSCs }\end{array}$ & - Fluoxetine (SSRI) & Le et al. (2017) \\
\hline$N L 1^{-/-}$ & $\begin{array}{l}\text { - Repetitive self-grooming } \\
\text { - Spatial learning deficits }\end{array}$ & $\begin{array}{l}\text { - Reduced NMDA/AMPA } \\
\text { receptor ratio in the } \\
\text { hippocampus and dorsal } \\
\text { striatum } \\
\text { - Reduced hippocampal LTP } \\
\text { - Abnormal function of } \\
\text { dopamine D1 MSNs } \\
\text { - Reduced GluN2A containing } \\
\text { NMDARs expression in } \\
\text { direct-pathway MSNs } \\
\text { - Reduced frequency of } \\
\text { miniature excitatory } \\
\text { neurotransmission in } \\
\text { indirect-pathway MSNs }\end{array}$ & $\begin{array}{l}\text { - NMDA receptor partial } \\
\text { co-agonist (D-cycloserine) }\end{array}$ & $\begin{array}{l}\text { Blundell et al. (2010) and } \\
\text { Espinosa et al. (2015) }\end{array}$ \\
\hline
\end{tabular}


TABLE 1 | Continued

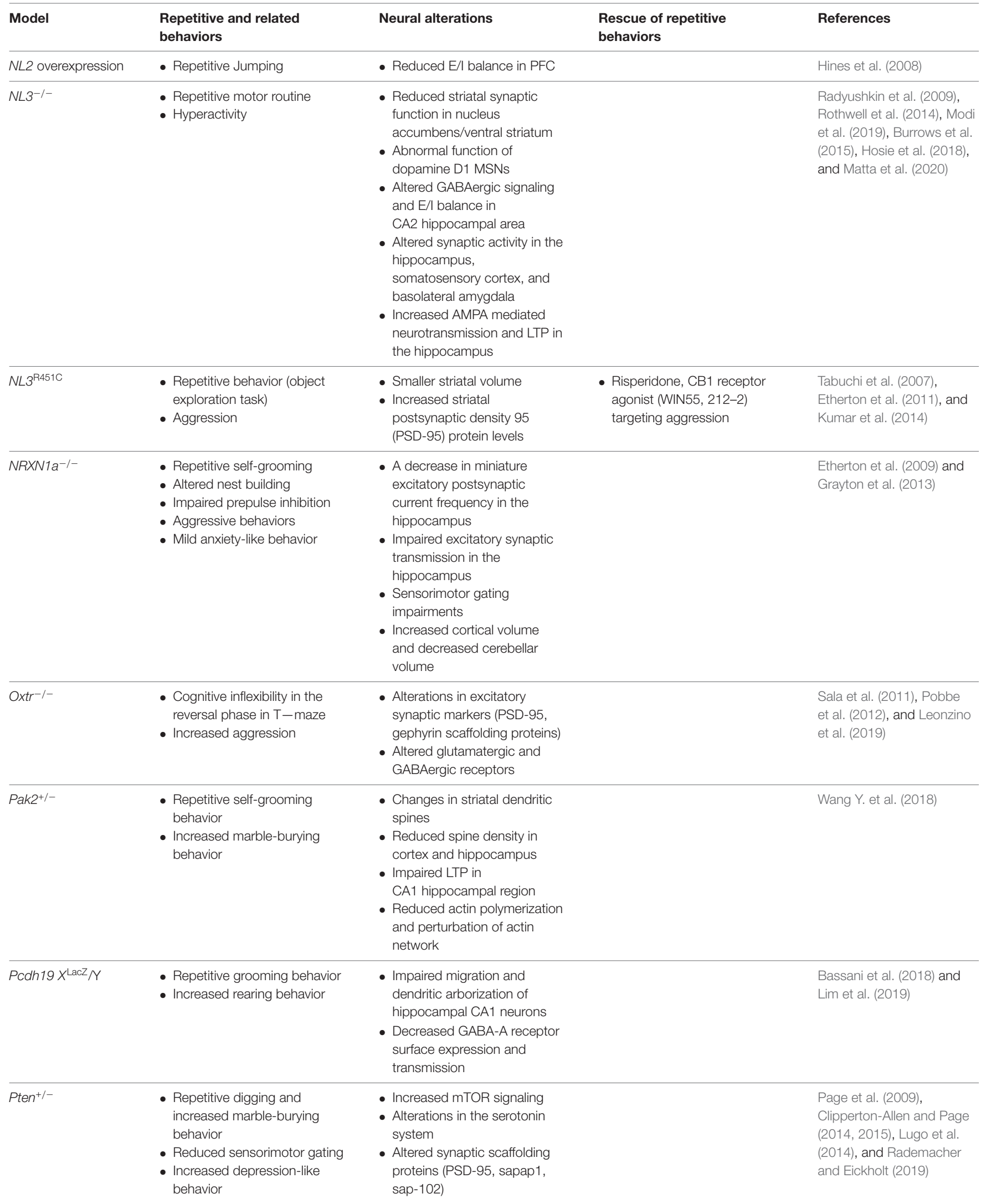


TABLE 1 | Continued

\begin{tabular}{|c|c|c|c|c|}
\hline Model & $\begin{array}{l}\text { Repetitive and related } \\
\text { behaviors }\end{array}$ & Neural alterations & $\begin{array}{l}\text { Rescue of repetitive } \\
\text { behaviors }\end{array}$ & References \\
\hline & & $\begin{array}{l}\text { - Decreased mGluR in the } \\
\text { hippocampus } \\
\text { - Structural aberrations in } \\
\text { Purkinje cells dendrites and } \\
\text { axons }\end{array}$ & & \\
\hline Sapap3 ${ }^{-/-}$ & - Compulsive self-grooming & $\begin{array}{l}\text { - Glutamatergic transmission } \\
\text { defects at cortico-striatal } \\
\text { synapses } \\
\text { - Elevated mGluR5 signaling }\end{array}$ & $\begin{array}{l}\text { - Sapap3 re-expression in the } \\
\text { striatum } \\
\text { - Optogenetic stimulation of } \\
\text { the lateral orbitofrontal cortex } \\
\text { - mGluR5 inhibition } \\
\text { - Serotonin uptake inhibitor } \\
\text { (fluoxetine) }\end{array}$ & $\begin{array}{l}\text { Welch et al. (2007), } \\
\text { Bienvenu et al. (2009), and } \\
\text { Burguière et al. (2013) }\end{array}$ \\
\hline Scn1a $a^{+/-}$ & $\begin{array}{l}\text { - Repetitive self-grooming and } \\
\text { circling } \\
\text { - Hyperactivity }\end{array}$ & $\begin{array}{l}\text { - Increased PFC excitation } \\
\text { - Altered GABAergic activity in } \\
\text { PFC }\end{array}$ & & Han et al. (2012) \\
\hline $\begin{array}{l}\text { Shank1 } 1^{+/-} \\
\text {Shank1-/- }\end{array}$ & $\begin{array}{l}\text { - Repetitive self-grooming } \\
\text { - increased acquisition of } \\
\text { spatial memory } \\
\text { - motor deficits } \\
\text { - mild anxiety-like phenotype } \\
\text { - Reduced exploratory } \\
\text { locomotion }\end{array}$ & $\begin{array}{l}\text { - A decrease in mEPSC, } \\
\text { altered glutamatergic } \\
\text { synapse } \\
\text { - Altered maturation of } \\
\text { postsynaptic dendritic spines } \\
\text { - Reduced density of } \\
\text { CA1 pyramidal neurons } \\
\text { dendritic spines }\end{array}$ & & $\begin{array}{l}\text { Hung et al. (2008), } \\
\text { Silverman et al. (2011), } \\
\text { Sungur et al. (2014), and } \\
\text { Sala et al. (2015) }\end{array}$ \\
\hline $\begin{array}{l}\text { Shank2 (exons 6, } \\
7 \text { deletions and } \\
\text { frameshift affecting } \\
\text { both splice variants } \\
\text { Shank2a and } \\
\text { Shank2b) }\end{array}$ & $\begin{array}{l}\text { - Stereotypic jumping } \\
\text { - Impaired spatial learning and } \\
\text { memory (Morris water maze) } \\
\text { - Impaired nesting behavior } \\
\text { - Hyperactivity } \\
\text { - Anxiety-like behavior } \\
\text { - Increased grooming in the } \\
\text { novel object recognition area }\end{array}$ & $\begin{array}{l}\text { - Reduced activity of } \\
\text { glutamatergic NMDA } \\
\text { receptors } \\
\text { - Impaired LTP and LTD at } \\
\text { Schaffer-collateral-CA1- } \\
\text { pyramidal (SC-CA1) } \\
\text { synapses } \\
\text { - Reduced NMDA/AMPA ratio } \\
\text { at SC-CA1 synapses } \\
\text { - Decreased } \\
\text { NMDAR-mediated synaptic } \\
\text { transmission }\end{array}$ & & Won et al. (2012) \\
\hline
\end{tabular}


TABLE 1 | Continued

\begin{tabular}{|c|c|c|c|c|}
\hline Model & $\begin{array}{l}\text { Repetitive and related } \\
\text { behaviors }\end{array}$ & Neural alterations & $\begin{array}{l}\text { Rescue of repetitive } \\
\text { behaviors }\end{array}$ & References \\
\hline $\begin{array}{l}\text { Shank3 (exon } \\
21 \text { deletions } \\
\text { including Homer } \\
\text { binding domain) }\end{array}$ & $\begin{array}{l}\text { - Repetitive grooming in older } \\
\text { mice } \\
\text { - A deficit in spatial learning } \\
\text { and memory } \\
\text { - Impaired motor coordination } \\
\text { - Aberrant locomotor response } \\
\text { to novelty } \\
\text { - Increased novel object } \\
\text { avoidance (in marble-burying } \\
\text { test) }\end{array}$ & $\begin{array}{l}\text { - Decreased excitatory } \\
\text { postsynaptic NMDA/AMPA } \\
\text { current ratio in the } \\
\text { hippocampal CA1 region } \\
\text { - Reduced LTP in } \\
\text { CA1 hippocampus } \\
\text { - Increased mGluR5 levels in } \\
\text { synaptic fractions }\end{array}$ & & Kouser et al. (2013) \\
\hline $\begin{array}{l}\text { Shank } 3^{\mathrm{e} 4-22} \text { (exons } \\
\text { 4-22 deletion) }\end{array}$ & $\begin{array}{l}\text { - Excessive Repetitive } \\
\text { self-grooming } \\
\text { - Reduced locomotion } \\
\text { - Deficient motor performance } \\
\text { - Anxiety-like behavior } \\
\text { - Impaired striatal learning }\end{array}$ & $\begin{array}{l}\text { - Impaired postsynaptic } \\
\text { SAPAP, mGluR5-Homer } \\
\text { scaffolding proteins, and } \\
\text { mGluR5 signaling in striatal } \\
\text { neurons } \\
\text { - Impaired striatal LTD and } \\
\text { synaptic plasticity } \\
\text { - Decreased } \\
\text { neurotransmission in } \\
\text { corticostriatal circuits } \\
\text { - Reduced striatal spine } \\
\text { density }\end{array}$ & - mGluR5 antagonist (MPEP) & Wang X. et al. (2016) \\
\hline $\begin{array}{l}\text { Shank3A }{ }^{\text {e4-9 }} \\
\text { heterozygous and } \\
\text { knockout (exons } \\
\text { 4-9 deletion } \\
\text { encoding ANK } \\
\text { domain) }\end{array}$ & $\begin{array}{l}\text { - Repetitive self-grooming } \\
\text { - An enhanced head pokes } \\
\text { (hole board test) } \\
\text { - Mild motor abnormalities } \\
\text { including difficulty in motor } \\
\text { coordination in KO mice } \\
\text { - Motor learning deficits in KO } \\
\text { mice } \\
\text { - Impaired novel and spatial } \\
\text { object recognition learning } \\
\text { and memory }\end{array}$ & $\begin{array}{l}\text { - Reduced Homer1b/c, GKAP, } \\
\text { and AMPAR subunit GluA1, } \\
\text { GluA2, GluA3 levels at PSD } \\
\text { in KO mice indicating altered } \\
\text { synaptic scaffolding proteins } \\
\text { and receptor subunits } \\
\text { - Reduced spine density and } \\
\text { increased spine length in } \\
\text { CA1 hippocampus } \\
\text { - Impaired hippocampal LTP (in } \\
\text { both KO and HTZ), } \\
\text { glutamatergic synaptic } \\
\text { transmission, and synaptic } \\
\text { plasticity in knockout mice } \\
\text { - Reduced NMDA/AMPA ratio } \\
\text { at excitatory synapses onto } \\
\text { striatal MSNs (in both KO } \\
\text { and HTZ) }\end{array}$ & & $\begin{array}{l}\text { Bozdagi et al. (2010), Wang } \\
\text { et al. (2011), Yang et al. } \\
\text { (2012), Drapeau et al. } \\
\text { (2014), and Jaramillo et al. } \\
\text { (2016) }\end{array}$ \\
\hline Shank3b-/- & $\begin{array}{l}\text { - Repetitive self-grooming } \\
\text { - Attention-deficit }\end{array}$ & $\begin{array}{l}\text { - Functionally impaired AMPA } \\
\text { and NMDA receptors } \\
\text { - Decreased D2 MSNs AMPA } \\
\text { receptor responses } \\
\text { - Deficits of hippocampal } \\
\text { synaptic plasticity and its } \\
\text { association with the impaired } \\
\text { remodeling of the actin } \\
\text { cytoskeleton }\end{array}$ & $\begin{array}{l}\text { - Enhancing the activity of the } \\
\text { indirect striatopallidal } \\
\text { pathway } \\
\text { - Subthalamic nucleus } \\
\text { stimulation } \\
\text { - Partial } 5-\mathrm{HT} 1 \mathrm{~A} \text { receptor } \\
\text { agonist (tandospirone) in } \\
\text { Shank3B } \mathrm{B}^{+-}\end{array}$ & $\begin{array}{l}\text { Bozdagi et al. (2010), Peça } \\
\text { et al. (2011), Wang et al. } \\
\text { (2011), Schmeisser et al. } \\
\text { (2012), Duffney et al. } \\
\text { (2013), Sala et al. (2015), } \\
\text { Chang et al. (2016), Peixoto } \\
\text { et al. (2016), } \\
\text { Harony-Nicolas et al. } \\
\text { (2017), and Dunn et al. } \\
\text { (2020) }\end{array}$ \\
\hline $\begin{array}{l}\text { Shank3B }{ }^{-1-}(P D Z \\
\text { domain deletion) }\end{array}$ & $\begin{array}{l}\text { - Excessive and self-injurious } \\
\text { self-grooming } \\
\text { - Anxiety-like behavior }\end{array}$ & $\begin{array}{l}\text { - Reduced levels of synaptic } \\
\text { scaffolding proteins SAPAP3, } \\
\text { Homer-1b/c, PSD93 and } \\
\text { glutamate receptor subunits } \\
\text { GluR2, NR2A, and NR2B at } \\
\text { PSD } \\
\text { - Neuronal hypertrophy } \\
\text { - Reduced dendritic spine } \\
\text { density }\end{array}$ & & Peça et al. (2011) \\
\hline
\end{tabular}


TABLE 1 | Continued

\begin{tabular}{|c|c|c|c|c|}
\hline Model & $\begin{array}{l}\text { Repetitive and related } \\
\text { behaviors }\end{array}$ & Neural alterations & $\begin{array}{l}\text { Rescue of repetitive } \\
\text { behaviors }\end{array}$ & References \\
\hline & & $\begin{array}{l}\text { - Increased caudate volume } \\
\text { - Decreased C-S circuits } \\
\text { neurotransmission }\end{array}$ & & \\
\hline Sh3rf2 $2^{+-}$ & $\begin{array}{l}\text { - Increased jumping and } \\
\text { rearing behavior } \\
\text { - Increased marble burying } \\
\text { and digging } \\
\text { - Hyperactivity }\end{array}$ & $\begin{array}{l}\text { - Abnormal dendritic spine } \\
\text { development in the } \\
\text { hippocampus } \\
\text { - Changes in the composition } \\
\text { of glutamate receptor } \\
\text { subunits NR2A and GluR2 } \\
\text { - Altered AMPA } \\
\text { receptor-mediated synaptic } \\
\text { transmission in } \\
\text { CA1 hippocampus }\end{array}$ & & Wang S. et al. (2018) \\
\hline $\begin{array}{l}\text { Tsc2f/-;Cre } \\
\text { (Tsc2 deletion in } \\
\text { cerebellar Purkinje } \\
\text { cells) }\end{array}$ & - Increase marble-burying & $\begin{array}{l}\text { - Cerebellar GABAergic } \\
\text { Purkinje cell loss } \\
\text { - Abnormalities in axonal } \\
\text { pathfinding }\end{array}$ & & Reith et al. (2013) \\
\hline Ube $3 A^{\mathrm{m}-/ \mathrm{p}+}$ & $\begin{array}{l}\text { - Decrease marble burying and } \\
\text { rearing } \\
\text { - Reversal learning deficit } \\
\text { (MWM) } \\
\text { - Impaired motor coordination }\end{array}$ & $\begin{array}{l}\text { - Reduced mGluR-LTD } \\
\text { - Altered mGluR signaling } \\
\text { - Changes in } \\
\text { calcium-dependent CAMKII } \\
\text { activity in the hippocampus }\end{array}$ & & $\begin{array}{l}\text { Weeber et al. (2003), } \\
\text { Huang et al. (2013), and } \\
\text { Pignatelli et al. (2014) }\end{array}$ \\
\hline VPA & $\begin{array}{l}\text { - Repetitive self-grooming } \\
\text { - Marble burying } \\
\text { - Decrease pre-pulse inhibition } \\
\text { - Reduced social behaviors }\end{array}$ & $\begin{array}{l}\text { - Increased glutamatergic } \\
\text { excitatory signaling } \\
\text { - Hyperexcitable local } \\
\text { connectivity } \\
\text { - A decrease in } \\
\text { parvalbumin-positive } \\
\text { inhibitory interneurons } \\
\text { - Elevated brain serotonin } \\
\text { levels } \\
\text { - Apical dendritic arborization } \\
\text { complexity } \\
\text { - Decreased PTEN expression } \\
\text { and increased p-AKT protein } \\
\text { levels in hippocampus and } \\
\text { cortex }\end{array}$ & $\begin{array}{l}\text { - mGluR5 receptor antagonist, } \\
\text { MPEP } \\
\text { - Environmental enrichment } \\
\text { - Betaine (methyl group donor } \\
\text { in homocysteine metabolism, } \\
\text { prevents homocysteine } \\
\text { accumulation) } \\
\text { - NMDA receptor antagonist } \\
\text { (agmatine) }\end{array}$ & $\begin{array}{l}\text { Schneider and Przewocki } \\
\text { (2005), Schneider et al. } \\
\text { (2006), Rinaldi et al. (2007), } \\
\text { Tsujino et al. (2007), Snow } \\
\text { et al. (2008), Mehta et al. } \\
\text { (2011), Choi et al. (2016), } \\
\text { Kim et al. (2017), Mahmood } \\
\text { et al. (2018), and Huang } \\
\text { et al. (2019) }\end{array}$ \\
\hline $16 p 11^{+/-}$ & $\begin{array}{l}\text { - Repetitive circling and } \\
\text { climbing } \\
\text { - Hyperactivity } \\
\text { - Increased locomotion }\end{array}$ & $\begin{array}{l}\text { - Increased dopamine } \\
\text { D2 receptor-expressing } \\
\text { striatal neurons } \\
\text { - Decreased dopamine } \\
\text { D2 receptor-expressing } \\
\text { cortical neurons } \\
\text { - Synaptic function defects } \\
\text { - Volumetric alterations in } \\
\text { striatum, hypothalamus, and } \\
\text { midbrain area }\end{array}$ & & $\begin{array}{l}\text { Horev et al. (2011) and } \\
\text { Portmann et al. (2014) }\end{array}$ \\
\hline $\begin{array}{l}5 K o \text { (deletion of } \\
5 \text { kainate receptor } \\
\text { subunits) }\end{array}$ & $\begin{array}{l}\text { - Elevated self-grooming } \\
\text { - Increased marble burying } \\
\text { and digging } \\
\text { - Increased perseverative } \\
\text { behavior (Y-maze) } \\
\text { - Motor problems }\end{array}$ & $\begin{array}{l}\text { - Impaired corticostriatal } \\
\text { synaptic transmission in the } \\
\text { dorsal striatum } \\
\text { - Altered NMDA/AMPA ratio } \\
\text { - Reduced mEPSC } \\
\text { frequencies } \\
\text { - Reduced spine density of } \\
\text { spiny projections neurons in } \\
\text { the dorsal striatum }\end{array}$ & & Xu et al. (2017) \\
\hline
\end{tabular}

Treatment strategies discussed are from preclinical studies in rodent models targeting behavioral abnormalities including stereotypic behaviors. 
in cell growth, protein synthesis, and axon formation (Choi et al., 2008; Huang and Manning, 2008). Tsc2 $2^{+/}$mice with heterozygous TSC2 gene mutations exhibit learning, and memory deficits associated with aberrant mTOR signaling mediated LTP in the hippocampal CA1 region (Ehninger et al., 2008). Mice with Tsc2 loss in cerebellar Purkinje cells (Tsc2f/-; Cre mice) display ASD-like behaviors, including social deficits and repetitive behavior (Reith et al., 2013). Further, Tsc2 mutant mice with Tsc2 gene deletion from radial glial progenitor cells exhibit lamination aberrations, enlargement of neurons and glia, myelination defects, and astrocytosis (Way et al., 2009). Also, mice with ablated TSC1 expression in neurons show seizures and neuropathological aberrations including enlarged, ectopic neurons in the hippocampus, cortical, thalamic brain areas, alterations in glutamatergic synapses, abnormalities in cortical lamination, cytoskeleton, dendritic spine structure, and myelination (Tavazoie et al., 2005; Meikle et al., 2007). Application of mTORC1 inhibitors rapamycin and RAD001 [40-O-(2-hydroxyethyl)-rapamycin] ameliorates synaptic, cognitive, and behavioral deficits in a mouse model of tuberous sclerosis (Ehninger et al., 2008; Meikle et al., 2008; Zeng et al., 2008; Ehninger and Silva, 2011; Bateup et al., 2013).

Rett syndrome (RTT) is caused by mutations in the MECP2 gene located on the X-chromosome, which encodes for methyl-CpG-binding protein 2 (MeCP2) and affects brain development mostly in females (Ghidoni, 2007). Several mouse models of autism have been developed to study the effects of MeCP2 mutations (Chahrour and Zoghbi, 2007; Samaco et al., 2008). Mutant mice with truncated MeCP2 protein show repeated forelimb motions similar to repetitive hand movements in individuals with Rett syndrome (Table 1) (Shahbazian et al., 2002; Moretti et al., 2005). Dopaminergic deficits are implicated in RTT, such as decreased levels of dopamine transporter (DAT) (Wong et al., 1998), the altered density of dopamine D2 receptors in the striatum (Chiron et al., 1993), and reduced levels of tyrosine hydroxylase (TH), dopamine synthetic enzyme, in the striatum (Panayotis et al., 2011), suggesting striatal dysfunction in RTT individuals. Additionally, MeCP2 null mice exhibit deficits in motor coordination and motor learning along with memory deficits in the MWM. Environmental enrichment alters excitatory synaptic density in cortex and cerebellum, LTP deficit, increased BDNF levels in cortex, and rescued motor learning deficits (Lonetti et al., 2010).

Autism susceptibility genes, such as neuroligin genes (NL1, $2,3,4)$ encode the eponymous members of postsynaptic cell surface adhesion proteins that are crucial for synapse formation and maintenance (Südhof, 2008). Deletion and point mutation of neuroligin-3 (NL3) are associated with autistic behavioral phenotypes (Jamain et al., 2003; Levy et al., 2011). Overexpression of neuroligin-2 (NL2) in PFC leads to repetitive jumping behavior in mice (Table 1) (Hines et al., 2008). Moreover, deficits in neurexins, which are presynaptic cell adhesion proteins that serve as ligands for neuroligins and modulates synapse differentiation and maturation, control transmitter release, result in stereotypic grooming and altered nest-building behaviors in neurexin1a mutant mice (Etherton et al., 2009; Li and Pozzo-Miller, 2020).
SH3 and multiple ankyrin repeat domains 1, 2, and 3 (SHANK1, SHANK2, and SHANK3) are postsynaptic scaffolding proteins present in excitatory synapses that are important for synaptic development and function (Grabrucker et al., 2011; Guilmatre et al., 2014). The Shank3 protein contains multiple conserved motifs, comprising an ANK repeat, PDZ, and SAM domains, a proline-rich cluster, and $\mathrm{SH} 3$ (Gundelfinger et al., 2006; Kreienkamp, 2008). The SHANK proteins also regulate spine morphology and receptor endocytosis, promote interaction of signaling pathways and facilitate synaptic plasticity, crucial for the process of learning and memory (Ehlers, 1999; Sheng and Kim, 2000; Monteiro and Feng, 2017). Mutations in Shank genes are implicated in ASD (Schmeisser, 2015). In particular, PMS or 22q13.3 deletion syndrome is characterized by developmental and speech delays, intellectual disability, reduced motor function, and ASD. PMS is caused by loss of function of the SHANK3 gene resulting in reduced expression of SHANK3 protein, affecting synaptic transmission and plasticity (Costales and Kolevzon, 2015). SH3 and multiple ankyrin repeat domains 3b mutant mice (Shank $3 \mathrm{~b}^{-/-}$) show repetitive grooming behavior (Table 1) (Peça et al., 2011; Schmeisser et al., 2012). Moreover, Shank3B mutant mice manifest functionally impaired AMPA and NMDA receptors (Peça et al., 2011; Sala et al., 2015; Peixoto et al., 2016) (Figure 2). Shank $1^{+/-}$mice display increased self-grooming behavior during adulthood (Sungur et al., 2014), while Shank $2^{-/}$mice manifest hyperactivity and repetitive jumping behavior along with the reduced activity of NMDA receptors (Table 1) (Schmeisser et al., 2012; Won et al., 2012). In contrast, Shank1 genotypes (Shank $1^{+/+}$, Shank $1^{+/-}$and Shank $1^{-/-}$) exhibit high self-grooming behaviors, but which are confounded by behavioral testing or housing conditions. Shank1 null mutant mice show decreased transitions in the light-dark test, suggesting anxiety-related phenotypes and reduced motor abilities (Silverman et al., 2011).

Contactin associated protein-like 2 (CASPR-2) transmembrane protein is encoded by the CNTNAP2 gene of the neurexin superfamily that primarily mediates cell-cell adhesions in the nervous system (RodenasCuadrado et al., 2014). Also, the CNTNAP2 gene plays an important role in the formation of dendritic spines and dendritic arborization (Anderson et al., 2012). Cntnap2 KO mice exhibit neuronal migration abnormalities, decreased cortical interneurons number, and aberrant hippocampal and cortical network activity (Peñagarikano et al., 2011). Also, the Cntnap2 mutant mice show reduced densities of dendritic spines along with decreased levels of AMPA receptors (AMPAR) subunit GluA1 in the spines (Gdalyahu et al., 2015; Varea et al., 2015; Gao et al., 2019). Further, the decreased number of parvalbuminpositive interneurons in the striatum results in altered activity of the cortico-striatal-thalamic pathway underlying repetitive behaviors (Lauber et al., 2018). Mice with the CNTNAP2 mutation display repetitive self-grooming behavior, rescued by risperidone, a dopamine D2 receptor antagonist (Table 1) (Peñagarikano et al., 2011), thereby, decreasing dopaminergic function and cortical activation (Parr-Brownlie and Hyland, 2005). 
In addition to the above autism susceptibility genes, many other genes implicated in autistic phenotypes have been investigated in preclinical studies. Mutations in protocadherin 19 (PCDH19) chromosome X-linked gene, leads to Epilepsy in Females with Mental Retardation (EFMR) disease, cognitive impairments, and autistic phenotype (Ryan et al., 1997; Dibbens et al., 2008; Hynes et al., 2010; Specchio et al., 2011). PCDH19 gene encodes PCDH19 protein which is a cell-adhesion protein. PCDH19 regulates hippocampal neurons maturation, migration, and GABAergic transmission via binding with GABA-A receptor alpha subunit (Bassani et al., 2018). Additionally, PCDH19 interacts with intracellular protein NONO, involved in the modulation of steroid hormone receptors (Pham et al., 2017). Male mice with $P c d h 19$ knockout (Pcdh19 $\mathrm{X}^{\text {LacZ } / Y)}$ exhibit increased rearing and stereotypic grooming behaviors (Lim et al., 2019).

Ephrins are membrane-bound proteins acting as ligands of ephrin receptors, belonging to receptor tyrosine kinases (RTKs) family which are transmembrane proteins. They serve important functions including angiogenesis, axon guidance, cell migration, tissue border formation, and synaptic plasticity (Chin-Sang et al., 1999; Kullander and Klein, 2002; Martínez and Soriano, 2005; Héroult et al., 2006; Aoto and Chen, 2007; Klein, 2009). In CNS, ephrins and Eph receptors are involved in axon pathfinding, topographic development of different brain regions and connectivity, neuronal migration, dendritic spine maturation, synapse formation, and plasticity (Gao et al., 1996; Dalva et al., 2000; Ethell et al., 2001; Grunwald et al., 2001, 2004; Henkemeyer et al., 2003; Murai et al., 2003; Palmer and Klein, 2003; Bolz et al., 2004; Klein, 2004; Yamaguchi and Pasquale, 2004; Egea and Klein, 2007; Akaneya et al., 2010; Triplett and Feldheim, 2012). Deletion of ephrin-A2 in mice exhibits impairment of behavioral flexibility in visual discrimination reversal-learning task (Arnall et al., 2010). Mice with a double knockout of ephrin-A2 and ephrin-A3 manifest excessive stereotypic facial grooming behaviors, resulting in face lesions. Also, they show reduced locomotor activity, shift towards grooming in the marble-burying assay, and increased pre-pulse inhibition of acoustic startle (Wurzman et al., 2015). The repetitive grooming behavior in double knockout mice suggests abnormalities in sensorimotor gating (Ben-Sasson et al., 2007; Perry et al., 2007; Wurzman et al., 2015). Ephrin-A2 and ephrin-A3 are located at excitatory synapses in multiple brain regions. Their deletions may result in altered excitability of forebrain networks suggesting defective processing of sensory information (Qiu et al., 2012; Wurzman et al., 2015).

Phosphoinositide signaling is important for cell survival and proliferation. Phosphoinositide 3-kinase (PI3K), Akt (serine/threonine kinase), and mammalian target of rapamycin (mTOR) are important interlinks in the PI3K pathway and are activated by upstream receptor tyrosine kinases (RTKs) and regulates protein synthesis for cell growth and proliferation (Cantley, 2002). Phosphatase and tensin homolog deleted on chromosome 10 (PTEN), a tumor suppressor gene is a negative regulator of the PI3K/AKT/mTOR signaling pathway (Ali et al., 1999; Sansal and Sellers, 2004). Pten is an ASD candidate risk gene and its mutation is reported in a subset of autistic cases with macrocephaly (Butler et al., 2005; Herman et al., 2007; Varga et al., 2009). Mice with PTEN deletions in cortical and hippocampal neurons show macrocephaly and ASD behavioral deficits, including seizures, increased anxiety, and learning deficits. The conditional Pten mutant mice exhibit neuronal hypertrophy associated with abnormal activation of the Akt/mTOR pathway and Gsk3b inactivation (Kwon et al., 2006). Additionally, conditional Pten knockout in astrocytes results in increases in their size (Fraser et al., 2004). Further, Pten conditional KO mice exhibit increased spine number, myelination defects, and changes in synaptic structure and transmission (Fraser et al., 2008). Germline Pten ${ }^{+/-}$male mice also exhibit increased marble burying and digging, suggesting repetitive behavioral phenotype (Clipperton-Allen and Page, 2014, 2015). Deletion of PTEN causes changes in synaptic scaffolding proteins (PSD-95, Sapap1, sap-102) and reduced mGluR expression in the hippocampus (Lugo et al., 2014). PTEN also exhibits critical functions during development, with significant implications for autism and neurodevelopmental disorders (Rademacher and Eickholt, 2019). Hence, PTEN dysfunction in neurons has profound effects on neuronal morphology and connectivity resulting in ASD-like behaviors.

Additionally, the Homeobox protein (Hoxb8) protein is encoded by the HOXB8 gene, a member of the homeoboxcontaining group of transcription factors, involved in developmental processes such as positioning along the anteriorposterior axis and other physiological functions. Hoxb8 mutant mice display excessive grooming behavior resulting in skin lesions and anxiety-like behavior (Greer and Capecchi, 2002). In mouse brains, Hoxb8 cell lineage is present in the microglia. Hoxb8 mutant mice with Hoxb8 mutations in microglia, exhibit increased cortical dendritic spine density and dendritic spines in the striatum, defects in synapse structure, LTP, and miniature postsynaptic currents. Long-term application of fluoxetine (SSRI) attenuates excessive grooming and hyperactivity in Hoxb8 mutant mice. Hence, Hoxb8 in microglia may play role in the modulation of cortico-striatal circuits and associated grooming behavior (Chen et al., 2010; Nagarajan et al., 2018).

$\mathrm{KCNQ} / \mathrm{K}_{\mathrm{v}} 7$ channels mediate voltage-dependent outward potassium currents regulating resting membrane potential and decreasing neuronal excitability. KCNQ2 encodes subunits of neuronal KCNQ/ $\mathrm{K}_{\mathrm{V}} 7-\mathrm{K}^{+}$channels, $\mathrm{K}_{\mathrm{V}} 7.2$, which are present in the hippocampus and cortex. Mutations in $\mathrm{K}_{\mathrm{V}} 7.2$ are associated with developmental delay and autism (Cooper et al., 2001; Yue and Yaari, 2006; Shah et al., 2008; Brown and Passmore, 2009). Mice with heterozygous null mutations in the KCNQ2 gene $\left(\mathrm{KCNQ}^{+/-}\right)$exhibit elevated locomotor activity, hyperactivity, exploratory and repetitive grooming, suggesting loss of $\mathrm{K}_{\mathrm{V}} 7.2$ is linked to ASD behavioral abnormalities (Kim et al., 2020).

Kin of Irregular Chiasm-like 3 (KIRREL3) gene mutations are linked with neurodevelopmental disorders including autism and intellectual disability (Bhalla et al., 2008; Iossifov et al., 2012; Baig et al., 2017). The KIRREL3 gene encodes the Kin of IRRE-like protein 1 (KIRREL3), also called NEPH2 (Sellin et al., 2003). KIRREL3 (NEPH2) is a member of the KIRREL protein family of transmembrane proteins that includes KIRREL (NEPH1) and KIRREL2 (NEPH3). KIRREL3 plays a role in kidney 
blood filtration function and is a synaptic cell-cell adhesion molecule (Gerke et al., 2006; Neumann-Haefelin et al., 2010). Kirrel3 in mice is present in the developing cochlea, retina, and olfactory neuroepithelial regions and in the adult nervous system comprising sensory regions (Morikawa et al., 2007). Disruption of the function of the KIRREL3 gene is associated with alterations in brain function. The gene is implicated in neural circuit development including neuronal migration, axonal fasciculation, and synapse formation (Serizawa et al., 2006; Nishida et al., 2011; Prince et al., 2013). KIRREL3 gene knockout in mice leads to alterations in synapses connecting dentate gyrus (DG) neurons to GABAergic neurons but no changes were observed in synapses linking DG neurons to CA3 neurons. This resulted in the disruption of DG synaptic activity and overactivation of CA3 neurons (Martin et al., 2015). KIRREL3 KO mice display increased rearing repetitive behavior, hyperactivity, impaired novel object recognition, and sensory abnormalities (Choi et al., 2015; Hisaoka et al., 2018).

Furthermore, Integrin-beta3 gene encodes integrin beta-3 protein which is a cell-surface protein (a member of alpha/beta heterodimeric receptors) and is involved in various functions including cell adhesion/migration, cell-extracellular matrix interactions, and axon/dendrite outgrowth (Sosnoski et al., 1988; De Arcangelis and Georges-Labouesse, 2000; Clegg et al., 2003). Increased integrin-beta3 activity leads to elevated SERT transport of 5-HT and increased blood serotonin levels which are reported in autistic individuals (Carneiro et al., 2008). Mice with a mutation in the integrin-beta3 gene exhibit elevated grooming in novel environments with no changes in activity in the open field test. Disruption of integrin-beta3 protein impairs platelet aggregation resulting in increased bleeding times and hemorrhages. Additional studies are required to ascertain behavioral abnormalities in integrin-beta3 deficient mice (Carter et al., 2011).

Netrin-G ligand 2 (NGL-2)/LRRC4 is a leucine-rich repeat comprising postsynaptic cell adhesion molecule which interacts with PSD-95, excitatory postsynaptic scaffolding protein, and netrin-G2, a presynaptic cell adhesion molecule (Lin et al., 2003; Kim et al., 2006; Woo et al., 2009; Matsukawa et al., 2014). NGL-2 is implicated in intellectual disability and ASD (Jiang et al., 2013; Sangu et al., 2017). NGL-2 is involved in the regulation of glutamatergic synapse development and excitatory transmission (DeNardo et al., 2012). Mice with mutations in NGL-2 $\left(\mathrm{LrCH}^{-/-}\right)$exhibit reduced hippocampal NMDA receptor synaptic plasticity (Soto et al., 2013, 2018; Um et al., 2018). Lrrc4 ${ }^{-/-}$mice show repetitive self-grooming behavior which is rescued by $\mathrm{D}$-cycloserine, the NMDAR agonist. Also, Lrrc $^{-/-}$mice exhibit impaired spatial learning in the MWM test and mild anxiety-like behavior (Um et al., 2018).

Similarly, Nerve injury-induced protein 1 (Ninjurin1/Ninj1), is a cell-adhesion molecule involved in nerve regeneration, angiogenesis, inflammation, and cancer (Araki and Milbrandt, 1996; Ifergan et al., 2011; Matsuki et al., 2015; Jang et al., 2016). Ninj1 is expressed in cortico-thalamic circuits and is implicated in the regulation of synaptic transmission. Mutation in Ninjurin1 (Ninj1) in mice leads to excessive grooming to the point of inducing hair loss and lesions and increased anxiety-like behavior. Also, Ninj1 mutant mice exhibit glutamatergic alterations in the brain, including elevated ionotropic glutamate receptors synaptic expression and mEPSCs amplitude. Stereotypic grooming in these mice is alleviated by fluoxetine (SSRI), correlating with direct inhibitory effects of fluoxetine on NMDA receptors (Le et al., 2017).

SH3RF2 gene present in the $1.8 \mathrm{Mb}$ microdeletion at 5 q32 is implicated in autism (Gau et al., 2012; Yuen et al., 2017). It plays a role as an anti-apoptotic regulator of the JNK pathway via degrading SH3RF1 protein that activates the JNK pathway (Wilhelm et al., 2012; Kim et al., 2014). Mice with haploinsufficiency of Sh3rf2 (Sh3rf2 ${ }^{+/-}$) show increased jumping, rearing behavior, bury more marbles in the marbleburying test correlating with elevated digging behavior and hyperactivity. Abnormalities in dendritic spine development in the hippocampus, AMPAR-mediated excitatory synaptic transmission in CA1 hippocampus, altered hippocampal pyramidal neurons membrane properties, and increases in NR2A and GluR2 glutamate receptor subunits in the hippocampus are observed in Sh3rf2 $2^{+/-}$mutant mice (Wang S. et al., 2018).

Additionally, the p21-activated kinase 2 (PAK2), a serine/threonine kinase, activated by Rho GTPases plays a crucial role in regulating cytoskeleton remodeling, dynamics, the formation of postsynaptic dendritic spines, and cortical neuronal migration (Bokoch, 2003; Boda et al., 2006; Asrar et al., 2009; Causeret et al., 2009; De La Torre-Ubieta et al., 2010). Mutations in the PAK2 gene are implicated in ASD (Willatt et al., 2005; Quintero-Rivera et al., 2010; Sagar et al., 2013). Haploinsufficiency of Pak2 leads to reduced spine densities in cortex and hippocampus, impaired hippocampal CA1 LTP, decreased phosphorylation of actin regulators LIMK1, cofilin, and reduced actin polymerization. Pak2 $2^{+/-}$mice show repetitive grooming behavior and bury more marbles in the marbleburying test (Wang Y. et al., 2018). This suggests PAK2 is critical in brain development and its mutation contributes to autistic phenotypes.

The SCN1A gene heterozygous loss of function mutation results in Dravet Syndrome. Haploinsufficiency of the SCN1A gene affects the $\alpha$ subunit of the voltage-gated sodium channel $\left(\mathrm{Na}_{V} 1.1\right)$ in mice leading to autistic behavioral phenotypes, including hyperactivity and stereotypic behaviors such as self-grooming and circling behaviors. Scn1a ${ }^{+/-}$mouse model of autism exhibit increased excitation in the prefrontal cortex (PFC). Deletion of sodium channels $\left(\mathrm{Na}_{\mathrm{v}} 1.1\right)$ in cortical interneurons causes reduced sodium $\left(\mathrm{Na}^{+}\right)$currents and neurotransmission of GABAergic interneurons resulting in altered GABAergic activity, hyperexcitability, and behavioral impairments in the mutant mice (Table 1) (Han et al., 2012).

Mutations in receptor proteins are also involved in autistic phenotypes. Oxytocin is a peptide produced in the brain, particularly in the paraventricular nuclei and hypothalamic supraoptic. It is secreted primarily by the posterior pituitary gland into the circulation (Lee et al., 2009). Oxytocin facilitates biological effects by binding to the oxytocin receptor (Oxtr). The oxytocin receptor is mainly found in the amygdala, hippocampus, olfactory lobe, and hypothalamus areas of the brain (Gould and Zingg, 2003). Oxtr ${ }^{-/-}$mice exhibit autistic-like 
phenotypes, increased self-grooming behavior in a visible burrow system (VBS) (Pobbe et al., 2012). Oxtr-/- mice also exhibit cognitive inflexibility during the reversal phase in the T-maze test and increased aggression. Oxtr ${ }^{-1-}$ mice exhibit alterations in excitatory synaptic markers including PSD95, gephyrin scaffolding proteins, and glutamatergic, GABAergic receptors along with changes in striatal dendritic spines, indicating striatal dysfunction (Sala et al., 2011; Leonzino et al., 2019).

Environmentally induced alterations to the developing nervous system, such as through specific teratogenic agents or restricted housing also contribute to the etiology of ASD. In utero valproic acid (VPA), an antiepileptic drug, exposed mice and rats show increased repetitive behaviors, such as self-grooming along with reduced social interactions and communication dysfunction (Schneider and Przewocki, 2005; Bromley et al., 2008).

C58/J, an inbred mice strain, show social deficits, repetitive backward somersaulting and hind limb jumping behaviors, restricted novel hole-board exploration, and reversal-learning deficits in the appetitive operant task (Moy et al., 2008b; Ryan et al., 2010; Muehlmann et al., 2012; Whitehouse et al., 2017). The hole-board test measures the number of nose-pokes (head-dipping) into holes in the floor arena as a measure of exploratory behavior (Moy et al., 2008a). Moreover, BTBR, an inbred mouse strain, shows ASD-like behavioral phenotype including social, communication deficits and stereotypic behaviors (McFarlane et al., 2008; Silverman et al., 2010; Wöhr et al., 2011). Balb/c mice, another inbred strain shows ASD-like behaviors, such as sociability deficits and stereotypic behaviors. Functional alterations in NMDAR mediated activity and elicitation of jumping and circling behavior by NMDAR antagonist MK-801 application is described in Balb/c strain (Deutsch et al., 1997; Burket et al., 2010).

Deer mice belong to a diverse Peromyscus genus of Cricetidae rodent family that is native to North America and utilized as a laboratory animal model for basic and applied research (Joyner et al., 1998; Crossland and Lewandowski, 2006). Deer mice exhibit repetitive behavior including hindlimb jumping and backward somersaulting upon being maintained in standard laboratory housing. The repetitive behaviors showed by deer mice occur at an increased rate, apparent during initial development and continuing across the lifespan. Deer mice also display reversal learning deficits in a procedural learning behavioral task involving learning to change spatial habits upon relocation of reinforcement in a T-maze (Hadley et al., 2006). Hence, deer mice are used as animal models of repetitive/restricted behaviors in autism (Powell et al., 2000; Lewis et al., 2007; Bechard et al., 2017).

\section{GLUTAMATERGIC AND GABAERGIC SIGNALING}

The normal balance of excitation and inhibition (E/I) in the forebrain is maintained by excitatory glutamatergic neurons and inhibitory GABAergic interneurons. The major excitatory neurotransmitter in the cortex is glutamate, which activates two types of receptors, i.e., ionotropic and metabotropic
G-protein coupled receptors (Mehta et al., 2011). Increased excitatory signaling, hyper-excitable local connectivity, and decreases in inhibitory interneurons accompany repetitive behavioral changes in the brains of ASD animals (Rinaldi et al., 2007; Gogolla et al., 2009). Interestingly, these behaviors are ameliorated by environmental enrichment, correlating to functional alterations in neural circuitry by modifying cortical excitatory and inhibitory synaptic density, LTP, increasing BDNF expression and synaptic plasticity in the cortical network (Schneider et al., 2006; Baroncelli et al., 2010; Lonetti et al., 2010; Reynolds et al., 2013; Jung and Herms, 2014).

Glutamatergic signaling plays a crucial role in the modulation of repetitive behaviors. On the one hand, NMDA receptors play important roles in the regulation of neurotransmitter release such as glutamate affecting excitatory neural pathways. For instance, intra-striatal injections of NMDA, glutamate receptor ligand, induces repetitive behaviors caused by elevated glutamatergic activity in the basal ganglia motor circuits (Karler et al., 1997). Deer mice exhibit repetitive behaviors, such as excessive jumping and backward flips, attenuated by interrupting cortico-striatal glutamatergic projections via striatal injection of NMDA receptor antagonist MK-801 (dizocilpine) (Presti et al., 2003). Mice with astrocyte-specific inducible deletion of GLT-1 (GLAST $^{\text {CreERT2/+ }} / \mathrm{GLT1}^{\text {flox/flox }}$, iKO) manifesting stereotypic grooming behavior is alleviated by memantine, NMDA receptor antagonist (Aida et al., 2015).

On the other hand, NMDA receptors are also expressed on the surface of GABAergic neurons modulating their inhibitory tone and controlling oscillations of pyramidal neurons involved in the regulation of neuronal rhythms and activity (Benes, 2010; Deutsch et al., 2010). For instance, systemic application of anti-glutamatergic agents, phencyclidine (PCP), an NMDA receptor antagonist, evokes stereotypic behaviors, including self-grooming in rodents. NMDA antagonist application might inhibit excitation of GABAergic inputs onto pyramidal neurons causing disinhibitory (i.e., hyperexcitation of pyramidal neurons) increase in glutamate efflux and glutamatergic neurotransmission via AMPA and non-NMDA receptors in the PFC, activating motor pathways (Liu and Moghaddam, 1995). This PCP or non-NMDA receptor-induced stereotypic grooming is alleviated by blocking AMPAR (non-NMDAR) mediated glutamatergic transmission between the prefrontal cortex (PFC) and ventral tegmental area (VTA) (Takahata and Moghaddam, 2003; Audet et al., 2006) (Figure 2). Also, neuroligin-1 (NL1) knockout mice exhibit a reduced NMDA/AMPA ratio in the dorsal striatum that correlates with repetitive grooming behavior, which is rescued by systemic administration of D-cycloserine, an NMDA receptor partial co-agonist (Blundell et al., 2010). Shank $2^{-/}$mice manifest reduced NMDA receptor function and social deficits, normalized by application of D-cycloserine (Won et al., 2012). D-cycloserine is also revealed to improve sociability deficits and stereotypies in BTBR and Balb/c inbred mouse strains of ASDs (Deutsch et al., 1997, 2011a,b; Burket et al., 2013).

Dysfunction of glutamatergic signaling at the metabotropic glutamate receptor 5 (mGluR5) is implicated in neuropsychiatric 


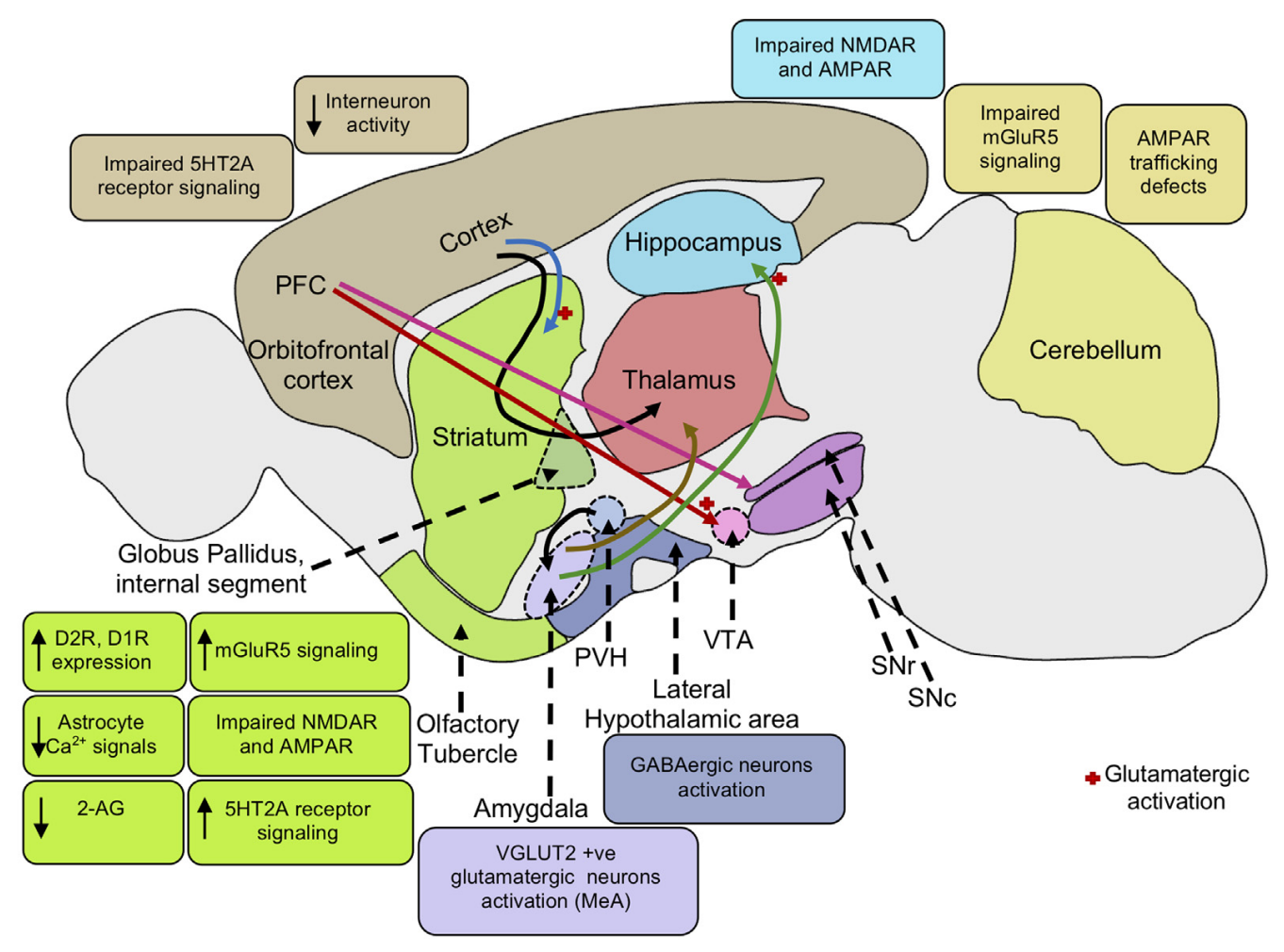

FIGURE 2 | Neural mechanisms underlying repetitive behaviors. Increased mGluR5 signaling activates the striatal direct pathway leading to heightened motor cortex activity inducing repetitive behaviors. Impaired NMDA and AMPA receptors in the striatum and hippocampus also mediates stereotypic behaviors. Cortico-striatal and PFC-VTA glutamatergic projections induce repetitive behavior. PFC projections to the SNc causes striatal dopaminergic release promoting movement. The decrease in interneuron activity in the cortex and increase in dopamine D2, D1 receptor expression in the striatum leads to reduced GABAergic signaling in the cortex, enhancing motor cortical activity, and repetitive behaviors. Elevation of serotonin $5 \mathrm{HT}_{2 \mathrm{~A}}$ receptor signaling in the dorsomedial striatum gives rise to stereotypic behaviors. Activation of VGLUT-positive glutamatergic neurons in the amygdala nucleus, MeA also results in stereotypic behaviors. Activation of glutamatergic projection from BLA to the ventral hippocampus leads to an increase in locomotor activity. Further, activation of lateral hypothalamic GABAergic neurons mediates an increase in locomotor activity and repetitive behaviors. Reduction in endocannabinoid 2-AG signaling in the striatum leads to an increase in glutamatergic output, enhancing motor cortex activity resulting in repetitive behaviors. Low astrocytic $\mathrm{Ca}^{2+}$ signals in the striatum elevate membrane GAT-3 expression that modulates striatal MSN activity via reduced ambient GABA levels inducing repetitive behavior. mGluR5, metabotropic glutamate receptor 5; NMDA, N-Methyl-d-aspartate; AMPA, $\alpha$-amino-3-hydroxy-5-methyl-4-isoxazolepropionic acid; PFC, prefrontal cortex; VTA, ventral tegmental area; SNc, substantia nigra pars compacta; SNr, substantia nigra pars reticulata; $\mathrm{PVH}$, paraventricular nucleus of the hypothalamus; GABA, gamma-aminobutyric acid; D2R, dopamine receptor D2; D1R, dopamine receptor D1; 5HT 2A, 5-hydroxy-tryptamine receptor 2A subtype; VGAT, vesicular GABA transporter; MeA, medial nucleus of the amygdala; BLA, basolateral amygdala; 2-AG, 2-arachidonoyl glycerol; GAT-3, GABA transporter 3; MSN, and medium spiny neuron.

disorders such as autism (Carlson, 2012) (Figure 2). As noted above, Fragile X Syndrome is a genetic disorder associated with autism and mental retardation. This disorder is caused by a loss of FMRP (Hagerman et al., 2017; Niu et al., 2017). The "mGluR theory of fragile X" suggests that FMRP and Group I metabotropic glutamate receptors (mGluRs) regulate protein synthesis at the synapse in an antagonist manner. mRNA translation at the synapse is activated by mGluRs and repressed by FMRP (Bear et al., 2004; Bear, 2005; Dölen and Bear, 2008). Fmr1-KO mice manifest increased expression of mGluR-dependent long-term depression (LTD) in the hippocampus, which is likely associated with alterations in mGluR signaling that contribute to repetitive behaviors in mutant mice (Table 1) (Yan et al., 2005; Nosyreva and Huber, 2006; Dölen and Bear, 2008; McNaughton et al., 2008; Pietropaolo et al., 2011). Also, Shank $3^{\Delta e 4-22-/-}$ mice (exons 4-22 deletion) exhibit excessive grooming and have reduced striatal postsynaptic mGluR5-Homer scaffolding proteins, altered mGluR5 signaling in the striatum and cortico-striatal circuit abnormalities (Wang X. et al., 2016). Interestingly, in the Ube $3 \mathrm{~A}^{\mathrm{m}-/ \mathrm{p}+}$ (maternal null mutation) mouse model of Angelman Syndrome, mGluR-dependent LTD and coupling of mGluR5 to Homer proteins in the hippocampus is enhanced (Pignatelli et al., 2014). A mouse model of Tuberous Sclerosis $\mathrm{Tsc}^{+/-}$exhibits reduced mGluR-LTD (LTD) in the hippocampus and altered levels of mGluR signaling Arc (activity-regulated cytoskeleton-associated) protein, which is crucial for AMPAR internalization in cerebellar LTD (Auerbach et al., 2011). This suggests that altered mGluR5 function may underlie cognitive and behavioral impairments in mutant mice models (Table 1) (Auerbach et al., 2011; Pignatelli et al., 2014). 
Several studies have demonstrated the therapeutic efficacy of the mGluR5 receptor antagonist, 2-methyl-6-phenyethylpyrididine (MPEP), on core behavioral deficits of autism. MPEP reduces repetitive and stereotypic behaviors in the VPA and BTBR mouse models of autism (Silverman et al., 2010; Mehta et al., 2011) (Figure 3). Additionally, MPEP application decreases marble burying stereotypic behavior in Fmr1 KO mice and excessive repetitive grooming in Shank3 $3^{\Delta e 4-22-/-}$ mice via modulation of mGluR5 signaling (Thomas et al., 2012; Gandhi et al., 2014; Wang X. et al., 2016). Also, in C58/J mice that exhibit stereotypic jumping behavior, backflips, and decreased exploratory behavior, blocking mGluR5 signaling via GRN-529, a mGluR5 negative allosteric modulator, rescues normal behavior (Silverman et al., 2012). The suppression of mGluR5 activity may modify NMDA receptor activity, since they are close associates at the postsynaptic density, suggesting NMDA receptor hyperfunction underlies jumping behavior in C58/J mice (Kim et al., 2016). Also, repetitive behavior and reversal learning deficits were attenuated by environmental enrichment in C58/J mice (Muehlmann et al., 2012; Whitehouse et al., 2017).

GABAergic signaling also plays a critical role in the regulation of stereotypic behaviors. For example, the application of GABA-enhancing drugs reduces self-grooming behavior in rodents (Silverman et al., 2015). Administration of Rbaclofen, a selective $\mathrm{GABA}_{\mathrm{B}}$ receptors agonist, alleviates repetitive self-grooming behavior in several ASD models, including the BTBR, Fragile $\mathrm{X}, \mathrm{C} 58 / \mathrm{J}$, and idiopathic mice models (Han et al., 2014; Silverman et al., 2015). Also, the application of a $\mathrm{GABA}_{\mathrm{A}}$ receptor-selective agonist, muscimol, into the bed nucleus of the stria terminalis (BNST) decreases self-grooming behavior induced by exposure to cat urine (Xu et al., 2012). Additionally, GABRB-3 knockout mice show hyperactivity and stereotypic behaviors such as circling (Moy et al., 2006). GABA also plays an important role in regulating stress and anxiety-related behaviors, with increased GABAergic signaling exerting anxiolytic effects and inhibition of stress and anxiety-induced grooming behaviors (Chao et al., 2010).

GABA receptor agonists regulate excitation and inhibition (E/I) balance, resulting in minimizing elevated excitation in motor cortical areas and parts of basal ganglia-thalamic circuitry (Lewis and Kim, 2009; Kim et al., 2016) (Figure 3). For instance, stereotypic behaviors evoked by amphetamine are diminished by the application of GABA receptor agonists (Lewis and Kim, 2009). Likewise, the application of $\mathrm{GABA}_{\mathrm{A}}$ receptor antagonist, bicuculline, in the VTA enhances self-grooming in mice induced by alpha-melanocytestimulating hormone (MSH; De Barioglio et al., 1991). Also, muscimol injections into the substantia nigra pars reticulata $(\mathrm{SNr})$ evoke repeated circling behavior in rats (Velíšek et al., 2005). Thus, altered GABA levels may modify basal ganglia activity by affecting dopaminergic neurons, leading to repetitive behaviors in rodents, as discussed further below (De Barioglio et al., 1991; Kim et al., 2016). Antidepressants/anxiolytics like fluvoxamine, bupropion, and diazepam alleviate repetitive digging behaviors
(Hayashi et al., 2010). Moreover, Fmr1 ${ }^{-/-}$mice, discussed above, exhibit hyperexcitability due to reduced activity of fast-spiking interneurons (FSI) in the somatosensory and barrel cortex (Figure 2). GABA-receptor agonists decrease marble-burying behavior in these Fmr1 knockout mice (Draper et al., 2014). Hence, altered neural signaling and E/I balance underlie repetitive behaviors associated with ASD. Enhanced GABAergic function results in reduced cortical excitation and alleviates repetitive self-grooming behavior (Kalueff et al., 2016).

\section{SEROTONERGIC SIGNALING}

Serotonergic $5 \mathrm{HT}_{2 \mathrm{~A}}$ receptors are found mainly in prefrontal cortical and striatal brain regions ( $\mathrm{Xu}$ and Pandey, 2000), which are associated with repetitive behaviors in ASD (Di Martino et al., 2011; Langen et al., 2012; Delmonte et al., 2013). Differences in serotonergic components in the basal ganglia are associated with repetitive behaviors (Di Giovanni et al., 2006). For instance, deer mice exhibit a decreased density of serotonin transporters in the striatum (Wolmarans et al., 2013). And, injection of escitalopram, a selective serotonergic reuptake inhibitor (SSRI) alleviates some of the repetitive movements in deer mice, but with no effect on jumping behavior (Wolmarans et al., 2013). Additionally, optogenetic repetitive stimulation of the medial orbitofrontal cortex-ventromedial striatum pathway in mice leads to abnormal grooming behavior, which is rescued by fluoxetine administration, also an SSRI (Schmeisser et al., 2012). Family-based genetic association studies demonstrate linkages between serotonin transporter locus (SLC6A4) variants and rigid compulsive behavior (Sutcliffe et al., 2005), with the serotonin transporter gene (SLC6A4) subtype, 5HTTLPR, consistently associated with repetitive sensory and motor behaviors (Brune et al., 2006). Also, depleting tryptophan, a precursor of serotonin augments repetitive motor behaviors in autistic adults (McDougle et al., 1996).

Clinical and preclinical studies have implicated alterations in serotonin receptor activity, particularly $5 \mathrm{HT}_{2 \mathrm{~A}}$ receptor signaling, in ASD symptomology (McBride et al., 1989; Veenstra-VanderWeele et al., 2012) (Figure 2). Systemic treatment with a serotonin $5 \mathrm{HT}_{2 \mathrm{~A}}$ receptor antagonist decreases repetitive behaviors in the BTBR mouse model of autism, an inbred strain that shows similar ASD-like behavioral deficits to an idiopathic mouse model of autism (McFarlane et al., 2008; Amodeo et al., 2012, 2014, 2016). Further, infusion of M100907, a highly selective antagonist for $5 \mathrm{HT}_{2 \mathrm{~A}}$ receptors into the dorsomedial striatum reduces grooming behavior and reversal learning deficits in BTBR mice. This regulation of reversal learning and grooming behavior by $5 \mathrm{HT}_{2 \mathrm{~A}}$ receptor antagonist infusion into the dorsomedial striatum may be associated with a reduction in striatal direct pathway activation (Reiner and Anderson, 1990; Amodeo et al., 2017). However, $5 \mathrm{HT}_{2 \mathrm{~A}}$ receptor antagonist infusion into the orbitofrontal cortex results in increased grooming behavior and perseveration in reversal learning (Amodeo et al., 2017). This altered grooming behavior by blocking 


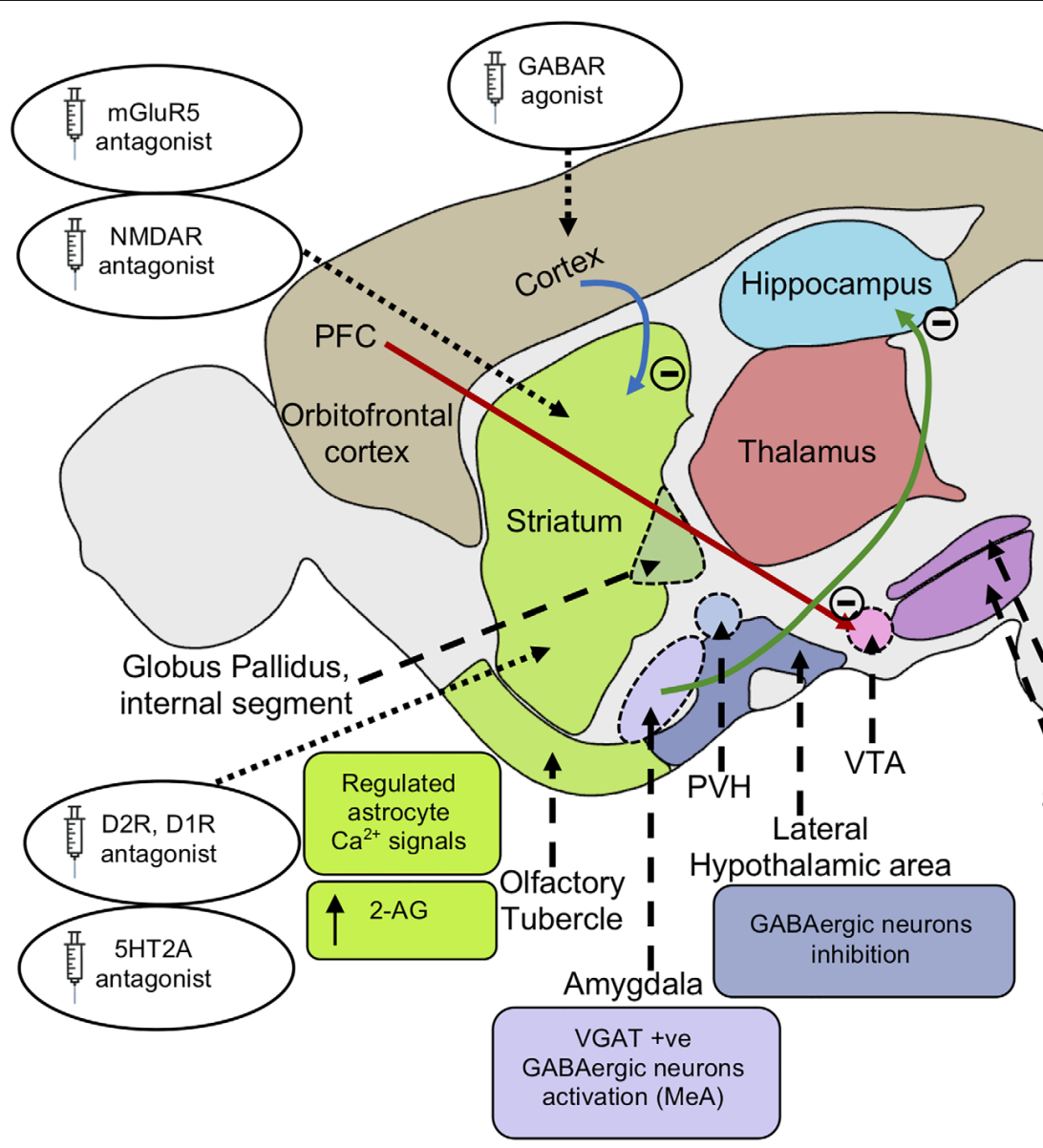

FIGURE 3 | Possible mechanisms alleviating repetitive behaviors. Inhibition of mGluR5 signaling inhibits striatal direct pathway via suppressing dopamine D1 receptor signaling. The reduced D1R signaling results in decreased motor cortex activity. Inhibition of cortico-striatal and PFC-VTA glutamatergic projections alleviate repetitive behaviors. Application of GABA agonists in the cortex and dopamine D2R, D1R antagonist in the striatum leads to an increase in GABAergic signaling in the cortex, reducing motor cortical activity and repetitive behaviors. Application of serotonin $5 \mathrm{HT}_{2 \mathrm{~A}}$ antagonist in the dorsomedial striatum also results in the rescue of repetitive behavior. Activation of VGAT-positive GABAergic neurons in the amygdala nucleus, MeA reduces repetitive behaviors. Inhibition of glutamatergic projection from BLA to the ventral hippocampus results in decreased locomotor activity. Inhibition of lateral hypothalamic GABAergic neurons leads to a decrease in locomotor activity and repetitive behaviors. Endocannabinoid 2-AG signaling in the striatum leads to reduced glutamatergic output, decreasing repetitive behaviors. Regulated astrocytes $\mathrm{Ca}^{2+}$ signals in the striatum modulate GAT-3 activity which maintains synaptic GABA levels, regulating striatal MSN activity and associated repetitive behavior. mGluR5, metabotropic glutamate receptor 5; NMDA, N-Methyl-d-aspartate; AMPA, $\alpha$-amino-3-hydroxy

-5-methyl-4-isoxazolepropionic acid; PFC, prefrontal cortex; VTA, ventral tegmental area; SNc, substantia nigra pars compacta; SNr, substantia nigra pars reticulata; $\mathrm{PVH}$, paraventricular nucleus of the hypothalamus; GABA, gamma-aminobutyric acid; D2R, dopamine receptor D2; D1R, dopamine receptor D1; 5HT 2A,

5-hydroxy-tryptamine receptor 2A subtype; VGAT, vesicular GABA transporter; MeA, medial nucleus of the amygdala; BLA, basolateral amygdala; 2-AG, 2-arachidonoyl glycerol; GAT-3, GABA transporter 3; MSN, the medium spiny neuron.

of $5 \mathrm{HT}_{2 \mathrm{~A}}$ receptor activity in the orbitofrontal cortex may be associated with an increased output by the orbitofrontal cortex via reduced interneuron activity, as the orbitofrontal infusion of GABA receptor agonist, muscimol, results in decreased grooming behavior in BTBR mice (Amodeo et al., 2017) (Figure 3).

Thus, elevated serotonin $5 \mathrm{HT}_{2 \mathrm{~A}}$ receptor signaling in the dorsomedial striatum plays a critical role in the development of stereotyped behaviors, whereas normal $5 \mathrm{HT}_{2 \mathrm{~A}}$ receptor activity in the orbitofrontal cortex contributes to attenuation of stereotyped behaviors in BTBR mice. Hence, abnormal serotonin receptor activity in various brain regions may contribute to restricted and repetitive behaviors.

\section{DOPAMINERGIC SIGNALING AND BASAL GANGLIA CIRCUITRY}

The cortico-basal ganglia-thalamic pathway implements motor patterned behaviors and is implicated in repetitive behaviors (Haber and Calzavara, 2009; Kalueff et al., 2016). Sequential patterns of behaviors, such as stereotyped sequential grooming movements, also called grooming chains, are carried out by these circuits in rodents (Berridge et al., 2005; Denys et al., 2013). Striatal lesions, particularly in the anterior dorsolateral region of the striatum, resulting in an inability to complete sequential grooming movements. Additionally, lesions of the ventral pallidum and globus pallidus result in disruption of 
grooming movements (Cromwell and Berridge, 1996), further underscoring their role in the regulation of complex and mechanistic sequenced behaviors.

Enhanced activity of basal ganglia circuitry results in increased hyperactivity and repetitive behaviors (Kim et al., 2015). In particular, the prefrontal cortical (PFC) projection to the substantia nigra pars compacta $(\mathrm{SNc})$, leads to a dopaminergic release in the striatum, which promotes movement through opposing actions on direct and indirect basal ganglia pathways. Dopamine through D1 receptors is involved in the activation of the direct pathway, which in turn activates the motor cortex, resulting in movement. In contrast, dopamine through D2 receptors on neurons present in the indirect pathway, results in inhibition of the indirect pathway, also promoting movement (Gerfen et al., 1990; Gerfen, 1995). For example, amphetamine pretreated rats, when injected with a dopamine D2, D3 receptor antagonist, sulpiride, or the GABA antagonist, bicuculine, leads to repetitive behavior (Morency et al., 1985; Karler et al., 1998; Kiyatkin and Rebec, 1999). Further, these circuits are disrupted in autistic mouse models, which display PFC abnormalities. Namely, mice with mutations in the SCN1A gene leads to autistic-like phenotypes, including hyperactivity and stereotypic self-grooming and circling behaviors and increased excitation in the PFC (Han et al., 2012).

Dopamine plays a major role in modulating striatal pathways resulting in locomotion and repetitive motor behaviors. Application of Risperidone, which acts on different molecular receptors, including blocking of dopamine D2 receptors, leads to decreases in repetitive self-grooming behavior, perseveration, hyperactivity and rescues nesting deficits in Cntnap $2^{-/-}$ mice. Similarly, systemic administration of haloperidol, a dopamine D2 receptor antagonist decreases motor cortex activity, thereby impeding locomotor movements in rats (Parr-Brownlie and Hyland, 2005). Interestingly, increased striatal dopamine D2 receptor expression leads to deficits in GABAergic activity, thereby enhancing prefrontal cortical (PFC) excitation (Li et al., 2011) (Figure 3). Hence, reduced repetitive and locomotory behavior caused by altered dopamine D2 receptor expression may be linked to heightened cortical GABAergic function and reduced PFC excitability.

Manipulation of the nigrostriatal dopamine pathway is sufficient for modulating many stereotyped behaviors (Lewis and Bodfish, 1998). Altered striatal dopamine activity is implicated in repetitive circling behaviors, which are observed in several mouse models of ASD (Vaccarino and Franklin, 1982; Ishiguro et al., 2007). Systemic administration of a dopamine precursor, L-DOPA, and a non-selective dopamine agonist, apomorphine into the striatum induces stereotyped behaviors in rodents (Ernst and Smelik, 1966; Presti et al., 2004). Likewise, injection of dopamine D1 receptor agonists evokes stereotypic and rigid behavioral phenotype in rodents (Berridge and Aldridge, 2000a,b). Furthermore, deer mice exhibit stereotyped behaviors, such as excessive jumping and backward flips, which are attenuated by intrastriatal injection of dopamine D1 receptor antagonist, SCH23390 (Presti et al., 2003) (Figure 3).
Spontaneous motor stereotypies observed in deer mice exhibit a negative association with neuropeptide enkephalin expression, a marker of striatopallidal neurons, and is attenuated by combined administration of adenosine A2A receptor agonist CGS21680 and A1 receptor agonist CPA in a dose-dependent manner, indicating altered striatal pathway activity (Tanimura Y. et al., 2010). Environmental enrichment attenuates repetitive behavior by increasing activation through the indirect basal ganglia pathway, which also results in changes in dendritic spine density in the subthalamic nucleus (STN) and globus pallidus (GP) (Bechard et al., 2016).

Several ASD mice models exhibit alterations to dopaminergic nigrostriatal signaling. Mutant mice with heterozygous deletion of the syntenic region on chromosome $7 \mathrm{~F} 3\left(16 \mathrm{p} 11^{+/-}\right)$display decreased self-grooming behavior along with hyperactivity and increased stereotypic circling behavior. Neuroanatomically, these mice have increased numbers of dopamine D2 receptorexpressing neurons in the striatum, reduced number of cortical neurons manifesting dopamine D1 receptors, and synaptic function defects (Portmann et al., 2014) (Figure 2). Mice deficient in the DAT have elevated levels of dopamine and increased stereotypic sequential grooming behavior. Dopamine D1A receptor-deficient mice manifest disrupted and shorter duration grooming bouts (Cromwell et al., 1998). Neuroligin NL3 mutations result in a selective decrease of synaptic inhibition onto dopamine D1-expressing medium spiny neurons (MSNs) in the nucleus accumbens (NAc) and result in behavioral changes in mutant mice via reduced selective striatal synaptic function in the nucleus accumbens/ventral striatum (Rothwell et al., 2014). Apart from this, neuroligin-1 and 3 mutant mice show the abnormal function of dopamine D1 MSNs leading to autistic-like repetitive behaviors (Rothwell et al., 2014; Espinosa et al., 2015). In the Shank3 gene deletion mouse model, striatopallidal D2 MSNs show postsynaptic defects and decreased AMPAR responses (Mei et al., 2016; Zhou et al., 2016). Repetitive grooming in Shank3B mutant mice is rescued by enhancing indirect striatopallidal pathway activity (Wang et al., 2017). Additionally, synaptic plasticity is impaired in dorsolateral striatal medium spiny neurons (MSN) in mutant mice carrying full Shank3 deletion in exons 4-22 $\left(\Delta \mathrm{e} 4-22^{-/-}\right)$, which also exhibit decreased striatal spine density and altered striatal synapse postsynaptic density (Peça et al., 2011; Sala et al., 2015; Peixoto et al., 2016; Wang X. et al., 2016). Finally, BTBR T + Itpr3tf/J mice show impairments in mesolimbic and striatal synaptic dopamine D2 receptor signaling resulting in reduced dopamine neurotransmission. Reductions in pre-and post-synaptic adenosine A2A receptor function also indicate associations with altered dopamine neurotransmission (Squillace et al., 2014).

Overall, dopaminergic circuitry in the basal ganglia mediates rigid and sequential behavioral phenotypes associated with ASD. As dopamine-containing neurons and pathways are crucial in movement and sequencing behaviors, the regulation of the dopaminergic system may provide a valuable tool for modulating repetitive behaviors. Hence, basal ganglia circuits play an instrumental role in the regulation of 
compulsive and repetitive behavioral phenotype associated with ASD.

\section{GLUTAMATERGIC SIGNALING AT CORTICO-STRIATAL SYNAPSES}

Striatal glutamatergic synapses express synapse-associated protein 90/postsynaptic density protein 95 (SAP90/PSD95) associated proteins (SAPAP), which form scaffolding protein complexes involved in the regulation of neurotransmitters trafficking and targeting to the post-synaptic membrane (Wu et al., 2012). Mutations in synapse-associated protein 90/postsynaptic density protein 95 -associated protein 3 (SAPAP3) that also binds to SHANK3 postsynaptic scaffolding protein is associated with stereotypic behaviors in mice (Sapap $3^{-/-}$), such as compulsive self-grooming to the point of inducing lesions, which is rescued by Sapap3 re-expression in the striatum and optogenetic stimulation of lateral orbitofrontal cortex (Welch et al., 2007; Bienvenu et al., 2009; Burguière et al., 2013).

Sapap3 mutant mice exhibit glutamatergic transmission defects at cortico-striatal synapses and elevated mGluR5 signaling, leading to abnormal striatal output and stereotyped behavior, which is alleviated by mGluR5 inhibition (Ade et al., 2016). This suppression of mGluR5 possibly inhibits the direct basal ganglia pathway resulting in reduced repetitive behaviors (Conn et al., 2005). NMDA and AMPARdependent cortico-striatal synaptic transmission is also altered. Intriguingly, systemic administration of fluoxetine, a serotonin uptake inhibitor attenuates obsessive grooming in mutant mice (Welch et al., 2007).

\section{ENDOCANNABINOID SIGNALING IN STRIATAL SYNAPSES}

Endocannabinoid signaling plays a crucial part in modulating striatal synaptic transmission and in regulating stereotypic behaviors (Chen et al., 2011; Gremel et al., 2016). The abundant endocannabinoid, 2-arachidonoyl glycerol (2-AG), activates cannabinoid-1 receptor (CB1R), mediating suppression of glutamatergic release via feedback inhibition at direct and indirect medium spiny neuron (MSN) synapses (Kano et al., 2009). Synthesis of 2-AG in the postsynaptic neuron is mediated by diacylglycerol lipase alpha (DGL $\alpha$ ) (Gao et al., 2010; Tanimura A. et al., 2010; Shonesy et al., 2014). Mice with DGL $\alpha$ knockout in direct-pathway MSN exhibit reduced levels of 2-AG in the striatum and absence of feedback inhibition mediated by $2-\mathrm{AG}$ at glutamatergic direct-pathway MSN synapses, resulting in excessive glutamatergic drive in direct-pathway MSNs (Figure 3). In addition, DGL $\alpha$ deletion in direct-pathway MSNs does not change GABAergic synaptic transmission, suggesting that alterations to excitation/inhibition balance may contribute to increased direct-pathway MSN output, resulting in excessive grooming behavior (Figure 4). Furthermore, mice with regional DGL $\alpha$ deletions in the ventral striatum (nucleus accumbens) exhibit repetitive grooming behavior (Shonesy et al., 2018). Thus, 2-AG signaling impairment in direct pathway MSNs leads to circuit alterations and ASD behavioral phenotypes, such as repetitive self-grooming behavior (Figure 2).

Group1 mGluRs play a role in mobilizing endocannabinoids in the hippocampus, contributing to increased excitability. In FMR1 null mice, mGluR5 dependent LTD is absent at excitatory synapses of PFC and ventral striatum, which is moderated by endocannabinoid 2-arachidonoylglycerol (2-AG). The Homer scaffolding complex linking mGluR5 to DGL $\alpha$ is disrupted resulting in impairment of endocannabinoid mediated LTD at excitatory synapses. Application of CB1R antagonist rimonabant improves cognitive deficits in Fmrl KO mice (Busquets-Garcia et al., 2013). Hence, endocannabinoid signaling contributes to increased excitability in FXS (Jung et al., 2012; Tang and Alger, 2015). Intriguingly, CB1, and CB2 receptor expression is upregulated in the brain of MeCP2 mutant mice. Treatment with cannabinoid cannabidivarin (CBDV) ameliorates memory deficits in $\mathrm{MeCP} 2$ mutant mice. $\mathrm{CBDV}$ also regulates $\mathrm{BDNF}$, $\mathrm{CB} 1, \mathrm{CB} 2$ receptor levels, and $\mathrm{PI} 3 \mathrm{~K} / \mathrm{AKT} / \mathrm{mTOR}$ pathway which is dysregulated in MeCP2 deficient mice (Zamberletti et al., 2019). Hence, altered endocannabinoid signaling is associated with behavioral abnormalities in neurodevelopmental disorders.

\section{ASTROCYTIC CALCIUM SIGNALING REGULATING STRIATAL CIRCUITRY}

Astrocytes perform numerous functions, including maintenance of the blood-brain barrier, extracellular ion homeostasis, synapse formation, and regulation of synaptic transmission (Khakh and Sofroniew, 2015). Astrocytes also propagate intercellular $\mathrm{Ca}^{2+}$ waves upon stimulation and modulate neuronal function through $\mathrm{Ca}^{2+}$ dependent signaling (Bazargani and Attwell, 2016). Astrocytic $\mathrm{Ca}^{2+}$ signaling stimulates the release of gliotransmitters such as glutamate, GABA, ATP, and D-serine that regulate neuronal activity (Bazargani and Attwell, 2016). Astrocytes regulate extracellular levels of glutamate via transporters like GLT1, hence influencing excitatory and inhibitory neuronal balance (Wu et al., 2012). High levels of glutamate in the extracellular space lead to over-activation of glutamate receptors, i.e., neuronal excitotoxicity. Astrocytes protect against neurotoxicity by mediating glutamate clearance from synaptic space via glutamate uptake transporters, thereby modulating neuronal activity. Astrocytes also supply ATP that is crucial for the process of glutamate uptake. In astrocytes, glutamate is converted to glutamine which acts as a precursor for the resynthesis of neurotransmitters like glutamate/GABA in neurons. Further, glutamate in the synapse induces astrocytic $\mathrm{Ca}^{2+}$ increase that results in release of glutamate from astrocytes to adjoining neurons, stimulating NMDA receptors and iGluRs (ionotropic glutamate receptors), modulating their activity. Therefore, astrocytes have dual roles in maintaining glutamate release and uptake (Bazargani and Attwell, 2016; Mahmoud et al., 2019). Astrocytes also modulate synaptic GABA levels via GABA transporters (GAT) that mediates GABA uptake. Expression of synaptic GAT1 regulates GABA levels in the synapses, thereby modulating neuronal excitability. The rise in astroglial $\mathrm{Ca}^{2+}$ signaling leads to inhibition of neuronal 


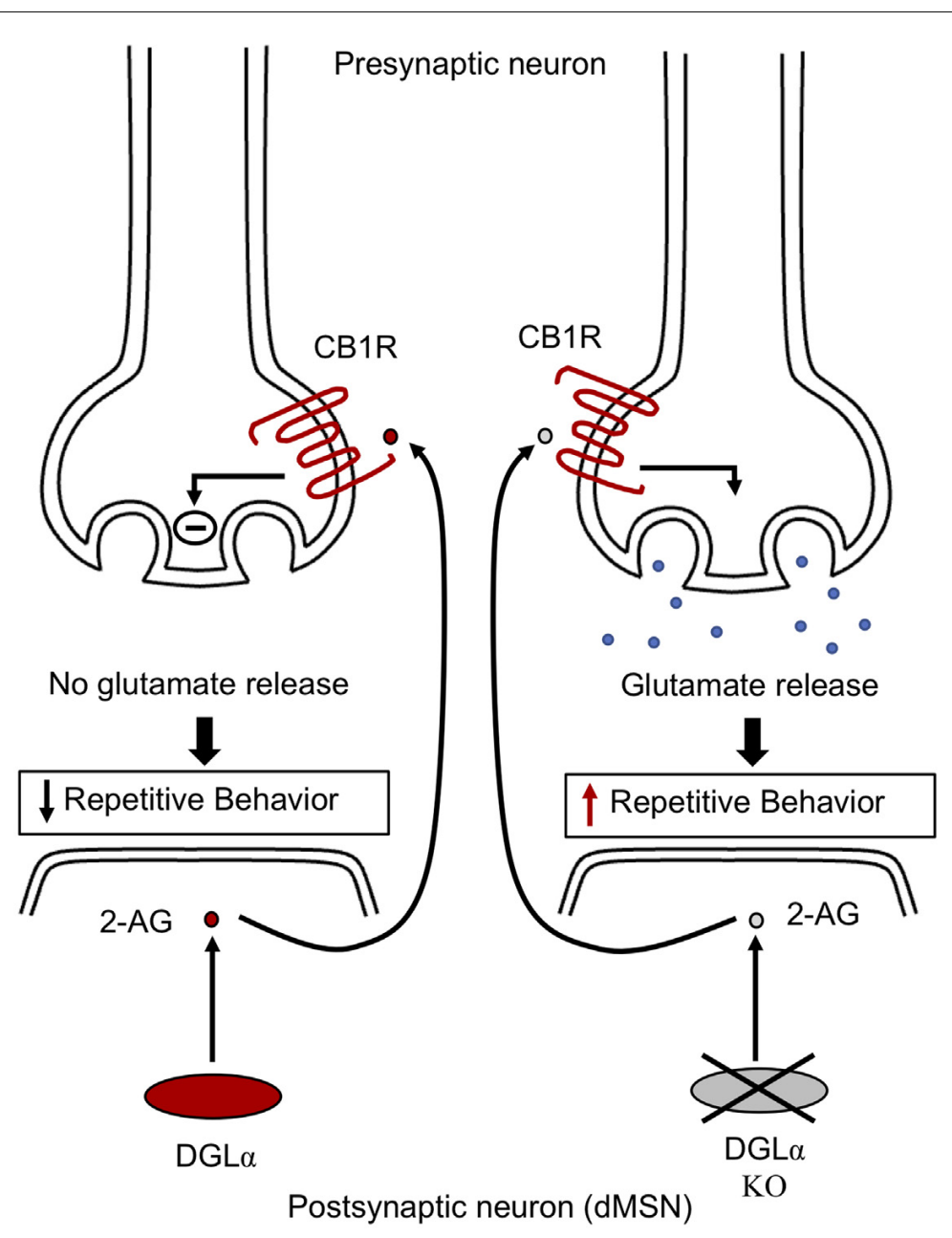

FIGURE 4 | Endocannabinoid signaling in striatal neurons. DGL $\alpha$ synthesizes 2-AG in the postsynaptic neuron. Postsynaptic 2-AG activates presynaptic cannabinoid-1 receptor (CB1R). The activated CB1 receptor via feedback inhibition leads to suppression of glutamate release at MSN synapses, thereby relieving repetitive behavior. However, mice with knockout of DGL $\alpha$ exhibit decreased striatal 2-AG levels, resulting in unrestricted synaptic glutamate release via an absence of feedback inhibition, thereby leading to elevated grooming behavior in mice. Impaired endocannabinoid signaling is involved in the alteration of striatal activity, contributing to the development of repetitive behavior. CB1R, cannabinoid type 1 receptor; DGL $\alpha$, diacylglycerol lipase alpha; 2-AG, 2-arachidonoyl glycerol; dMSN, direct pathway medium spiny neurons.

activity. This is associated with elevated GABA levels in the synapse caused by decreases in astroglial membrane GAT levels via endocytosis into astrocytes. The membrane trafficking of GAT is regulated by Rab11, Rab family small GTPases. Rab11 suppression counteracts the decrease in neuronal activity by elevated astroglial $\mathrm{Ca}^{2+}$ levels via repressing GAT endocytosis. Therefore, astrocytes regulate activity of neuronal circuits (Zhang et al., 2017). Alterations in astroglial uptake processes or gliotransmitters release is implicated in the pathogenesis of neurological disorders including epilepsy and may contribute to the development of behavioral impairments in these disorders (Mahmoud et al., 2019).

Also, astrocytic dysfunction is implicated in stereotypic behaviors associated with neuropsychiatric disorders (Molofsky et al., 2012; Aida et al., 2015; Yu et al., 2018). Mutant mice with GLT-1 inducible deletion in astrocytes
(GLAST $^{\text {CreERT2/+ }} / \mathrm{GLT1}^{\text {flox/flox }}$ iKO) display excessive self-grooming repetitive behavior resulting in self-induced injury. The knockout of astroglial GLT1 leads to alteration in the cortico-striatal synapse, suggesting glial dysfunction involvement in the pathophysiology of repetitive behaviors (Aida et al., 2015). In wild-type C57BL/6NTac mice, decreased astrocyte $\mathrm{Ca}^{2+}$ signaling in the striatum leads to increased stereotypic grooming behavior (Figure 2). In these experiments, wild-type C57BL/6NTac mice were injected with hPMCA2w/b construct to impair striatal astrocytic $\mathrm{Ca}^{2+}$ signals. The hPMCA2w/b construct consists of a w/b splice variant in human plasma membrane $\mathrm{Ca}^{2+}$-ATPases pump (hPMCA2) deficient in the cytosolic interaction domains (Yu et al., 2018). Membrane targeting of PMCA2 is determined by alternative splicing of protein cytosolic loop, in which "w" form (w splice variant) containing 45 amino acid residue 
insertion, display membrane localization of PMCA2. The b splice variant is generated at the $\mathrm{COOH}$ terminal site of the protein, an important regulatory region of the pump and its terminal sequence interacts with $\mathrm{PDZ}$ proteins (Chicka and Strehler, 2003). Astrocytes express the plasma membrane $\mathrm{Ca}^{2+}$ pump (PMCA2) that function to expel cytosolic $\mathrm{Ca}^{2+}$. The generated hPMCA2w/b mice exhibit excessive repetitive self-grooming behavior. Reduced astrocyte $\mathrm{Ca}^{2+}$ signaling decreases ambient GABA levels via enhanced GABA transporter 3 (GAT-3) activity (Figure 5). Also, Rab11a gene downregulation leads to increased GAT-3 functional activity, thereby reducing inhibition of MSNs in the striatum. The elevated self-grooming behavior is also observed in a mouse model of Huntington's disease, R6/2 that is associated with decreases in astrocytic $\mathrm{Ca}^{2+}$ signals and alleviated by blocking astrocytic GAT-3. Hence, attenuated astrocytic $\mathrm{Ca}^{2+}$ signaling decreases striatal MSN inhibition, via altered GABA levels resulting in repetitive behavior (Yu et al., 2018) (Figure 5). Moreover, astrocytic GLT1 deficient mice show increased grooming, rearing, and jumping behavior, suggesting reduced synaptic glutamate clearance resulting in glutamatergic dysfunction underlying these behaviors (Jia et al., 2021). Hence, astrocytes regulate striatal activity and associated stereotypic behavior.

Further, mice with inactivation of $T s c 1$ gene in astrocytes (Tsc1 ${ }^{\text {GFAP }}$ CKO) displays epilepsy, learning deficits, reduced GLT-1 protein expression, elevated levels of glutamate in the hippocampus, and impairment of hippocampus-LTP suggesting altered glutamate homeostasis and synaptic plasticity in a mouse model of Tuberous Sclerosis (Wong et al., 2003; Zeng et al., 2007).

Glial ephrin-A3 also plays an important role in modulating hippocampal activity. In the adult hippocampus, dendritic spines of pyramidal neurons express EphA4 tyrosine kinase receptor, the activation of which is dependent on ligand ephrin-A3, present in the perisynaptic processes of astrocytes, is involved in the regulation of dendritic spine morphology and synapse formation (Murai et al., 2003; Klein, 2009). Mice with a knockout of ephrin-A3 or EphA4 exhibits spine irregularities and results in increased expression of astroglial glutamate transporters GLT-1 and GLAST in the hippocampus. Hence, bidirectional signals between neuronal EphA4 and astroglial ephrin-A3 regulate spine morphology, glutamate transport, and excitatory synaptic function (Carmona et al., 2009; Filosa et al., 2009).

Neural circuit refinement is associated with experiencedependent synaptic pruning. In the cortex of ephrin-A2 knockout mice, experience-dependent removal of postsynaptic dendritic spines was mediated by activation of NMDA glutamate receptors, thereby leading to changes in adult neural circuits. Ephrin-A2 null mice also showed reduced glutamate transporters, contributing to increasing synaptic glutamate and promoting spine elimination (Yu et al., 2013).

Hence, astroglial expressed ephrin-A3 and ephrin-A2 in the hippocampus and cortex, respectively, have opposite effects on the modulation of glutamate transporters and spine morphology. Treatment interventions targeting astroglial ephrin-A3/A2 signaling may alter the expression of glutamate transporters and protect against glutamate excitotoxicity, maintaining the synapse structure and dynamics.

\section{AMYGDALA AND LIMBIC CIRCUITRY IN REPETITIVE BEHAVIORS}

The amygdala is involved in the regulation of emotions, anxiety, and fear, as well as regulating repetitive behaviors. High levels of anxiety in rodents are accompanied by increased self-grooming behaviors, rescued by anxiolytic treatments (Kalueff and Tuohimaa, 2004a; Ahmari and Dougherty, 2015). Anxietyrelated behavior in rats is correlated with reduced dopamine release in the amygdala and increased grooming episodes. In the medial nucleus of the amygdala (MeA), activation of vesicular glutamate transporter 2 (vGLUT2) expressing glutamatergic neurons increases repetitive self-grooming behavior (Figure 2), whereas activation of vesicular GABA transporter (VGAT)positive GABAergic neurons represses self-grooming behavior in mice (Figure 3) (Hong et al., 2014). Also, injections of Orexin-B, a neuropeptide that regulates food intake, mood, and wakefulness in the central nucleus of the amygdala (CeA), lead to enhanced grooming frequency in hamsters. Orexin-B-induced grooming behavior is potentiated by infusion of NMDA receptor agonists (Alò et al., 2015). In the lateral amygdala, the Fmr1 KO mouse model shows synaptic defects including impaired mGluRdependent LTP, and reduced AMPAR subunit, GluR1 surface expression (Suvrathan et al., 2010).

The basolateral nucleus of the amygdala (BLA) sends projections to the hippocampus and the prefrontal cortex (PFC; Obeso and Lanciego, 2011). Activation of glutamatergic projections from the basolateral amygdala (BLA) to the ventral hippocampus heightens self-grooming in mice (FelixOrtiz and Tye, 2014) (Figure 2), while its inhibition leads to reduced locomotor activity, suggesting a crucial role for the ventral hippocampus in repetitive behaviors (Figure 3) (Bast et al., 2001; Zhang et al., 2002). Shank3 deficient rats show attention deficit and decreased synaptic plasticity in the hippocampal-medial prefrontal cortex pathway. Mouse models of Shank3 deletion also exhibit impaired synaptic plasticity in the hippocampus, associated with deficits in actin cytoskeleton remodeling, along with changes in NMDA glutamatergic receptors and mGluR-Homer scaffolding complex, resulting in abnormalities in corticostriatal circuits underlying repetitive behaviors (Bozdagi et al., 2010; Duffney et al., 2013; Kouser et al., 2013; Wang X. et al., 2016). In addition, the Shank postsynaptic protein scaffold helps regulate synaptic transmission at hippocampal Schaffer Collateral-CA1 synapses (Shi et al., 2017). Further, altered synaptic transmission at thalamo-amygdala circuits is associated with obsessive self-grooming behavior in rodents (Ullrich et al., 2018).

The hypothalamus is another limbic brain region involved in regulating numerous behaviors, including self-grooming in rodents (Qualls-Creekmore and Münzberg, 2018). The hypothalamic paraventricular nucleus and the dorsal hypothalamus are associated with grooming behavior observed by local electrical stimulation in the hypothalamus that induces 


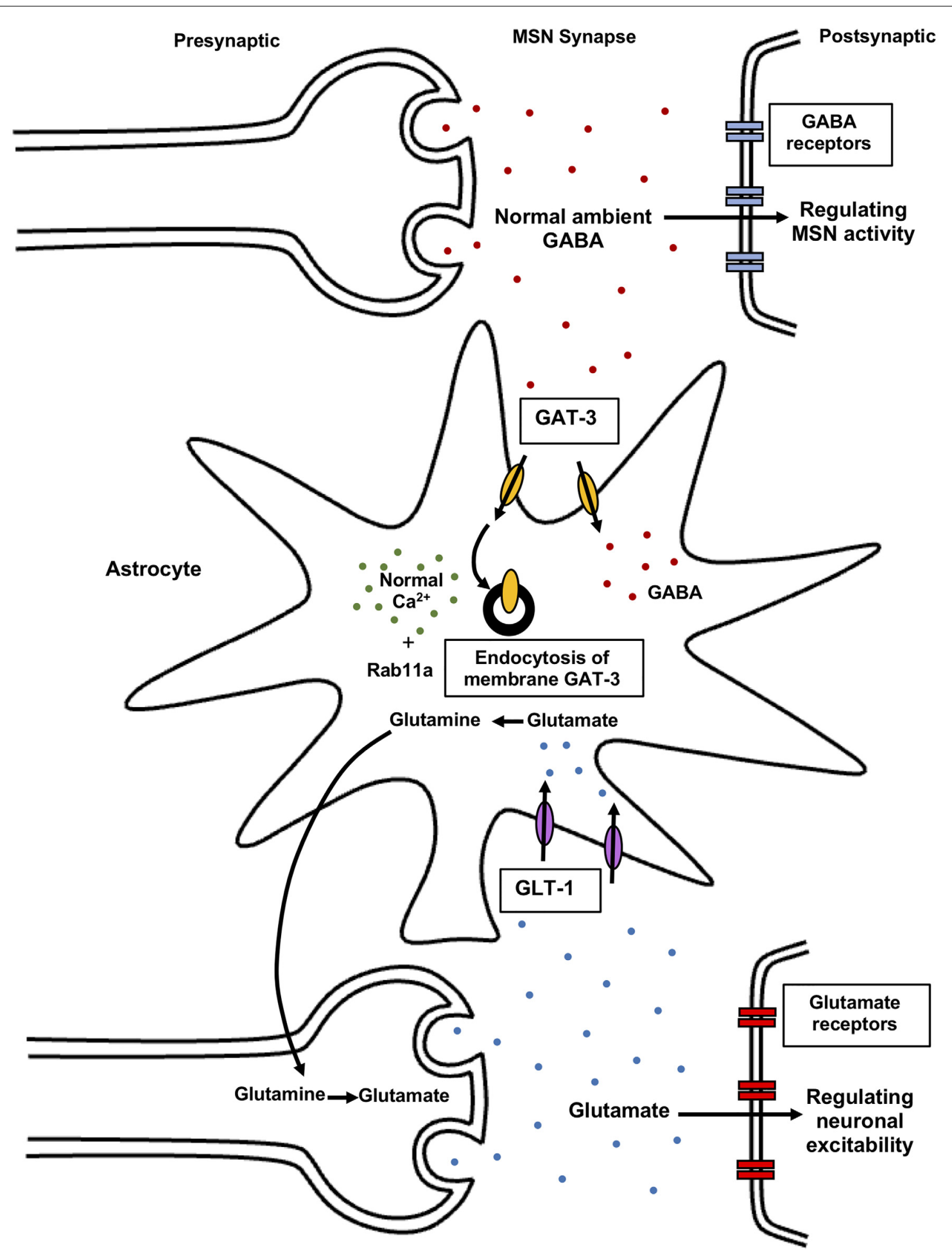

FIGURE 5 | Astrocytic regulation of synaptic glutamate and GABA levels. Normal astrocytic $\mathrm{Ca}^{2+}$ signals modulate GAT-3 levels in the presence of Rab11a GTPase mediating GAT-3 endocytosis. As a result, controlled ambient GABA levels in the synapses regulate striatal MSNs activity, resulting in normal behavior. Reduced striatal astrocyte $\mathrm{Ca}^{2+}$ signaling contributes to elevated self-grooming behavior via altered striatal MSN activity. Astrocytes also regulate synaptic glutamate levels via transporters like GLT-1. Elevated glutamate levels in the extracellular space induce over-activation of glutamate receptors resulting in excitotoxicity. Astrocytes protect against this excitotoxicity by clearance of synaptic glutamate via glutamate uptake transporters. In astrocytes, glutamate is converted to glutamine which acts as a precursor for re-synthesis of glutamate in neurons, mediating both uptake and release of glutamate. Astrocytes regulate glutamate and GABA in the synapse, thereby modulating neuronal activity and behavior. GABA, gamma-aminobutyric acid; GAT-3, GABA transporter 3; GLT-1, glutamate transporter 1; Rab, small Rab GTPase. 
self-grooming in rats. The paraventricular nucleus projects to the posterior dorsal part of the medial amygdala (MeApd) which is involved in self-grooming behavior (Roeling et al., 1993). Lateral hypothalamic glutamatergic neurons adjacent to the MeApd play roles in repetitive self-grooming behaviors in mice (Figure 3). Moreover, MeApd also projects to the medial hypothalamus (Hong et al., 2014). Finally, the central nucleus of the amygdala $(\mathrm{CeA})$ and $\mathrm{MeA}$ projects to the BNST that connects the amygdala and hypothalamus (Heimer et al., 2007). Hence, the limbic system, incorporating the amygdala, hippocampus, hypothalamus, and basal ganglia regions, play important roles in regulating repetitive behaviors.

\section{NEUROANATOMY OF ASD}

Magnetic resonance imaging (MRI) studies in humans have contributed to the understanding of the neuroanatomical basis of ASD, such as a period of early brain overgrowth in autism, particularly in frontal, temporal and cingulate cortices, hippocampus, cerebellum, and amygdala (Palmen and van Engeland, 2004; Bauman and Kemper, 2005; Courchesne et al., 2007; Amaral et al., 2008). Further, atypical functional connectivity between caudate and cortical areas has been observed in autistic subjects (Turner et al., 2006). These findings match neuroanatomical alterations observed in several of the mice models discussed above, which also show alterations to the hippocampal commissure, decreased frontal-cortical, occipital, and thalamic gray matter volume along with reduced cortical thickness (Wahlsten et al., 2003).

Neuroimaging studies also suggest an association of repetitive behaviors, with the volume of basal ganglia areas, such as the caudate-putamen (Sears et al., 1999; Calderoni et al., 2014). Autistic individuals show significantly larger right caudate and putamen volumes compared to matched controls. Moreover, total putamen and right caudate volumes reveal a positive association with ADI-C domain repetitive behavior scores (Hollander et al., 2005). Neuroimaging of individuals with fragile $\mathrm{X}$ syndrome (FXS) also exhibit altered gray matter volume in the caudate and white matter of the ventral frontostriatal pathway (Haas et al., 2009; Hallahan et al., 2011). Moreover, imaging studies of RTT individuals show reduced caudate nucleus and midbrain volumes (Casanova et al., 1991; Reiss et al., 1993; Subramaniam et al., 1997).

The medial frontal gyri, right fusiform gyrus, and left hippocampal volumes are also enlarged in autistic groups (Rojas et al., 2006; Verhoeven et al., 2010). The increased regional brain volumes show a positive correlation with stereotypic behaviors; however, the decreased volume of the cerebellum in autistic subjects shows a negative correlation with repetitive behavioral measures (Rojas et al., 2006). One study on autistic children demonstrated a positive association of repetitive behavior and frontal lobe volume and a negative association with cerebellar vermis volume (Pierce and Courchesne, 2001). Also, developmental studies in rodents and non-human primates show that damage to the amygdala, hippocampus, and temporal cortex induces ASD-like behaviors such as stereotypies (Bachevalier and Loveland, 2006). Early in life, amygdala and hippocampal lesions result in self-directed and stereotypic head twisting behaviors in juvenile monkeys (Bauman et al., 2008).

The anterior cingulate cortex (ACC) is also implicated in repetitive behaviors in ASD (Thakkar et al., 2008). An fMRI study in high-functioning autistic individuals revealed a negative correlation of repetitive/restricted behaviors with ACC and posterior parietal activation implicating frontalstriatal circuitry in stereotyped behaviors (Shafritz et al., 2008). Additional consistent neuroimaging findings are required to understand the neural circuitry of stereotypic behaviors in neurodevelopmental disorders.

Imaging studies in preclinical animal models are limited and research in this area is still ongoing (Wilkes and Lewis, 2018). There are a few MRI studies that have utilized diffusion tensor imaging (DTI) and functional MRI (fMRI) in animal models of repetitive behaviors (Ellegood et al., 2010, 2013; Dodero et al., 2013; Squillace et al., 2014; Haberl et al., 2015; Allemang-Grand et al., 2017). Mice with hemizygous $(-/ \mathrm{Y})$, heterozygous $(-/+)$ and homozygous (-/-) Mecp2 mutation show enlarged cerebellar volume, including the vermis, cerebellar cortex region, and smaller cortical volumes including somatosensory, frontal, motor, and cingulate regions. Also, Mecp2 hemizygous male mice $(-/ Y)$ exhibit increased brainstem volume and reduced volumes in the striatum, thalamus, frontal cortex, and corpus callosum. These studies correlate with imaging findings in individuals with Rett syndrome (Dunn et al., 2002; Carter et al., 2008; Ellegood et al., 2015; Allemang-Grand et al., 2017).

MRI imaging in Fmr1 KO mice reveals decreased cerebellar nuclei and striatal volumes (Ellegood et al., 2010). Also, diffusion tensor MRI and functional MRI (fMRI) studies show changes in structural connectivity of the corpus callosum and functional connectivity between cortical regions such as visual, somatosensory, auditory, and motor regions (Haberl et al., 2015). MRI analysis of $16 \mathrm{p} 11.2 \mathrm{CNV}$ mice demonstrates volumetric alterations in brain regions including basal forebrain, hypothalamus, midbrain, and superior colliculus (Horev et al., 2011). Additionally, 16p11 $11^{+/}$pups show reduced brain volume at postnatal day 7 , while the relative volume i.e., normalized to total brain volume of nucleus accumbens (NAc) and globus pallidus (GP) regions is increased. Structural abnormalities in cortical areas are also observed in $16 \mathrm{p} 11^{+/-}$pups (Portmann et al., 2014). Adult heterozygous $16 \mathrm{p} 11.2$ mice after controlling for total brain volume show neuroanatomical alterations in different brain regions including increased midbrain, hypothalamus, superior colliculus volumes, and reduced striatal volume (Ellegood et al., 2015). Mice with chromosome 15 mutations, particularly with duplication of the 15q11-13 region show reduced relative volumes for different brain areas like basal forebrain, midbrain, hypothalamus, and thalamus (Ellegood et al., 2015).

Decreases in parvalbumin-containing interneurons in the medial prefrontal cortex are observed in ASD individuals (Hashemi et al., 2017). Parvalbumin knockout mice show ASD behavioral phenotypes, such as deficits in social 
interaction behaviors, ultrasonic vocalizations, and higherorder reversal learning in the T-maze assay (Wöhr et al., 2015). An MRI study of juvenile Parvalbumin knockout mice revealed reduced cortical volume and increased cerebellar volume. However, these anatomical alterations are not consistent in adult Parvalbumin knockout mice (Wöhr et al., 2015). Additional studies are required for elucidating other repetitive behaviors and brain region structural alterations in this mouse model. In utero VPA exposed rats exhibit decreased total brain volume, relative cortical and brainstem volumes, and hippocampus volume (Frisch et al., 2009; Petrenko et al., 2013).

BTBR mice exhibit reduced cerebral white and gray matter, ventricular volumes, and larger olfactory, brainstem, and cerebellum volumes compared to C67BL/6 mice (Ellegood et al., 2013). An fMRI study of BTBR mice showed decreased bilateral functional connectivity for cingulate, striatum, insular, motor cortex, and reduced striatal-thalamic connectivity. However, hippocampus, temporal and occipital areas show increased interhemispheric connectivity in BTBR mice (Sforazzini et al., 2016).

Molecularly, scaffolding proteins, glutamate receptorinteracting proteins $1 / 2$ (Grip1/2), plays a role in AMPAR trafficking and its absence contributes to cerebellar LTD deficit in cultured Purkinje cells and social preference changes in cell-specific Grip1/2 mutant mice (Takamiya et al., 2008; Mejias et al., 2011). Grip1/2 KO mice exhibit repetitive grooming with no changes in social interaction and anxiety, normal mEPSCs but weakened mGluR-LTD at the parallel fiber-PC synapses and altered expression of arc, mGluR5, phosphorylated P38 and AKT in the Purkinje cells. So, defects in Grip1/2 mediating AMPAR trafficking at cerebellar Purkinje cells along with impaired mGluR5 signaling in cerebellum results in the pathogenesis of repetitive behaviors (Mejias et al., 2019). Mice with conditional Pten inactivation in Purkinje cells show stereotyped jumping and decreased motor learning with a structural aberration in PC dendrites, axons, reduced excitability, altered parallel fiber and climbing fiber synapses (Cupolillo et al., 2016). Further, the mouse model of Tuberous Sclerosis with Tsc2 loss in Purkinje cells (Tsc2f/-; Cre mice) displays increased marble burying repetitive behavior and Purkinje cell dysfunction, suggesting Purkinje cell loss contribution to ASD phenotype (Reith et al., 2013). Therefore, the cerebellum, particularly Purkinje cells and associated signaling pathways play important role in the regulation of repetitive behaviors.

Post-mortem studies of autistic cases have also implicated many of these same brain regions. Purkinje cells (PC) in the cerebellum are consistently altered in neuropathological analyses of ASD brain samples (Fatemi et al., 2002; Palmen and van Engeland, 2004; Whitney et al., 2008). However, the limitation of imaging studies includes poor tissue quality and small sample sizes, as well as an analysis of samples from adult brains which does not provide information regarding development (Amaral et al., 2008).

Overall, neuroanatomical alterations are largely found in frontal, temporal cortical regions, basal ganglia areas, and cerebellum in human studies and mouse models showing repetitive behaviors (Ellegood et al., 2010, 2013, 2015; Portmann et al., 2014; Haberl et al., 2015; Wöhr et al., 2015). Basal ganglia areas such as striatum and globus pallidus show volumetric alterations related to stereotyped behaviors (Ellegood et al., 2010, 2013, 2015; Portmann et al., 2014). Associations between repetitive behavioral phenotypes and changes in specific brain region structural and functional aspects require additional studies in animal models of ASD and other neurodevelopmental disorders.

\section{ANXIETY AND REPETITIVE BEHAVIORS}

ASD is associated with anxiety disorders and the prevalence estimates of anxiety in ASD individuals vary widely from $22 \%$ to 84\% (van Steensel et al., 2011; Lai et al., 2014; Vasa and Mazurek, 2015; Lever and Geurts, 2016; Russell et al., 2016; Nimmo-Smith et al., 2020). There is also a significant relationship between anxiety and restricted/repetitive behaviors in the ASD population (Gotham et al., 2013; Stratis and Lecavalier, 2013; Postorino et al., 2017; Russell et al., 2019; Baribeau et al., 2020). Association of anxiety with ritualistic behaviors is related to abnormal sensory gating suggesting altered sensory processing (Green et al., 2012; Mazurek et al., 2013; Lidstone et al., 2014).

Grooming behavior reflects repetitive, stress-coping behavior and complex interplay with anxiety and motor activity in rodents (Kalueff and Tuohimaa, 2005a; Lewis et al., 2007; O'Leary et al., 2013). Some ASD mouse models demonstrate both anxiety and repetitive behaviors. In a mouse model of Rett syndrome, deletion of $\mathrm{MeCP} 2$ in the basolateral amygdala causes increases anxiety and learning deficits (Adachi et al., 2009). The increased grooming behavior in EphrinA2/A3 double $\mathrm{KO}$ mice may correlate with sensorimotor gating deficits and abnormal sensory processing as a result of exposure to novel environments (Wurzman et al., 2015). The Shank1 mice model of ASD manifests mild anxiety and repetitive behavior (Hung et al., 2008). ASD mice models with FMR1, PTEN, UBE3A, and GABRB3 mutations exhibit learning deficits, stereotypic behaviors, and anxiety phenotypes (Jiang et al., 2010; Tanaka et al., 2012; Gandhi et al., 2014; Clipperton-Allen and Page, 2015; Zieba et al., 2019). Additionally, the BTBR mouse model of autism displays anxiety traits and repetitive behaviors (McFarlane et al., 2008; Pobbe et al., 2011). In contrast, some mouse models exhibiting repetitive behaviors do not show anxiety-like behaviors or are not reported in some cases. Mouse models including mutations in CNTNAP2, neuroligin1, the oxytocin receptor, and 16p11.2 chromosomal deletions do not display anxiety behaviors or are not reported in some studies (Peñagarikano et al., 2011; Crawley, 2012; Kazdoba et al., 2016). Thus, future studies are required to elucidate the anxiety phenotype along with the repetitive behavior in different rodent models of ASD.

Acute and chronic stress plays a role in alterations of grooming activity (Katz and Roth, 1979; Fentress, 1988; Kalueff and Tuohimaa, 2004b; Komorowska and Pellis, 2004). For instance, C57BL/6J male mice following chronic social defeat stressors, display disorganized cephalo-caudal grooming 
patterning and induces anxiety (Veenema et al., 2003; Kinsey et al., 2007; Denmark et al., 2010). Additionally, Wistar rats exposed to the lightbox show increased grooming frequency and duration as compared to rats exposed to the dark box. The light-dark paradigm helps in assessing stress levels in rats via counting the number of defecation boli and urination spots, indicating more anxiety in rats exposed to the lightbox. This may suggest that stress and anxiety may affect grooming activity and its microstructure in rodents (Kalueff and Tuohimaa, 2005b, 2004b). Surprisingly, some inbred mouse strains demonstrate high or low grooming in response to anxiety. The BALB/c mice show increased grooming compared to $129 \mathrm{~S} 1$ mice. The high grooming in $\mathrm{BALB} / \mathrm{c}$ mice may correlate with increased anxiety as assessed by high defecation boli scores, one of the stress markers in rodents. In contrast, $129 \mathrm{~S} 1$ mice show low-grooming and high anxiety levels, indicating that different rodent strains exhibit variation in anxiety-induced behaviors (Kalueff and Tuohimaa, 2004a, 2005a). Anxiolytics like bupropion (noradrenaline and dopamine reuptake inhibitor), fluvoxamine (SSRI), diazepam (benzodiazepine), and imipramine (tricyclic antidepressant) decreased marble burying and digging behavior in mice (Hayashi et al., 2010). Further, minocycline ameliorates marble-burying behavior and correlates with proper dendritic spines maturation in Fmr1 KO mice (Dansie et al., 2013). Studies on marble-burying are controversial as some indicate that marble-burying correlates with anxiety whereas others indicate that it reflects repetitive digging (Njung'e and Handley, 1991; Thomas et al., 2009; Taylor et al., 2017; de Brouwer et al., 2019). Minocycline also alleviates aberrant grooming behavior and modulates hippocampal GABA levels in rats (Zhang et al., 2019).

Neuropsychiatric and neurodevelopmental disorders including autism, OCD, schizophrenia, and anxiety share some symptoms and overlap in common pathological genes, circuits, and mechanisms (Shavitt et al., 2006; Kalueff and Nutt, 2007; Kalueff et al., 2008; Szechtman et al., 2017). For instance, GABAergic activity alterations are associated with anxiety, depression, and autistic phenotypes, indicating common underlying neural pathology (Persico and Bourgeron, 2006; Kalueff and Nutt, 2007). Altered GABA receptor activity by anxiolytic (GABA enhancing) and anxiogenic (GABA inhibiting) drugs correlates with a decrease and increase in stress-induced grooming behavior. This may indicate that these drugs regulate the strength of the anxiogenic stimuli perception and grooming behavior (Kalueff and Tuohimaa, 2005c; Nin et al., 2012; Xu et al., 2012; Kalueff et al., 2016). Similarly, BDNF and serotonin transporter (SERT) gene has been linked to cognitive deficits, anxiety, depression, schizophrenia, OCD, and autism (Devlin et al., 2005; Hu et al., 2006; Kaufman et al., 2006; Kalueff et al., 2007; Kas et al., 2007; Moy and Nadler, 2008). Rodents manifest heightened grooming behavior in response to changes in the environment by stressful and/or anxiogenic stimuli (Gispen and Isaacson, 1981; Florijn et al., 1993; Gargiulo and Donoso, 1996). Dopaminergic activity in the basal ganglia pathways likely mediates the stress-coping grooming behavior (Spruijt et al., 1986, 1992; Cools et al., 1988; Kametani, 1988; Reis-Silva et al., 2019). Anxiety-like behaviors correlate with decreased dopamine release in PFC, substantia nigra, and amygdala of rats spending more time self-grooming induced by stress on exposure to the elevated plus-maze (EPM). This suggests that self-grooming is associated with reward systems and may be reflective of de-arousal activity instead of a direct response to anxiety (Homberg et al., 2002). Additionally, serotonin plays a role in regulating stress-coping behavior such as self-grooming (Houwing et al., 2019). Hence, rodent grooming may represent one method for stress reduction or de-arousal, instead of directly involved in the stress response (Estanislau et al., 2013, 2019).

Also, several common brain regions have been associated with anxiety and repetitive behavioral disorders, particularly the amygdala and PFC. For instance, muscimol (GABA agonist) infusion into the basolateral nucleus of the amygdala and PFC decreases anxiety in rats (Shah et al., 2004; Bueno et al., 2005). Intriguingly, muscimol injection into BNST (extended amygdala), a region that regulates innate fear responses leads to decreased self-grooming behavior in rats (Xu et al., 2012). Additionally, GABAergic neurons in the MeApD region reduce self-grooming behavior (Hong et al., 2014). Further, injections of GABA-A receptor antagonist bicuculline into the basolateral amygdala increases anxiety in rats (Sajdyk and Shekhar, 2000). In the MeApD region, glutamatergic neurons promote stereotypic self-grooming (Hong et al., 2014). Alterations in GABA, serotonin, kainate, and glutamate receptor densities in various amygdala nuclei correlate with anxiety-like behavior in some inbred mouse strains (Yilmazer-Hanke et al., 2003; Caldji et al., 2004). Amygdala stimulation leads to increases in anxiety and facilitates compulsive behaviors (McGrath et al., 1999). In the case of OCD, basolateral amygdala projections to medial PFC modulate repetitive checking behavior in rodents (Sun et al., 2019). One of the brain regions involved in stress coping responses, the periaqueductal gray (PAG) and its pathways, influences self-grooming behavior (Bandler et al., 2000). Alteration in striatal neurons, CeA and mPFC projections to the PAG region may affect self-grooming behavior (Spruijt et al., 1992; Floyd et al., 2000). Increased expression of c-fos is observed in the hippocampus, hypothalamus, PFC after administration of anxiogenic drugs, and hypothalamic injection of GABAergic anxiolytic drugs reduces anxiety in rats (Jardim and Guimarães, 2001; Singewald et al., 2003). Hence, regulated GABAergic activity and consequent excitatory neurotransmission in these brain regions are critical for the modulation of anxiety and repetitive behaviors, indicating overlapping circuits in anxiety and repetitive behaviors.

However, further studies are required to ascertain regional and circuit differences between anxiety-induced and repetitive self-grooming behavior. Investigations of animal models displaying both anxiety and repetitive behavior simultaneously or induction of one disorder by another will help in providing innovative insight into the common and specific neural alterations underlying these disorders.

\section{SUMMARY}

Animal models of neuropsychiatric and neurodevelopmental disorders such as autism have provided relevant knowledge 
on the neuronal circuitry and receptor targets implicated in the etiology and pathophysiology of repetitive behaviors. Several brain regions and neural circuits including corticobasal ganglia-thalamic circuits, limbic circuits, prefrontal cortex, cerebellum, hypothalamus, and striatum are involved in the regulation of core autistic behaviors. Genetic mutations and environmental risk factors resulting in the presentation of repetitive behaviors in rodent models involve multiple cellular, molecular, and network factors. The majority of ASD alterations involve excitatory glutamatergic, inhibitory GABAergic, serotonergic and dopaminergic neurons, receptors, neurotransmitters, neuronal migration, and spine densities resulting in changes in signaling pathways and synaptic activity which may converge on common neural circuits (Golden et al., 2018).

Genome-wide association studies (GWAS) have indicated various ASD risk genes including neuronal cell adhesion molecules (neurexins, neuroligins, CNTNAP), postsynaptic scaffolding proteins (Shanks, SAPAP), neurotransmitter signaling and trafficking (Glutamate, GABA, EphA3), and molecules involved in protein synthesis in the brain (Fmr1, TSC, MeCP2) (Stearns et al., 2007; Tabuchi et al., 2007; Hung et al., 2008; Samaco et al., 2008; Etherton et al., 2009; Radyushkin et al., 2009; Peñagarikano et al., 2011; Peça et al., 2011; Silverman et al., 2011; Casey et al., 2012; Eadie et al., 2012; Schmeisser et al., 2012; Grayton et al., 2013; Monteiro and Feng, 2017; Wang et al., 2017; Zerbi et al., 2018). Many of the autism risk genes encode for proteins involved in excitatory glutamatergic signaling, converging at excitatory synapses (Peça et al., 2011; Qiu et al., 2012). For instance, Shank3 forms a scaffolding complex comprised of SAPAP that also interconnects with ephrins/Ephs and neurexin/neuroligin complexes (Qiu et al., 2012). This suggests that alterations in these molecules may converge on common synaptic and circuit mechanisms underlying autistic behavioral phenotypes. Understanding the mechanisms by which these factors affect neuronal circuits will provide insight into relevant targets of sensorimotor repetitive behaviors.

Although ASD etiological heterogeneity leads to complex and sometimes divergent behavioral outcomes in affected populations, a large literature exists, including neuroimaging studies, that have determined the crucial role of cortico-basal ganglia and limbic circuit alterations in mediating stereotypic behaviors. Altogether, common neural modifications in specific pathways and neural circuits lead to the emergence of repetitive behaviors in ASD. Inconsistencies in some studies and factors influencing generality of the repetitive behavioral findings may be related to sample, environment, and experimental heterogeneity. Future research integrating disparate findings hold immense potential to ascertain the involvement of common neural changes converging at the level of circuit alterations in neurodevelopmental disorders. More detailed work with additional animal models is required to dissect the molecular and neuroanatomical alterations in other pathways and brain regions implicated in repetitive behavioral phenotypes, to identify potential targets and treatment strategies for attenuating repetitive behaviors in affected individuals. Finally, early interventions for repetitive behaviors hold great promise for improving the quality of life for affected individuals.

\section{FUTURE DIRECTIONS AND LIMITATIONS}

The scope of this review is narrowed to neural mechanisms underlying lower-order repetitive behaviors in rodent models of ASD. Most of the literature in rodent models of ASD discusses lower-order stereotyped sensory-motor behaviors. However, some studies address higher-order insistence on sameness behaviors, such as circumscribed interests and resistance to change in a few rodent models. Future studies are required to evaluate common underlying molecular and circuit alterations in repetitive and restricted behaviors in autism. Further, characterization of both repetitive motor behaviors and insistence on sameness behaviors should be performed in different rodent models of ASD and other neurodevelopmental disorders to increase their translational value and to identify overlapping neurobiological alterations underlying these behaviors.

Although the studies reviewed here contribute to our understanding of the underlying neural alterations in rodent models displaying robust repetitive behaviors, the relation of such alterations with repetitive behavioral expression is unresolved. A focus of most investigations has been on the pathophysiology of mutations resulting in the expression of general ASD phenotype and rescuing the core ASD behavioral deficits rather than focusing exclusively on repetitive behaviors. Future findings targeting specific brain regions and focusing on neural alterations elemental to repetitive behaviors solely, while controlling for other behaviors, will provide a better understanding of how individual genetic and environmental changes converge at molecular and circuit levels to mediate repetitive behaviors. Alternatively, the generation of mutant rodent models with a targeted knockout of susceptibility genes in circumscribed brain regions may help in clarifying particular behavioral phenotypes. For instance, in NL3 mice, inhibition is elevated in the somatosensory cortex, whereas AMPAR mediated excitation is heightened in the CA1 hippocampal region (Etherton et al., 2011). Consequently, the specific neural circuitry associated with particular cognitive and behavioral components in ASD remains to be fully dissected. Regardless of these challenges, common circuits and molecular alterations provide a basis for understanding ASD etiological factors and behavioral abnormalities.

Also, very few studies have incorporated different methodological approaches to elucidate changes fundamental in mediating repetitive behaviors in rodents (Squillace et al., 2014; Wöhr et al., 2015; Sforazzini et al., 2016). A combination of different methodological approaches such as neuroimaging, histological and molecular analysis may provide a more comprehensive understanding of alterations in specific brain regions and their neural projections primarily mediating repetitive behaviors in rodent models of ASD. Also, future studies incorporating both male and female rodent models may help in elucidating any gender differences 
in brain structure and function associated with repetitive behaviors. Another important requirement is to evaluate molecular and circuit modifications fundamental to repetitive behaviors in other neurodevelopmental and neuropsychiatric disorders. Corroboration of findings across varied rodent models displaying repetitive behaviors may illuminate similar and dissimilar changes in brain pathways underlying these disorders.

A somewhat underexplored therapeutic avenue in rodent models is environmental enrichment (EE), which attenuates the repetitive behaviors in models of ASD. The EE reduces repetitive behaviors in deer mice by elevating indirect basal ganglia pathway function via increasing neuronal activation and dendritic spine densities in the subthalamic nucleus (STN) and globus pallidus (GP) (Bechard et al., 2016). However, mechanisms by which environmental enrichment alters repetitive behavior and correlations with structural, functional, and molecular modifications in brain regions demand a detailed investigation. Also, investigations of the effectiveness of environmental enrichment in attenuating repetitive behaviors should be extended to different rodent models of repetitive behavioral and neurodevelopmental disorders. This may help in probing the efficacy of environmental enrichment concerning repetitive behaviors.

Pharmacologically, systemic and local applications of glutamatergic inhibitors, GABAergic, serotonergic and dopaminergic agents have varied effects in different brain regions and circuits mediating repetitive behaviors. However, it remains to be determined whether these agents are applicable for alleviating behaviors beyond lower-order motor stereotypies in rodent models. Further research is required to ascertain if these various receptor agents also play a role in higher-order stereotypies in rodent models. Also, investigating the cross-over

\section{REFERENCES}

Adachi, M., Autry, A. E., Covington, H. E. III., and Monteggia, L. M. (2009). MeCP2-mediated transcription repression in the basolateral amygdala may underlie heightened anxiety in a mouse model of Rett syndrome. J. Neurosci. 29, 4218-4227. doi: 10.1523/JNEUROSCI.4225-08.2009

Ade, K. K., Wan, Y., Hamann, H. C., O’Hare, J. K., Guo, W., Quian, A., et al. (2016). Increased metabotropic glutamate receptor 5 signaling underlies obsessivecompulsive disorder-like behavioral and striatal circuit abnormalities in mice. Biol. Psychiatry 80, 522-533. doi: 10.1016/j.biopsych.2016.04.023

Ahmari, S. E., and Dougherty, D. D. (2015). Dissecting OCD circuits: from animal models to targeted treatments. Depress. Anxiety 32, 550-562. doi: 10.1002/da. 22367

Aida, T., Yoshida, J., Nomura, M., Tanimura, A., Iino, Y., Soma, M., et al. (2015). Astroglial glutamate transporter deficiency increases synaptic excitability and leads to pathological repetitive behaviors in mice. Neuropsychopharmacology 40, 1569-1579. doi: 10.1038/npp. 2015.26

Akaneya, Y., Sohya, K., Kitamura, A., Kimura, F., Washburn, C., Zhou, R., et al. (2010). Ephrin-A5 and EphA5 interaction induces synaptogenesis during early hippocampal development. PLoS One 5:e12486. doi: 10.1371/journal.pone. 0012486

Ali, I. U., Schriml, L. M., and Dean, M. (1999). Mutational spectra of PTEN/MMAC1 gene: a tumor suppressor with lipid phosphatase activity. J. Natl. Cancer Inst. 91, 1922-1932. doi: 10.1093/jnci/91.22.1922 effects of these agents in different neural pathways may help to understand the underlying cellular and molecular pathologies concerning repetitive behaviors.

Also, future research studying overlapping or common pathways underlying stress, anxiety, and repetitive behaviors may provide some critical insight into targets directed towards these behavioral domains.

This review summarizes findings on molecular, signaling pathways, circuit, and neuroanatomical alterations in rodent models of ASD displaying robust repetitive behaviors. These findings emphasize important molecular, structural, and functional connectivity changes in brain regions like the prefrontal cortex, basal ganglia structures, limbic areas, and cerebellum, suggesting a major role of cortical-basal ganglia circuits. Besides, signaling pathways involving different neurotransmitters and their receptors such as glutamate, GABA, serotonin, and dopamine are also involved in the pathophysiology of stereotypic motor behaviors. Understanding the hierarchy of changes in different brain regions molecular, structure, function, and connectivity aspects mediating repetitive behaviors in rodent models will provide an important platform for translational study.

Last, comparative research involving human clinical population and animal models of ASD and other neurodevelopmental disorders holds enormous potential for unraveling the underlying neural alterations mediating repetitive behaviors and identifying directed pharmacological and circuit-based targets for treatment interventions.

\section{AUTHOR CONTRIBUTIONS}

TG and CL wrote the review article. All authors contributed to the article and approved the submitted version.

Allemang-Grand, R., Ellegood, J., Noakes, L. S., Ruston, J., Justice, M. Nieman, B. J., et al. (2017). Neuroanatomy in mouse models of Rett syndrome is related to the severity of Mecp2 mutation and behavioral phenotypes. Mol. Autism 8:32. doi: 10.1186/s13229-017-0138-8

Alò, R., Avolio, E., Mele, M., Di Vito, A., and Canonaco, M. (2015). Central amygdalar nucleus treated with orexin neuropeptides evoke differing feeding and grooming responses in the hamster. J. Neurol. Sci. 351, 46-51. doi: 10.1016/j.jns.2015.02.030

Alpatov, R., Lesch, B. J., Nakamoto-Kinoshita, M., Blanco, A., Chen, S., Stützer, A., et al. (2014). A chromatin-dependent role of the fragile $\mathrm{X}$ mental retardation protein FMRP in the DNA damage response. Cell 157, 869-881. doi: 10.1016/j. cell.2014.03.040

Aman, M. G., McDougle, C. J., Scahill, L., Handen, B., Arnold, L. E., Johnson, C., et al. (2009). Medication and parent training in children with pervasive developmental disorders and serious behavior problems: results from a randomized clinical trial. J. Am. Acad. Child Adolesc. Psychiatry 48, 1143-1154. doi: 10.1097/CHI.0b013e3181bfd669

Amaral, D. G., Schumann, C. M., and Nordahl, C. W. (2008). Neuroanatomy of autism. Trends Neurosci. 31, 137-145. doi: 10.1016/j.tins.2007.12.005

Amodeo, D. A., Jones, J. H., Sweeney, J. A., and Ragozzino, M. E. (2012). Differences in BTBR $\mathrm{T}+\mathrm{tf} / \mathrm{J}$ and $\mathrm{C} 57 \mathrm{BL} / 6 \mathrm{~J}$ mice on probabilistic reversal learning and stereotyped behaviors. Behav. Brain Res. 227, 64-72. doi: 10.1016/j.bbr.2011.10.032

Amodeo, D. A., Jones, J. H., Sweeney, J. A., and Ragozzino, M. E. (2014). Risperidone and the $5 \mathrm{HT}_{2 \mathrm{~A}}$ receptor antagonist M100907 improve 
probabilistic reversal learning in BTBR T+ tf/J mice. Autism Res. 7, 555-567. doi: 10.1002/aur.1395

Amodeo, D. A., Rivera, E., Cook, E. Jr., Sweeney, J. A., and Ragozzino, M. E. (2017). $5 \mathrm{HT}_{2 \mathrm{~A}}$ receptor blockade in dorsomedial striatum reduces repetitive behaviors in BTBR mice. Genes Brain Behav. 16, 342-351. doi: 10.1111/gbb. 12343

Amodeo, D. A., Rivera, E., Dunn, J. T., and Ragozzino, M. E. (2016). M100907 attenuates elevated grooming behavior in the BTBR mouse. Behav. Brain Res. 313, 67-70. doi: 10.1016/j.bbr.2016.06.064

Anderson, G. R., Galfin, T., Xu, W., Aoto, J., Malenka, R. C., and Südhof, T. C. (2012). Candidate autism gene screen identifies critical role for cell-adhesion molecule CASPR2 in dendritic arborization and spine development. Proc. Natl. Acad. Sci. U S A 109, 18120-18125. doi: 10.1073/pnas. 1216398109

Aoto, J., and Chen, L. (2007). Bidirectional ephrin/Eph signaling in synaptic functions. Brain Res. 1184, 72-80. doi: 10.1016/j.brainres.2006.11.033

Araki, T., and Milbrandt, J. (1996). Ninjurin, a novel adhesion molecule, is induced by nerve injury and promotes axonal growth. Neuron 17, 353-361. doi: 10.1016/s0896-6273(00)80166-x

Arnall, S., Cheam, L., Smart, C., Rengel, A., Fitzgerald, M., Thivierge, J., et al. (2010). Abnormal strategies during visual discrimination reversal learning in ephrin-A2 ${ }^{-/-}$mice. Behav. Brain Res. 209, 109-113. doi: 10.1016/j.bbr.2010. 01.023

Asrar, S., Meng, Y., Zhou, Z., Todorovski, Z., Huang, W. W., and Jia, Z. (2009). Regulation of hippocampal long-term potentiation by $\mathrm{p} 21$-activated protein kinase 1 (PAK1). Neuropharmacology 56, 73-80. doi: 10.1016/j.neuropharm. 2008.06.055

Astrinidis, A., and Henske, E. P. (2005). Tuberous sclerosis complex: linking growth and energy signaling pathways with human disease. Oncogene 24, 7475-7481. doi: 10.1038/sj.onc. 1209090

Audet, M.-C., Goulet, S., and Doré, F. Y. (2006). Repeated subchronic exposure to phencyclidine elicits excessive atypical grooming in rats. Behav. Brain Res. 167, 103-110. doi: 10.1016/j.bbr.2005.08.026

Auerbach, B. D., Osterweil, E. K., and Bear, M. F. (2011). Mutations causing syndromic autism define an axis of synaptic pathophysiology. Nature 480, 63-68. doi: 10.1038/nature10658

Bachevalier, J., and Loveland, K. A. (2006). The orbitofrontal-amygdala circuit and self-regulation of social-emotional behavior in autism. Neurosci. Biobehav. Rev. 30, 97-117. doi: 10.1016/j.neubiorev.2005.07.002

Baig, D. N., Yanagawa, T., and Tabuchi, K. (2017). Distortion of the normal function of synaptic cell adhesion molecules by genetic variants as a risk for autism spectrum disorders. Brain Res. Bull. 129, 82-90. doi: 10.1016/j. brainresbull.2016.10.006

Bandler, R., Keay, K. A., Floyd, N., and Price, J. (2000). Central circuits mediating patterned autonomic activity during active vs. passive emotional coping. Brain Res. Bull. 53, 95-104. doi: 10.1016/s0361-9230(00)00313-0

Baranek, G. T. (1999). Autism during infancy: a retrospective video analysis of sensory-motor and social behaviors at 9-12 months of age. J. Autism Dev. Disord. 29, 213-224. doi: 10.1023/a:1023080005650

Baribeau, D. A., Vigod, S., Pullenayegum, E., Kerns, C. M., Mirenda, P., Smith, I. M., et al. (2020). Repetitive behavior severity as an early indicator of risk for elevated anxiety symptoms in autism spectrum disorder. J. Am. Acad. Child Adolesc. Psychiatry 59, 890.e3-899.e3. doi: 10.1016/j.jaac.2019. 08.478

Baroncelli, L., Braschi, C., Spolidoro, M., Begenisic, T., Sale, A., and Maffei, L. (2010). Nurturing brain plasticity: impact of environmental enrichment. Cell Death Differ. 17, 1092-1103. doi: 10.1038/cdd.2009.193

Bassani, S., Cwetsch, A. W., Gerosa, L., Serratto, G. M., Folci, A., Hall, I. F., et al. (2018). The female epilepsy protein PCDH19 is a new $\mathrm{GABA}_{\mathrm{A}} \mathrm{R}$ binding partner that regulates GABAergic transmission as well as migration and morphological maturation of hippocampal neurons. Hum. Mol. Genet. 27, 1027-1038. doi: $10.1093 / \mathrm{hmg} / \mathrm{ddy} 019$

Bast, T., Zhang, W.-N., and Feldon, J. (2001). The ventral hippocampus and fear conditioning in rats. Exp. Brain Res. 139, 39-52. doi: 10.1007/s002210100746

Bateup, H. S., Johnson, C. A., Denefrio, C. L., Saulnier, J. L., Kornacker, K., and Sabatini, B. L. (2013). Excitatory/inhibitory synaptic imbalance leads to hippocampal hyperexcitability in mouse models of tuberous sclerosis. Neuron 78, 510-522. doi: 10.1016/j.neuron.2013.03.017
Bauman, M. L., and Kemper, T. L. (2005). Neuroanatomic observations of the brain in autism: a review and future directions. Int. J. Dev. Neurosci. 23, 183-187. doi: 10.1016/j.ijdevneu.2004.09.006

Bauman, M. D., Toscano, J., Babineau, B., Mason, W., and Amaral, D. G. (2008). Emergence of stereotypies in juvenile monkeys (Macaca mulatta) with neonatal amygdala or hippocampus lesions. Behav. Neurosci. 122:1005. doi: $10.1177 / 2398212820972599$

Bazargani, N., and Attwell, D. (2016). Astrocyte calcium signaling: the third wave. Nat. Neurosci. 19, 182-189. doi: 10.1038/nn.4201

Bear, M. F. (2005). Therapeutic implications of the mGluR theory of fragile X mental retardation. Genes Brain Behav. 4, 393-398. doi: 10.1111/j.1601-183X. 2005.00135.x

Bear, M. F., Huber, K. M., and Warren, S. T. (2004). The mGluR theory of fragile X mental retardation. Trends Neurosci. 27, 370-377. doi: 10.1016/j.tins.2004. 04.009

Bechard, A. R., Bliznyuk, N., and Lewis, M. H. (2017). The development of repetitive motor behaviors in deer mice: effects of environmental enrichment, repeated testing and differential mediation by indirect basal ganglia pathway activation. Dev. Psychobiol. 59, 390-399. doi: 10.1002/dev. 21503

Bechard, A. R., Cacodcar, N., King, M. A., and Lewis, M. H. (2016). How does environmental enrichment reduce repetitive motor behaviors? Neuronal activation and dendritic morphology in the indirect basal ganglia pathway of a mouse model. Behav. Brain Res. 299, 122-131. doi: 10.1016/j.bbr.2015.11.029

Bechard, A., and Lewis, M. (2012). Modeling restricted repetitive behavior in animals. Autism 6:2. doi: 10.4172/2165-7890.s1-006

Beckel-Mitchener, A., and Greenough, W. T. (2004). Correlates across the structural, functional, and molecular phenotypes of fragile X syndrome. Ment. Retard. Dev. Disabil. Res. Rev. 10, 53-59. doi: 10.1002/mrdd.20009

Benes, F. M. (2010). Amygdalocortical circuitry in schizophrenia: from circuits to molecules. Neuropsychopharmacology 35, 239-257. doi: 10.1038/npp.2009.116

Ben-Sasson, A., Cermak, S. A., Orsmond, G. I., Tager-Flusberg, H., Carter, A. S., Kadlec, M. B., et al. (2007). Extreme sensory modulation behaviors in toddlers with autism spectrum disorders. Am. J. Occup. Ther. 61, 584-592. doi: 10.5014/ajot.61.5.584

Berridge, K. C., and Aldridge, J. W. (2000a). Super-stereotypy I: enhancement of a complex movement sequence by systemic dopamine D1 agonists. Synapse 37, 194-204. doi: 10.1002/1098-2396(20000901)37:3<194::AID-SYN3>3 . $0 . \mathrm{CO} ; 2-\mathrm{A}$

Berridge, K. C., and Aldridge, J. W. (2000b). Super-stereotypy II: enhancement of a complex movement sequence by intraventricular dopamine D1 agonists. Synapse 37, 205-215. doi: 10.1002/1098-2396(20000901)37:3<205::AIDSYN4>3.0.CO;2-A

Berridge, K. C., Aldridge, J. W., Houchard, K. R., and Zhuang, X. (2005). Sequential super-stereotypy of an instinctive fixed action pattern in hyperdopaminergic mutant mice: a model of obsessive compulsive disorder and Tourette's. BMC Biol. 3:4. doi: 10.1186/1741-7007-3-4

Berry-Kravis, E. (2014). Mechanism-based treatments in neurodevelopmental disorders: fragile X syndrome. Pediatr. Neurol. 50, 297-302. doi: 10.1016/j. pediatrneurol.2013.12.001

Bhalla, K., Luo, Y., Buchan, T., Beachem, M. A., Guzauskas, G. F., Ladd, S., et al. (2008). Alterations in CDH15 and KIRREL3 in patients with mild to severe intellectual disability. Am. J. Hum. Genet. 83, 703-713. doi: 10.1016/j.ajhg.2008. 10.020

Bhattacharya, A., Mamcarz, M., Mullins, C., Choudhury, A., Boyle, R. G., Smith, D. G., et al. (2016). Targeting translation control with p70 S6 kinase 1 inhibitors to reverse phenotypes in fragile $\mathrm{X}$ syndrome mice. Neuropsychopharmacology 41, 1991-2000. doi: 10.1038/npp.2015.369

Bienvenu, O. J., Wang, Y., Shugart, Y., Welch, J., Grados, M., Fyer, A., et al. (2009). Sapap3 and pathological grooming in humans: results from the OCD collaborative genetics study. Am. J. Med. Genet. B Neuropsychiatr. Genet. 150, 710-720. doi: 10.1002/ajmg.b.30897

Bilousova, T., Dansie, L., Ngo, M., Aye, J., Charles, J. R., Ethell, D. W., et al. (2009). Minocycline promotes dendritic spine maturation and improves behavioural performance in the fragile X mouse model. J. Med. Genet. 46, 94-102. doi: 10.1136/jmg.2008.061796

Blundell, J., Blaiss, C. A., Etherton, M. R., Espinosa, F., Tabuchi, K., Walz, C., et al. (2010). Neuroligin-1 deletion results in impaired spatial memory and increased 
repetitive behavior. J. Neurosci. 30, 2115-2129. doi: 10.1523/JNEUROSCI. 4517-09.2010

Boda, B., Nikonenko, I., Alberi, S., and Muller, D. (2006). Central nervous system functions of PAK protein family. Mol. Neurobiol. 34, 67-80. doi: 10.1385/mn:34:1:67

Bokoch, G. M. (2003). Biology of the p21-activated kinases. Annu. Rev. Biochem. 72, 743-781. doi: 10.1146/annurev.biochem.72.121801.161742

Bolz, J., Uziel, D., Mühlfriedel, S., Güllmar, A., Peuckert, C., Zarbalis, K., et al. (2004). Multiple roles of ephrins during the formation of thalamocortical projections: maps and more. J. Neurobiol. 59, 82-94. doi: 10.1002/neu.10346

Boyd, B. A., McDonough, S. G., and Bodfish, J. W. (2012). Evidence-based behavioral interventions for repetitive behaviors in autism. J. Autism Dev. Disord. 42, 1236-1248. doi: 10.1007/s10803-011-1284-z

Bozdagi, O., Sakurai, T., Papapetrou, D., Wang, X., Dickstein, D. L., Takahashi, N., et al. (2010). Haploinsufficiency of the autism-associated Shank3 gene leads to deficits in synaptic function, social interaction, and social communication. Mol. Autism 1:15. doi: 10.1186/2040-2392-1-15

Bromley, R., Mawer, G., Clayton-Smith, J., and Baker, G. (2008). Autism spectrum disorders following in utero exposure to antiepileptic drugs. Neurology 71, 1923-1924. doi: 10.1212/01.wnl.0000339399.64213.1a

Brown, M. R., Kronengold, J., Gazula, V.-R., Chen, Y., Strumbos, J. G., Sigworth, F. J., et al. (2010). Fragile X mental retardation protein controls gating of the sodium-activated potassium channel Slack. Nat. Neurosci. 13, 819-821. doi: 10.1038/nn.2563

Brown, D. A., and Passmore, G. M. (2009). Neural KCNQ (kv7) channels. Br. J. Pharmacol. 156, 1185-1195. doi: 10.1111/j.1476-5381.2009.00111.x

Brune, C. W., Kim, S.-J., Salt, J., Leventhal, B. L., Lord, C., Cook, M. Jr., et al. (2006). 5-HTTLPR genotype-specific phenotype in children and adolescents with autism. Am. J. Psychiatry 163, 2148-2156. doi: 10.1176/ajp.2006.163. 12.2148

Bueno, C. H., Zangrossi, H. Jr., and Viana, M. B. (2005). The inactivation of the basolateral nucleus of the rat amygdala has an anxiolytic effect in the elevated T-maze and light/dark transition tests. Braz. J. Med. Biol. Res. 38, 1697-1701. doi: 10.1590/s0100-879x2005001100019

Burguière, E., Monteiro, P., Feng, G., and Graybiel, A. M. (2013). Optogenetic stimulation of lateral orbitofronto-striatal pathway suppresses compulsive behaviors. Science 340, 1243-1246. doi: 10.1126/science.1232380

Burket, J. A., Benson, A. D., Tang, A. H., and Deutsch, S. I. (2013). D-Cycloserine improves sociability in the BTBR T+ Itpr3tf/J mouse model of autism spectrum disorders with altered Ras/Raf/ERK1/2 signaling. Brain Res. Bull. 96, 62-70. doi: 10.1016/j.brainresbull.2013.05.003

Burket, J. A., Cannon, W. R., Jacome, L. F., and Deutsch, S. I. (2010). MK801, a noncompetitive NMDA receptor antagonist, elicits circling behavior in the genetically inbred Balb/c mouse strain. Brain Res. Bull. 83, 337-339. doi: 10.1016/j.brainresbull.2010.08.014

Burrows, E. L., Laskaris, L., Koyama, L., Churilov, L., Bornstein, J. C., HillYardin, E. L., et al. (2015). A neuroligin-3 mutation implicated in autism causes abnormal aggression and increases repetitive behavior in mice. Mol. Autism 6:62. doi: 10.1186/s13229-015-0055-7

Busquets-Garcia, A., Gomis-González, M., Guegan, T., Agustín-Pavón, C., Pastor, A., Mato, S., et al. (2013). Targeting the endocannabinoid system in the treatment of fragile X syndrome. Nat. Med. 19, 603-607. doi: 10.1038/ nm. 3127

Butler, M. G., Dasouki, M. J., Zhou, X.-P., Talebizadeh, Z., Brown, M., Takahashi, T. N., et al. (2005). Subset of individuals with autism spectrum disorders and extreme macrocephaly associated with germline PTEN tumour suppressor gene mutations. J. Med. Genet. 42, 318-321. doi: 10.1136/jmg.2004. 024646

Calderoni, S., Bellani, M., Hardan, A., Muratori, F., and Brambilla, P. (2014). Basal ganglia and restricted and repetitive behaviours in autism spectrum disorders: current status and future perspectives. Epidemiol. Psychiatr. Sci. 23, 235-238. doi: 10.1017/S2045796014000171

Caldji, C., Diorio, J., Anisman, H., and Meaney, M. J. (2004). Maternal behavior regulates benzodiazepine/GABA $\mathrm{A}$ receptor subunit expression in brain regions associated with fear in BALB/c and C57BL/6 mice. Neuropsychopharmacology 29, 1344-1352. doi: 10.1038/sj.npp.1300436

Cantley, L. C. (2002). The phosphoinositide 3-kinase pathway. Science 296, 1655-1657. doi: 10.1126/science.296.5573.1655
Cao, F., Liu, J. J., Zhou, S., Cortez, M. A., Snead, O. C., Han, J., et al. (2020). Neuroligin 2 regulates absence seizures and behavioral arrests through GABAergic transmission within the thalamocortical circuitry. Nat. Commun. 11, 1-15. doi: 10.1038/s41467-020-17560-3

Carlson, G. C. (2012). Glutamate receptor dysfunction and drug targets across models of autism spectrum disorders. Pharmacol. Biochem. Behav. 100, 850-854. doi: 10.1016/j.pbb.2011.02.003

Carmona, M. A., Murai, K. K., Wang, L., Roberts, A. J., and Pasquale, E. B. (2009). Glial ephrin-A3 regulates hippocampal dendritic spine morphology and glutamate transport. Proc. Natl. Acad. Sci. U S A 106, 12524-12529. doi: 10.1073/pnas.0903328106

Carneiro, A. M. D., Cook, E. H., Murphy, D. L., and Blakely, R. D. (2008). Interactions between integrin $\alpha \operatorname{IIb} \beta 3$ and the serotonin transporter regulate serotonin transport and platelet aggregation in mice and humans. J. Clin. Invest. 118, 1544-1552. doi: 10.1172/JCI33374

Carter, J., Lanham, D., Pham, D., Bibat, G., Naidu, S., and Kaufmann, W. E. (2008). Selective cerebral volume reduction in Rett syndrome: a multiple-approach MR imaging study. Am. J. Neuroradiol. 29, 436-441. doi: 10.3174/ajnr. A0857

Carter, M. D., Shah, C. R., Muller, C. L., Crawley, J. N., Carneiro, A. M., and Veenstra-VanderWeele, J. (2011). Absence of preference for social novelty and increased grooming in integrin $\beta 3$ knockout mice: initial studies and future directions. Autism Res. 4, 57-67. doi: 10.1002/aur.180

Casanova, M., Naidu, S., Goldberg, T., Moser, H., Khoromi, S., Kumar, A., et al. (1991). Quantitative magnetic resonance imaging in Rett syndrome. J. Neuropsychiatry Clin. Neurosci. 3, 66-72. doi: 10.1176/jnp.3.1.66

Casey, J. P., Magalhaes, T., Conroy, J. M., Regan, R., Shah, N., Anney, R., et al. (2012). A novel approach of homozygous haplotype sharing identifies candidate genes in autism spectrum disorder. Hum. Genet. 131, 565-579. doi: 10.1007/s00439-011-1094-6

Causeret, F., Terao, M., Jacobs, T., Nishimura, Y. V., Yanagawa, Y., Obata, K., et al. (2009). The p21-activated kinase is required for neuronal migration in the cerebral cortex. Cereb. Cortex 19, 861-875. doi: 10.1093/cercor/ bhn133

Chahin, S. S., Apple, R. W., Kuo, K. H., and Dickson, C. A. (2020). Autism spectrum disorder: psychological and functional assessment and behavioral treatment approaches. Transl. Pediatr. 9:S66. doi: 10.21037/tp. 2019.11.06

Chahrour, M., and Zoghbi, H. Y. (2007). The story of Rett syndrome: from clinic to neurobiology. Neuron 56, 422-437. doi: 10.1016/j.neuron.2007. 10.001

Chang, A. D., Berges, V. A., Chung, S. J., Fridman, G. Y., Baraban, J. M., and Reti, I. M. (2016). High-frequency stimulation at the subthalamic nucleus suppresses excessive self-grooming in autism-like mouse models. Neuropsychopharmacology 41, 1813-1821. doi: 10.1038/npp.2015.350

Chao, H.-T., Chen, H., Samaco, R. C., Xue, M., Chahrour, M., Yoo, J., et al. (2010). Dysfunction in GABA signalling mediates autism-like stereotypies and Rett syndrome phenotypes. Nature 468, 263-269. doi: 10.1038/nature09582

Chaste, P., and Leboyer, M. (2012). Autism risk factors: genes, environment, and gene-environment interactions. Dialogues Clin. Neurosci. 14:281. doi: 10.31887/DCNS.2012.14.3/pchaste

Chavez, B., Chavez-Brown, M., and Rey, J. A. (2006). Role of risperidone in children with autism spectrum disorder. Ann. Pharmacother. 40, 909-916. doi: 10.1345/aph.1G389

Chen, S.-K., Tvrdik, P., Peden, E., Cho, S., Wu, S., Spangrude, G., et al. (2010). Hematopoietic origin of pathological grooming in Hoxb8 mutant mice. Cell 141, 775-785. doi: 10.1016/j.cell.2010.03.055

Chen, M., Wan, Y., Ade, K., Ting, J., Feng, G., and Calakos, N. (2011). Sapap3 deletion anomalously activates short-term endocannabinoid-mediated synaptic plasticity. J. Neurosci. 31, 9563-9573. doi: 10.1523/JNEUROSCI.170111.2011

Chiarotti, F., and Venerosi, A. (2020). Epidemiology of autism spectrum disorders: a review of worldwide prevalence estimates since 2014. Brain Sci. 10:274. doi: 10.3390/brainsci10050274

Chicka, M. C., and Strehler, E. E. (2003). Alternative splicing of the first intracellular loop of plasma membrane $\mathrm{Ca}^{2+}$-ATPase isoform 2 alters its membrane targeting. J. Biol. Chem. 278, 18464-18470. doi: 10.1074/jbc. M301482200 
Chin-Sang, I. D., George, S. E., Ding, M., Moseley, S. L., Lynch, A. S., and Chisholm, A. D. (1999). The ephrin VAB-2/EFN-1 functions in neuronal signaling to regulate epidermal morphogenesis in C. elegans. Cell 99, 781-790. doi: 10.1016/s0092-8674(00)81675-x

Chiron, C., Bulteau, C., Loc'h, C., Raynaud, C., Garreau, B., Syrota, A., et al. (1993). Dopaminergic D2 receptor SPECT imaging in Rett syndrome: increase of specific binding in striatum. J. Nucl. Med. 34, 1717-1721.

Choi, Y.-J., Di Nardo, A., Kramvis, I., Meikle, L., Kwiatkowski, D. J., Sahin, M., et al. (2008). Tuberous sclerosis complex proteins control axon formation. Genes Dev. 22, 2485-2495. doi: 10.1101/gad.1685008

Choi, C. S., Gonzales, E. L., Kim, K. C., Yang, S. M., Kim, J.-W., Mabunga, D. F., et al. (2016). The transgenerational inheritance of autism-like phenotypes in mice exposed to valproic acid during pregnancy. Sci. Rep. 6:36250. doi: $10.1038 /$ srep36250

Choi, S.-Y., Han, K., Cutforth, T., Chung, W., Park, H., Lee, D., et al. (2015). Mice lacking the synaptic adhesion molecule Neph2/Kirrel3 display moderate hyperactivity and defective novel object preference. Front. Cell. Neurosci. 9:283. doi: 10.3389/fncel.2015.00283

Clegg, D. O., Wingerd, K. L., Hikita, S. T., and Tolhurst, E. C. (2003). Integrins in the development, function and dysfunction of the nervous system. Front. Biosci. 8:d723-50. doi: 10.2741/1020

Clipperton-Allen, A. E., and Page, D. T. (2014). Pten haploinsufficient mice show broad brain overgrowth but selective impairments in autism-relevant behavioral tests. Hum. Mol. Genet. 23, 3490-3505. doi: 10.1093/hmg/ ddu057

Clipperton-Allen, A. E., and Page, D. T. (2015). Decreased aggression and increased repetitive behavior in Pten haploinsufficient mice. Genes Brain Behav. 14, 145-157. doi: 10.1111/gbb.12192

Cogram, P., Alkon, D. L., Crockford, D., Deacon, R. M., Hurley, M. J., Altimiras, F., et al. (2020). Chronic bryostatin-1 rescues autistic and cognitive phenotypes in the fragile X mice. Sci. Rep. 10:18058. doi: 10.1038/s41598-020-74848-6

Cogram, P., Deacon, R. J., Warner-Schmidt, J., von Schimmelmann, M. J., Abrahams, B. S., and During, M. J. (2019). Gaboxadol normalizes behavioral abnormalities in a mouse model of fragile X syndrome. Front. Behav. Neurosci. 13:141. doi: 10.3389/fnbeh.2019.00141

Colacicco, G., Welzl, H., Lipp, H.-P., and Würbel, H. (2002). Attentional set-shifting in mice: modification of a rat paradigm and evidence for straindependent variation. Behav. Brain Res. 132, 95-102. doi: 10.1016/s01664328(01)00391-6

Comery, T. A., Harris, J. B., Willems, P. J., Oostra, B. A., Irwin, S. A., Weiler, I. J., et al. (1997). Abnormal dendritic spines in fragile X knockout mice: maturation and pruning deficits. Proc. Natl. Acad. Sci. U S A 94, 5401-5404. doi: 10.1073/pnas.94.10.5401

Conn, P. J., Battaglia, G., Marino, M. J., and Nicoletti, F. (2005). Metabotropic glutamate receptors in the basal ganglia motor circuit. Nat. Rev. Neurosci. 6, 787-798. doi: 10.1038/nrn1763

Cook, E. H. Jr., and Scherer, S. W. (2008). Copy-number variations associated with neuropsychiatric conditions. Nature 455, 919-923. doi: 10.1038/nature 07458

Cools, A. R., Spruijt, B. M., and Ellenbroek, B. A. (1988). Role of central dopamine in ACTH-induced grooming behavior in rats. Ann. N Y Acad. Sci. 525, 338-349. doi: 10.1111/j.1749-6632.1988.tb38618.x

Cooper, E. C., Harrington, E., Jan, Y. N., and Jan, L. Y. (2001). M channel KCNQ2 subunits are localized to key sites for control of neuronal network oscillations and synchronization in mouse brain. J. Neurosci. 21, 9529-9540. doi: 10.1523/JNEUROSCI.21-24-09529.2001

Costales, J. L., and Kolevzon, A. (2015). Phelan-McDermid syndrome and SHANK3: implications for treatment. Neurotherapeutics 12, 620-630. doi: 10.1007/s13311-015-0352-Z

Courchesne, E., Pierce, K., Schumann, C. M., Redcay, E., Buckwalter, J. A., Kennedy, D. P., et al. (2007). Mapping early brain development in autism. Neuron 56, 399-413. doi: 10.1016/j.neuron.2007.10.016

Crawley, J. N. (2012). Translational animal models of autism and neurodevelopmental disorders. Dialogues Clin. Neurosci. 14:293. doi: 10.31887/DCNS.2012.14.3/jcrawley

Cromwell, H. C., and Berridge, K. C. (1996). Implementation of action sequences by a neostriatal site: a lesion mapping study of grooming syntax. J. Neurosci. 16, 3444-3458. doi: 10.1523/JNEUROSCI.16-10-03444.1996
Cromwell, H. C., Berridge, K. C., Drago, J., and Levine, M. S. (1998). Action sequencing is impaired in D1A-deficient mutant mice. Eur. J. Neurosci. 10, 2426-2432. doi: 10.1046/j.1460-9568.1998.00250.x

Crossland, J., and Lewandowski, A. (2006). Peromyscus-a fascinating laboratory animal model. Techtalk 11, 1-2.

Cupolillo, D., Hoxha, E., Faralli, A., De Luca, A., Rossi, F., Tempia, F., et al. (2016). Autistic-like traits and cerebellar dysfunction in purkinje cell PTEN knock-out mice. Neuropsychopharmacology 41, 1457-1466. doi: 10.1038/npp.2015.339

Curatolo, P., and Bombardieri, R. (2007). Tuberous sclerosis. Handb. Clin. Neurol. 87, 129-151. doi: 10.1016/S0072-9752(07)87009-6

Dalva, M. B., Takasu, M. A., Lin, M. Z., Shamah, S. M., Hu, L., Gale, N. W., et al. (2000). EphB receptors interact with NMDA receptors and regulate excitatory synapse formation. Cell 103, 945-956. doi: 10.1016/s0092-8674(00)00197-5

Dansie, L. E., Phommahaxay, K., Okusanya, A. G., Uwadia, J., Huang, M., Rotschafer, S. E., et al. (2013). Long-lasting effects of minocycline on behavior in young but not adult Fragile X mice. Neuroscience 246, 186-198. doi: 10.1016/j.neuroscience.2013.04.058

Davis, J. K., and Broadie, K. (2017). Multifarious functions of the fragile X mental retardation protein. Trends Genet. 33, 703-714. doi: 10.1016/j.tig.2017.07.008

De Arcangelis, A., and Georges-Labouesse, E. (2000). Integrin and ECM functions: roles in vertebrate development. Trends Genet. 16, 389-395. doi: 10.1016/s0168-9525(00)02074-6

De Barioglio, S. R., Lezcano, N., and Celis, M. E. (1991). Alpha MSH-induced excessive grooming behavior involves a GABAergic mechanism. Peptides 12, 203-205. doi: 10.1016/0196-9781(91)90189-v

de Brouwer, G., Fick, A., Harvey, B. H., and Wolmarans, W. (2019). A critical inquiry into marble-burying as a preclinical screening paradigm of relevance for anxiety and obsessive-compulsive disorder: mapping the way forward. Cogn. Affect. Behav. Neurosci. 19, 1-39. doi: 10.3758/s13415-018-00653-4

De La Torre-Ubieta, L., Gaudillière, B., Yang, Y., Ikeuchi, Y., Yamada, T., DiBacco, S., et al. (2010). A FOXO-Pak1 transcriptional pathway controls neuronal polarity. Genes Dev. 24, 799-813. doi: 10.1101/gad.1880510

De La Torre-Ubieta, L., Won, H., Stein, J. L., and Geschwind, D. H. (2016). Advancing the understanding of autism disease mechanisms through genetics. Nat. Med. 22, 345-361. doi: 10.1038/nm.4071

De Rubeis, S., and Buxbaum, J. D. (2015). Genetics and genomics of autism spectrum disorder: embracing complexity. Hum. Mol. Genet. 24, R24-R31. doi: $10.1093 / \mathrm{hmg} / \mathrm{ddv} 273$

DeFilippis, M., and Wagner, K. D. (2016). Treatment of autism spectrum disorder in children and adolescents. Psychopharmacol. Bull. 46, 18-41.

Delmonte, S., Gallagher, L., O’Hanlon, E., Mc Grath, J., and Balsters, J. H. (2013). Functional and structural connectivity of frontostriatal circuitry in autism spectrum disorder. Front. Hum. Neurosci. 7:430. doi: 10.3389/fnhum.2013. 00430

DeLorey, T., Handforth, A., Anagnostaras, S., Homanics, G., Minassian, B., Asatourian, A., et al. (1998). Mice lacking the $\beta 3$ subunit of the GABA $_{A}$ receptor have the epilepsy phenotype and many of the behavioral characteristics of Angelman syndrome. J. Neurosci. 18, 8505-8514. doi: 10.1523/JNEUROSCI.18-20-08505.1998

DeLorey, T. M., Sahbaie, P., Hashemi, E., Homanics, G. E., and Clark, J. D. (2008). Gabrb3 gene deficient mice exhibit impaired social and exploratory behaviors, deficits in non-selective attention and hypoplasia of cerebellar vermal lobules: a potential model of autism spectrum disorder. Behav. Brain Res. 187, 207-220. doi: 10.1016/j.bbr.2007.09.009

DeNardo, L. A., de Wit, J., Otto-Hitt, S., and Ghosh, A. (2012). NGL-2 regulates input-specific synapse development in CA1 pyramidal neurons. Neuron 76 , 762-775. doi: 10.1016/j.neuron.2012.10.013

Denmark, A., Tien, D., Wong, K., Chung, A., Cachat, J., Goodspeed, J., et al. (2010). The effects of chronic social defeat stress on mouse self-grooming behavior and its patterning. Behav. Brain Res. 208, 553-559. doi: 10.1016/j.bbr. 2009.12.041

Denys, D., de Vries, F., Cath, D., Figee, M., Vulink, N., Veltman, D. J., et al. (2013). Dopaminergic activity in Tourette syndrome and obsessive-compulsive disorder. Eur. Neuropsychopharmacol. 23, 1423-1431. doi: 10.1016/j. euroneuro.2013.05.012

Deutsch, S. I., Burket, J. A., Jacome, L. F., Cannon, W. R., and Herndon, A. L. (2011a). D-Cycloserine improves the impaired sociability of the Balb/c mouse. Brain Res. Bull. 84, 8-11. doi: 10.1016/j.brainresbull.2010.10.006 
Deutsch, S. I., Burket, J. A., Urbano, M. R., Herndon, A. L., and Winebarger, E. E. (2011b). "Impaired sociability of the Balb/c mouse, an animal model of autism spectrum disorders, is attenuated by NMDA receptor agonist interventions: clinical implications," in A Comprehensive Book on Autism Spectrum Disorders, ed M. A. Mohammadi (London: IntechOpen), 323-342.

Deutsch, S. I., Rosse, R. B., Paul, S. M., Riggs, R. L., and Mastropaolo, J. (1997). Inbred mouse strains differ in sensitivity to "popping" behavior elicited by MK-801. Pharmacol. Biochem. Behav. 57, 315-317. doi: 10.1016/s00913057(96)00347-4

Deutsch, S. I., Rosse, R. B., Schwartz, B. L., Mastropaolo, J., Burket, J. A., and Weizman, A. (2010). Regulation of intermittent oscillatory activity of pyramidal cell neurons by GABA inhibitory interneurons is impaired in schizophrenia: rationale for pharmacotherapeutic GABAergic interventions. Isr. J. Psychiatry Relat. Sci. 47, 17-26.

Devlin, B., and Scherer, S. W. (2012). Genetic architecture in autism spectrum disorder. Curr. Opin. Genet. Dev. 22, 229-237. doi: 10.1016/j.gde.2012.03.002

Devlin, B., Cook, E. H. Jr., Coon, H., Dawson, G., Grigorenko, E., McMahon, W., et al. (2005). Autism and the serotonin transporter: the long and short of it. Mol. Psychiatry 10, 1110-1116. doi: 10.1038/sj.mp.4001724

D’Hooge, R., Nagels, G., Franck, F., Bakker, C., Reyniers, E., Storm, K., et al. (1997). Mildly impaired water maze performance in male Fmr1 knockout mice. Neuroscience 76, 367-376. doi: 10.1016/s0306-4522(96)00224-2

Di Giovanni, G., Di Matteo, V., Pierucci, M., Benigno, A., and Esposito, E. (2006). Serotonin involvement in the basal ganglia pathophysiology: could the 5-HT2C receptor be a new target for therapeutic strategies? Curr. Med. Chem. 13, 3069-3081. doi: 10.2174/092986706778521805

Di Martino, A., Kelly, C., Grzadzinski, R., Zuo, X.-N., Mennes, M., Mairena, M. A., et al. (2011). Aberrant striatal functional connectivity in children with autism. Biol. Psychiatry 69, 847-856. doi: 10.1016/j.biopsych.2010. 10.029

Dibbens, L. M., Tarpey, P. S., Hynes, K., Bayly, M. A., Scheffer, I. E., Smith, R., et al. (2008). X-linked protocadherin 19 mutations cause female-limited epilepsy and cognitive impairment. Nat. Genet. 40, 776-781. doi: 10.1038/ng.149

Dodero, L., Damiano, M., Galbusera, A., Bifone, A., Tsaftsaris, S. A., Scattoni, M. L., et al. (2013). Neuroimaging evidence of major morphoanatomical and functional abnormalities in the BTBR T+ TF/J mouse model of autism. PLoS One 8:e76655. doi: 10.1371/journal.pone.00 76655

Dolan, B. M., Duron, S. G., Campbell, D. A., Vollrath, B., Rao, B. S., Ko, H.-Y., et al. (2013). Rescue of fragile X syndrome phenotypes in Fmrl KO mice by the small-molecule PAK inhibitor FRAX486. Proc. Natl. Acad. Sci. U S A 110, 5671-5676. doi: 10.1073/pnas.1219383110

Dölen, G., and Bear, M. F. (2008). Role for metabotropic glutamate receptor 5 (mGluR5) in the pathogenesis of fragile X syndrome. J. Physiol. 586, 1503-1508. doi: 10.1113/jphysiol.2008.150722

Dölen, G., Osterweil, E., Rao, B. S., Smith, G. B., Auerbach, B. D., Chattarji, S., et al. (2007). Correction of fragile X syndrome in mice. Neuron 56, 955-962. doi: 10.1016/j.neuron.2007.12.001

Doyle, C. A., and McDougle, C. J. (2012). Pharmacologic treatments for the behavioral symptoms associated with autism spectrum disorders across the lifespan. Dialogues Clin. Neurosci. 14, 263-279. doi: 10.31887/DCNS.2012.14. 3/cdoyle

Drapeau, E., Dorr, N. P., Elder, G. A., and Buxbaum, J. D. (2014). Absence of strong strain effects in behavioral analyses of Shank3-deficient mice. Dis. Model. Mech. 7, 667-681. doi: 10.1242/dmm.013821

Draper, A., Stephenson, M. C., Jackson, G. M., Pépés, S., Morgan, P. S., Morris, P. G., et al. (2014). Increased GABA contributes to enhanced control over motor excitability in Tourette syndrome. Curr. Biol. 24, 2343-2347. doi: 10.1016/j.cub.2014.08.038

Duffney, L. J., Wei, J., Cheng, J., Liu, W., Smith, K. R., Kittler, J. T., et al. (2013). Shank3 deficiency induces NMDA receptor hypofunction via an actin-dependent mechanism. J. Neurosci. 33, 15767-15778. doi: 10.1523/JNEUROSCI.1175-13.2013

Dunn, J. T., Mroczek, J., Patel, H. R., and Ragozzino, M. E. (2020). Tandospirone, a partial $5-\mathrm{HT}_{\mathrm{A}}$ receptor agonist, administered systemically or into anterior cingulate attenuates repetitive behaviors in Shank3B mice. Int. J. Neuropsychopharmacol. 23, 533-542. doi: 10.1093/ijnp/ pyaa047
Dunn, H. G., Stoessl, A. J., Ho, H. H., MacLeod, P. M., Poskitt, K. J., Doudet, D. J., et al. (2002). Rett syndrome: investigation of nine patients, including PET scan. Can. J. Neurol. Sci. 29, 345-357. doi: 10.1017/s0317167100002213

Eadie, B. D., Cushman, J., Kannangara, T. S., Fanselow, M. S., and Christie, B. R. (2012). NMDA receptor hypofunction in the dentate gyrus and impaired context discrimination in adult Fmr1 knockout mice. Hippocampus 22, 241-254. doi: 10.1002/hipo.20890

Egea, J., and Klein, R. (2007). Bidirectional Eph-ephrin signaling during axon guidance. Trends Cell Biol. 17, 230-238. doi: 10.1016/j.tcb.2007.03.004

Ehlers, M. D. (1999). Synapse structure: glutamate receptors connected by the shanks. Curr. Biol. 9, R848-R850. doi: 10.1016/s0960-9822(00)80043-3

Ehninger, D., Han, S., Shilyansky, C., Zhou, Y., Li, W., Kwiatkowski, D. J., et al. (2008). Reversal of learning deficits in a Tsc2 $+/-$ mouse model of tuberous sclerosis. Nat. Med. 14, 843-848. doi: 10.1038/nm1788

Ehninger, D., and Silva, A. J. (2011). Rapamycin for treating Tuberous sclerosis and Autism spectrum disorders. Trends Mol. Med. 17, 78-87. doi: 10.1016/j. molmed.2010.10.002

Eissa, N., Al-Houqani, M., Sadeq, A., Ojha, S. K., Sasse, A., and Sadek, B. (2018). Current enlightenment about etiology and pharmacological treatment of autism spectrum disorder. Front. Neurosci. 12:304. doi: 10.3389/fnins.2018. 00304

El-Kordi, A., Winkler, D., Hammerschmidt, K., Kästner, A., Krueger, D., Ronnenberg, A., et al. (2013). Development of an autism severity score for mice using Nlgn4 null mutants as a construct-valid model of heritable monogenic autism. Behav. Brain Res. 251, 41-49. doi: 10.1016/j.bbr.2012.11.016

Ellegood, J., Anagnostou, E., Babineau, B., Crawley, J., Lin, L., Genestine, M., et al. (2015). Clustering autism: using neuroanatomical differences in 26 mouse models to gain insight into the heterogeneity. Mol. Psychiatry 20, 118-125. doi: $10.1038 / \mathrm{mp} .2014 .98$

Ellegood, J., Babineau, B. A., Henkelman, R. M., Lerch, J. P., and Crawley, J. N. (2013). Neuroanatomical analysis of the BTBR mouse model of autism using magnetic resonance imaging and diffusion tensor imaging. NeuroImage 70, 288-300. doi: 10.1016/j.neuroimage.2012.12.029

Ellegood, J., Henkelman, R. M., and Lerch, J. P. (2012). Neuroanatomical assessment of the integrin $\beta 3$ mouse model related to autism and the serotonin system using high resolution MRI. Front. Psychiatry 3:37. doi: 10.3389/fpsyt. 2012.00037

Ellegood, J., Pacey, L. K., Hampson, D. R., Lerch, J. P., and Henkelman, R. M. (2010). Anatomical phenotyping in a mouse model of fragile X syndrome with magnetic resonance imaging. NeuroImage 53, 1023-1029. doi: 10.1016/j. neuroimage.2010.03.038

Ernst, A., and Smelik, P. (1966). Site of action of dopamine and apomorphine on compulsive gnawing behaviour in rats. Experientia 22, 837-838. doi: $10.1007 / \mathrm{BF} 01897450$

Errijgers, V., Fransen, E., D’Hooge, R., De Deyn, P. P., and Kooy, R. F. (2008). Effect of genetic background on acoustic startle response in fragile X knockout mice. Genet. Res. 90, 341-345. doi: 10.1017/S0016672308009415

Espinosa, F., Xuan, Z., Liu, S., and Powell, C. M. (2015). Neuroligin 1 modulates striatal glutamatergic neurotransmission in a pathway and NMDAR subunitspecific manner. Front. Synaptic Neurosci. 7:11. doi: 10.3389/fnsyn.2015.00011

Estanislau, C., Díaz-Morán, S., Cañete, T., Blázquez, G., Tobeña, A., and Fernández-Teruel, A. (2013). Context-dependent differences in grooming behavior among the NIH heterogeneous stock and the Roman high- and low-avoidance rats. Neurosci. Res. 77, 187-201. doi: 10.1016/j.neures.2013. 09.012

Estanislau, C., Veloso, A. W. N., Filgueiras, G. B., Maio, T. P., Dal-Cól, M. L. C., Cunha, D. C., et al. (2019). Rat self-grooming and its relationships with anxiety, dearousal and perseveration: evidence for a self-grooming trait. Physiol. Behav. 209:112585. doi: 10.1016/j.physbeh.2019.112585

Ethell, I. M., Irie, F., Kalo, M. S., Couchman, J. R., Pasquale, E. B., and Yamaguchi, Y. (2001). EphB/syndecan-2 signaling in dendritic spine morphogenesis. Neuron 31, 1001-1013. doi: 10.1016/s0896-6273(01)00440-8

Etherton, M., Földy, C., Sharma, M., Tabuchi, K., Liu, X., Shamloo, M., et al. (2011). Autism-linked neuroligin-3 R451C mutation differentially alters hippocampal and cortical synaptic function. Proc. Natl. Acad. Sci. U S A 108, 13764-13769. doi: 10.1073/pnas.1111093108

Etherton, M. R., Blaiss, C. A., Powell, C. M., and Südhof, T. C. (2009). Mouse neurexin-1 $\alpha$ deletion causes correlated electrophysiological and behavioral 
changes consistent with cognitive impairments. Proc. Natl. Acad. Sci. U S A 106, 17998-18003. doi: 10.1073/pnas.0910297106

Fatemi, S. H., Halt, A. R., Realmuto, G., Earle, J., Kist, D. A., Thuras, P., et al. (2002). Purkinje cell size is reduced in cerebellum of patients with autism. Cell. Mol. Neurobiol. 22, 171-175. doi: 10.1023/a:1019861721160

Feliciano, P., Zhou, X., Astrovskaya, I., Turner, T. N., Wang, T., Brueggeman, L., et al. (2019). Exome sequencing of 457 autism families recruited online provides evidence for autism risk genes. NPJ Genomic Med. 4:19. doi: 10.1038/s41525019-0093-8

Felix-Ortiz, A. C., and Tye, K. M. (2014). Amygdala inputs to the ventral hippocampus bidirectionally modulate social behavior. J. Neurosci. 34, 586-595. doi: 10.1523/JNEUROSCI.4257-13.2014

Fentress, J. C. (1988). Expressive contexts, fine structure and central mediation of rodent grooming. Ann. N Y Acad. Sci. 525, 18-26. doi: 10.1111/j.1749-6632. 1988.tb38592.x

Filice, F., Lauber, E., Vörckel, K. J., Wöhr, M., and Schwaller, B. (2018). 17$\beta$ estradiol increases parvalbumin levels in Pvalb heterozygous mice and attenuates behavioral phenotypes with relevance to autism core symptoms. Mol. Autism 9:15. doi: 10.1186/s13229-018-0199-3

Filippini, A., Bonini, D., Lacoux, C., Pacini, L., Zingariello, M., Sancillo, L., et al. (2017). Absence of the fragile X mental retardation protein results in defects of RNA editing of neuronal mRNAs in mouse. RNA Biol. 14, 1580-1591. doi: $10.1080 / 15476286.2017 .1338232$

Filosa, A., Paixão, S., Honsek, S. D., Carmona, M. A., Becker, L., Feddersen, B., et al. (2009). Neuron-glia communication via EphA4/ephrin-A3 modulates LTP through glial glutamate transport. Nat. Neurosci. 12, 1285-1292. doi: $10.1038 / \mathrm{nn} .2394$

Florijn, W. J., Holtmaat, A. J., de Lang, H., Spierenburg, H., Gispen, W. H., and Versteeg, D. H. (1993). Peptide-induced grooming behavior and caudate nucleus dopamine release. Brain Res. 625, 169-172. doi: 10.1016/00068993(93)90151-c

Floyd, N. S., Price, J. L., Ferry, A. T., Keay, K. A., and Bandler, R. (2000). Orbitomedial prefrontal cortical projections to distinct longitudinal columns of the periaqueductal gray in the rat. J. Comp. Neurol. 422, 556-578. doi: 10.1002/1096-9861(20000710)422:4<556::aid-cne6>3.0.co;2-u

Fraser, M. M., Bayazitov, I. T., Zakharenko, S. S., and Baker, S. J. (2008). Phosphatase and tensin homolog, deleted on chromosome 10 deficiency in brain causes defects in synaptic structure, transmission and plasticity, and myelination abnormalities. Neuroscience 151, 476-488. doi: 10.1016/j. neuroscience.2007.10.048

Fraser, M. M., Zhu, X., Kwon, C. H., Uhlmann, E. J., Gutmann, D. H., and Baker, S. J. (2004). Pten loss causes hypertrophy and increased proliferation of astrocytes in vivo. Cancer Res. 64, 7773-7779. doi: 10.1158/0008-5472.CAN04-2487

Frisch, C., Hüsch, K., Angenstein, F., Kudin, A., Kunz, W., Elger, C. E., et al. (2009). Dose-dependent memory effects and cerebral volume changes after in utero exposure to valproate in the rat. Epilepsia 50, 1432-1441. doi: 10.1111/j.15281167.2008.01943.x

Fung, L. K., Mahajan, R., Nozzolillo, A., Bernal, P., Krasner, A., Jo, B., et al. (2016). Pharmacologic treatment of severe irritability and problem behaviors in autism: a systematic review and meta-analysis. Pediatrics 137, S124-S135. doi: 10.1542/peds.2015-2851K

Gandhi, R. M., Kogan, C. S., and Messier, C. (2014). 2-Methyl-6-(phenylethynyl) pyridine (MPEP) reverses maze learning and PSD-95 deficits in fMRI knock-out mice. Front. Cell. Neurosci. 8:70. doi: 10.3389/fncel.2014. 00070

Gao, Y., Vasilyev, D. V., Goncalves, M. B., Howell, F. V., Hobbs, C., Reisenberg, M., et al. (2010). Loss of retrograde endocannabinoid signaling and reduced adult neurogenesis in diacylglycerol lipase knock-out mice. J. Neurosci. 30, 2017-2024. doi: 10.1523/JNEUROSCI.5693-09.2010

Gao, R., Zaccard, C. R., Shapiro, L. P., Dionisio, L. E., Martin-de-Saavedra, M. D., Piguel, N. H., et al. (2019). The CNTNAP2-CASK complex modulates GluA1 subcellular distribution in interneurons. Neurosci. Lett. 701, 92-99. doi: 10.1016/j.neulet.2019.02.025

Gao, P., Zhang, J., Yokoyama, M., Racey, B., Dreyfus, C., Black, I., et al. (1996). Regulation of topographic projection in the brain: Elf-1 in the hippocamposeptal system. Proc. Natl. Acad. Sci. U S A 93, 11161-11166. doi: 10.1073/pnas.93.20.11161
Gargiulo, P. A., and Donoso, A. O. (1996). Distinct grooming patterns induced by intracerebroventricular injection of CRH, TRH and LHRH in male rats. Braz. J. Med. Biol. Res. 29, 375-379.

Gau, S. S.-F., Liao, H.-M., Hong, C.-C., Chien, W.-H., and Chen, C.-H. (2012). Identification of two inherited copy number variants in a male with autism supports two-hit and compound heterozygosity models of autism. Am. J. Med. Genet. B Neuropsychiatr. Genet. 159, 710-717. doi: 10.1002/ajmg.b. 32074

Gdalyahu, A., Lazaro, M., Penagarikano, O., Golshani, P., Trachtenberg, J. T., and Gescwind, D. H. (2015). The autism related protein contactin-associated protein-like 2 (CNTNAP2) stabilizes new spines: an in vivo mouse study. PLoS One 10:e0125633. doi: 10.1371/journal.pone.0125633

Gencer, O., Emiroglu, F. N., Miral, S., Baykara, B., Baykara, A., and Dirik, E. (2008). Comparison of long-term efficacy and safety of risperidone and haloperidol in children and adolescents with autistic disorder. An open label maintenance study. Eur. Child Adolesc. Psychiatry 17, 217-225. doi: 10.1007/s00787-007-0656-6

Gerfen, C. R. (1995). Dopamine receptor function in the basal ganglia. Clin. Neuropharmacol. 18, S162-S177. doi: 10.1002/mds. 870080303

Gerfen, C. R., Engber, T. M., Mahan, L. C., Susel, Z., Chase, T. N., Monsma, F. J., et al. (1990). D1 and D2 dopamine receptor-regulated gene expression of striatonigral and striatopallidal neurons. Science 250, 1429-1432. doi: $10.1126 /$ science. 2147780

Gerke, P., Benzing, T., Höhne, M., Kispert, A., Frotscher, M., Walz, G., et al. (2006). Neuronal expression and interaction with the synaptic protein CASK suggest a role for Neph1 and Neph2 in synaptogenesis. J. Comp. Neurol. 498, 466-475. doi: 10.1002/cne.21064

Geschwind, D. H. (2011). Genetics of autism spectrum disorders. Trends Cogn. Sci. 15, 409-416. doi: 10.1016/j.tics.2011.07.003

Geschwind, D. H., and State, M. W. (2015). Gene hunting in autism spectrum disorder: on the path to precision medicine. Lancet Neurol. 14, 1109-1120. doi: 10.1016/S1474-4422(15)00044-7

Ghidoni, B. B. Z. (2007). Rett syndrome. Child Adolesc. Psychiatr. Clin. N. Am. 16, 723-743. doi: 10.1016/j.chc.2007.03.004

Gholizadeh, S., Arsenault, J., Xuan, I. C. Y., Pacey, L. K., and Hampson, D. R. (2014). Reduced phenotypic severity following adeno-associated virusmediated Fmrl gene delivery in fragile X mice. Neuropsychopharmacology 39 , 3100-3111. doi: 10.1038/npp.2014.167

Gispen, W. H., and Isaacson, R. L. (1981). ACTH-induced excessive grooming in the rat. Pharmacol. Ther. 12, 209-246. doi: 10.1016/0163-7258(81)90081-4

Gogolla, N., LeBlanc, J. J., Quast, K. B., Südhof, T. C., Fagiolini, M., and Hensch, T. K. (2009). Common circuit defect of excitatory-inhibitory balance in mouse models of autism. J. Neurodev. Disord. 1, 172-181. doi: 10.1007/s11689-009-9023-x

Golden, C. E., Buxbaum, J. D., and De Rubeis, S. (2018). Disrupted circuits in mouse models of autism spectrum disorder and intellectual disability. Curr. Opin. Neurobiol. 48, 106-112. doi: 10.1016/j.conb.2017.11.006

Gotham, K., Bishop, S. L., Hus, V., Huerta, M., Lund, S., Buja, A., et al. (2013). Exploring the relationship between anxiety and insistence on sameness in autism spectrum disorders. Autism Res. 6, 33-41. doi: 10.1002/aur.1263

Gould, G. G., Hensler, J. G., Burke, T. F., Benno, R. H., Onaivi, E. S., and Daws, L. C. (2011). Density and function of central serotonin (5-HT) transporters, $5-\mathrm{HT} 1_{\mathrm{A}}$ and $5-\mathrm{HT} 2_{\mathrm{A}}$ receptors and effects of their targeting on BTBR T+tf/J mouse social behavior. J. Neurochem. 116, 291-303. doi: $10.1111 /$ j.1471-4159.2010.07104.x

Gould, B. R., and Zingg, H. H. (2003). Mapping oxytocin receptor gene expression in the mouse brain and mammary gland using an oxytocin receptor-LacZ reporter mouse. Neuroscience 122, 155-167. doi: 10.1016/s03064522(03)00283-5

Grabrucker, A. M. (2013). Environmental factors in autism. Front. Psychiatry 3:118. doi: $10.3389 /$ fpsyt.2012.00118

Grabrucker, A. M., Schmeisser, M. J., Schoen, M., and Boeckers, T. M. (2011). Postsynaptic ProSAP/Shank scaffolds in the cross-hair of synaptopathies. Trends Cell Biol. 21, 594-603. doi: 10.1016/j.tcb.2011.07.003

Grayton, H. M., Missler, M., Collier, D. A., and Fernandes, C. (2013). Altered social behaviours in neurexin $1 \alpha$ knockout mice resemble core symptoms in neurodevelopmental disorders. PLoS One 8:e67114. doi: 10.1371/journal.pone. 0067114 
Green, S. A., Ben-Sasson, A., Soto, T. W., and Carter, A. S. (2012). Anxiety and sensory over-responsivity in toddlers with autism spectrum disorders: bidirectional effects across time. J. Autism Dev. Disord. 42, 1112-1119. doi: 10.1007/s10803-011-1361-3

Greer, J. M., and Capecchi, M. R. (2002). Hoxb8 is required for normal grooming behavior in mice. Neuron 33, 23-34. doi: 10.1016/s0896-6273(01) 00564-5

Gremel, C. M., Chancey, J. H., Atwood, B. K., Luo, G., Neve, R., Ramakrishnan, C., et al. (2016). Endocannabinoid modulation of orbitostriatal circuits gates habit formation. Neuron 90, 1312-1324. doi: 10.1016/j.neuron.2016. 04.043

Gross, C., Banerjee, A., Tiwari, D., Longo, F., White, A. R., Allen, A., et al. (2019). Isoform-selective phosphoinositide 3-kinase inhibition ameliorates a broad range of fragile $\mathrm{X}$ syndrome-associated deficits in a mouse model. Neuropsychopharmacology 44, 324-333. doi: 10.1038/s41386-0180150-5

Grove, J., Ripke, S., Als, T. D., Mattheisen, M., Walters, R. K., Won, H., et al. (2019). Identification of common genetic risk variants for autism spectrum disorder. Nat. Genet. 51, 431-444. doi: 10.1038/s41588-019-0344-8

Grunwald, I. C., Korte, M., Adelmann, G., Plueck, A., Kullander, K., Adams, R. H., et al. (2004). Hippocampal plasticity requires postsynaptic ephrinBs. Nat. Neurosci. 7, 33-40. doi: 10.1038/nn1164

Grunwald, I. C., Korte, M., Wolfer, D., Wilkinson, G. A., Unsicker, K., Lipp, H.-P., et al. (2001). Kinase-independent requirement of EphB2 receptors in hippocampal synaptic plasticity. Neuron 32, 1027-1040. doi: 10.1016/s08966273(01)00550-5

Guilmatre, A., Huguet, G., Delorme, R., and Bourgeron, T. (2014). The emerging role of SHANK genes in neuropsychiatric disorders. Dev. Neurobiol. 74, 113-122. doi: 10.1002/dneu.22128

Gulisano, M., Barone, R., Alaimo, S., Ferro, A., Pulvirenti, A., Cirnigliaro, L., et al. (2020). Disentangling restrictive and repetitive behaviors and social impairments in children and adolescents with gilles de la tourette syndrome and autism spectrum disorder. Brain Sci. 10:308. doi: 10.3390/brainsci10 050308

Gundelfinger, E. D., Boeckers, T. M., Baron, M. K., and Bowie, J. U. (2006). A role for zinc in postsynaptic density asSAMbly and plasticity? Trends Biochem. Sci. 31, 366-373. doi: 10.1016/j.tibs.2006.05.007

Guo, H., Duyzend, M. H., Coe, B. P., Baker, C., Hoekzema, K., Gerdts, J., et al. (2019). Genome sequencing identifies multiple deleterious variants in autism patients with more severe phenotypes. Genet. Med. 21, 1611-1620. doi: 10.1038/s41436-018-0380-2

Gurney, M. E., Cogram, P., Deacon, R. M., Rex, C., and Tranfaglia, M. (2017). Multiple behavior phenotypes of the fragile-X syndrome mouse model respond to chronic inhibition of phosphodiesterase-4D (PDE4D). Sci. Rep. 7:14653. doi: 10.1038/s41598-017-15028-x

Haas, B. W., Barnea-Goraly, N., Lightbody, A. A., Patnaik, S. S., Hoeft, F., Hazlett, H., et al. (2009). Early white-matter abnormalities of the ventral frontostriatal pathway in fragile X syndrome. Dev. Med. Child Neurol. 51, 593-599. doi: 10.1111/j.1469-8749.2009.03295.x

Haber, S. N., and Calzavara, R. (2009). The cortico-basal ganglia integrative network: the role of the thalamus. Brain Res. Bull. 78, 69-74. doi: 10.1016/j. brainresbull.2008.09.013

Haberl, M. G., Zerbi, V., Veltien, A., Ginger, M., Heerschap, A., and Frick, A. (2015). Structural-functional connectivity deficits of neocortical circuits in the fMR1-/y mouse model of autism. Sci. Adv. 1:e1500775. doi: 10.1126/sciadv. 1500775

Hadley, C., Hadley, B., Ephraim, S., Yang, M., and Lewis, M. H. (2006). Spontaneous stereotypy and environmental enrichment in deer mice (Peromyscus maniculatus): reversibility of experience. Appl. Anim. Behav. Sci. 97, 312-322. doi: 10.1016/j.applanim.2005.08.006

Hagerman, R. J., Berry-Kravis, E., Hazlett, H. C., Bailey, D. B. Jr., Moine, H., Kooy, R. F., et al. (2017). Fragile X syndrome. Nat. Rev. Dis. Primers 3:17065. doi: $10.1038 /$ nrdp. 2017.65

Hallahan, B. P., Craig, M. C., Toal, F., Daly, E. M., Moore, C. J., Ambikapathy, A., et al. (2011). In vivo brain anatomy of adult males with Fragile $\mathrm{X}$ syndrome: an MRI study. NeuroImage 54, 16-24. doi: 10.1016/j.neuroimage.2010.08.015

Han, S., Tai, C., Jones, C. J., Scheuer, T., and Catterall, W. A. (2014). Enhancement of inhibitory neurotransmission by $\mathrm{GABA}_{\mathrm{A}}$ receptors having $\alpha 2,3$-subunits ameliorates behavioral deficits in a mouse model of autism. Neuron 81, 1282-1289. doi: 10.1016/j.neuron.2014.01.016

Han, S., Tai, C., Westenbroek, R. E., Frank, H. Y., Cheah, C. S., Potter, G. B., et al. (2012). Autistic-like behaviour in $\mathrm{Scnla}+/-$ mice and rescue by enhanced GABA-mediated neurotransmission. Nature 489, 385-390. doi: 10.1038/nature11356

Harony-Nicolas, H., Kay, M., du Hoffmann, J., Klein, M. E., Bozdagi-Gunal, O., Riad, M., et al. (2017). Oxytocin improves behavioral and electrophysiological deficits in a novel Shank3-deficient rat. eLife 6:e18904. doi: 10.7554/eLife.18904

Hashemi, E., Ariza, J., Rogers, H., Noctor, S. C., and Martínez-Cerdeño, V. (2017). The number of parvalbumin-expressing interneurons is decreased in the prefrontal cortex in autism. Cereb. Cortex 27, 1931-1943. doi: 10.1093/cercor/bhw021

Hayashi, E., Kuratani, K., Kinoshita, M., and Hara, H. (2010). Pharmacologically distinctive behaviors other than burying marbles during the marble burying test in mice. Pharmacology 86, 293-296. doi: 10.1159/000321190

Heimer, L., Van Hoesen, G. W., Trimble, M., and Zahm, D. S. (2007). Anatomy of Neuropsychiatry: The New Anatomy of the Basal Forebrain and Its Implications for Neuropsychiatric Illness. New York, NY: Academic Press.

Henderson, C., Wijetunge, L., Kinoshita, M. N., Shumway, M., Hammond, R. S., Postma, F. R., et al. (2012). Reversal of disease-related pathologies in the fragile $\mathrm{X}$ mouse model by selective activation of $\mathrm{GABA}_{\mathrm{B}}$ receptors with arbaclofen. Sci. Transl. Med. 4:152ra128. doi: 10.1126/scitranslmed.3004218

Henkemeyer, M., Itkis, O. S., Ngo, M., Hickmott, P. W., and Ethell, I. M. (2003). Multiple EphB receptor tyrosine kinases shape dendritic spines in the hippocampus. J. Cell Biol. 163, 1313-1326. doi: 10.1083/jcb.200306033

Herman, G. E., Butter, E., Enrile, B., Pastore, M., Prior, T. W., and Sommer, A. (2007). Increasing knowledge of PTEN germline mutations: two additional patients with autism and macrocephaly. Am. J. Med. Genet. A 143A, 589-593. doi: 10.1002/ajmg.a.31619

Héroult, M., Schaffner, F., and Augustin, H. G. (2006). Eph receptor and ephrin ligand-mediated interactions during angiogenesis and tumor progression. Exp. Cell Res. 312, 642-650. doi: 10.1055/s-0040-1719018

Hines, R. M., Wu, L., Hines, D. J., Steenland, H., Mansour, S., Dahlhaus, R., et al. (2008). Synaptic imbalance, stereotypies, and impaired social interactions in mice with altered neuroligin 2 expression. J. Neurosci. 28, 6055-6067. doi: 10.1523/JNEUROSCI.0032-08.2008

Hisaoka, T., Komori, T., Kitamura, T., and Morikawa, Y. (2018). Abnormal behaviours relevant to neurodevelopmental disorders in Kirrel3-knockout mice. Sci. Rep. 8:1408. doi: 10.1038/s41598-018-19844-7

Hollander, E., Anagnostou, E., Chaplin, W., Esposito, K., Haznedar, M. M., Licalzi, E., et al. (2005). Striatal volume on magnetic resonance imaging and repetitive behaviors in autism. Biol. Psychiatry 58, 226-232. doi: 10.1016/j. biopsych.2005.03.040

Homberg, J. R., van den Akker, M., Raasø, H. S., Wardeh, G., Binnekade, R., Schoffelmeer, A. N., et al. (2002). Enhanced motivation to self-administer cocaine is predicted by self-grooming behaviour and relates to dopamine release in the rat medial prefrontal cortex and amygdala. Eur. J. Neurosci. 15, 1542-1550. doi: 10.1046/j.1460-9568.2002.01976.x

Hong, W., Kim, D.-W., and Anderson, D. J. (2014). Antagonistic control of social versus repetitive self-grooming behaviors by separable amygdala neuronal subsets. Cell 158, 1348-1361. doi: 10.1016/j.cell.2014.07.049

Horev, G., Ellegood, J., Lerch, J. P., Son, Y.-E. E., Muthuswamy, L., Vogel, H., et al. (2011). Dosage-dependent phenotypes in models of 16p11. 2 lesions found in autism. Proc. Natl. Acad. Sci. U S A 108, 17076-17081. doi: 10.1073/pnas. 1114042108

Hosie, S., Malone, D. T., Liu, S., Glass, M., Adlard, P. A., Hannan, A. J., et al. (2018). Altered amygdala excitation and CB1 receptor modulation of aggressive behavior in the neuroligin- $3^{\mathrm{R} 451 \mathrm{C}}$ mouse model of autism. Front. Cell. Neurosci. 12:234. doi: 10.3389/fncel.2018.00234

Houwing, D. J., Heijkoop, R., Olivier, J. D. A., and Snoeren, E. M. S. (2019). Perinatal fluoxetine exposure changes social and stress-coping behavior in adult rats housed in a seminatural environment. Neuropharmacology 151, 84-97. doi: 10.1016/j.neuropharm.2019.03.037

Hu, X. Z., Lipsky, R. H., Zhu, G., Akhtar, L. A., Taubman, J., Greenberg, B. D., et al. (2006). Serotonin transporter promoter gain-of-function genotypes are linked to obsessive-compulsive disorder. Am. J. Hum. Genet. 78, 815-826. doi: $10.1086 / 503850$ 
Huang, H.-S., Burns, A. J., Nonneman, R. J., Baker, L. K., Riddick, N. V., Nikolova, V. D., et al. (2013). Behavioral deficits in an Angelman syndrome model: effects of genetic background and age. Behav. Brain Res. 243, 79-90. doi: 10.1016/j.bbr.2012.12.052

Huang, F., Chen, X., Jiang, X., Niu, J., Cui, C., Chen, Z., et al. (2019). Betaine ameliorates prenatal valproic-acid-induced autism-like behavioral abnormalities in mice by promoting homocysteine metabolism. Psychiatry Clin. Neurosci. 73, 317-322. doi: 10.1111/pcn.12833

Hung, A. Y., Futai, K., Sala, C., Valtschanoff, J. G., Ryu, J., Woodworth, M. A., et al. (2008). Smaller dendritic spines, weaker synaptic transmission, but enhanced spatial learning in mice lacking Shank1. J. Neurosci. 28, 1697-1708. doi: 10.1523/JNEUROSCI.3032-07.2008

Huang, J., and Manning, B. D. (2008). The TSC1-TSC2 complex: a molecular switchboard controlling cell growth. Biochem. J. 412, 179-190. doi: 10.1042/BJ20080281

Hynes, K., Tarpey, P., Dibbens, L. M., Bayly, M. A., Berkovic, S. F., Smith, R., et al. (2010). Epilepsy and mental retardation limited to females with PCDH19 mutations can present de novo or in single generation families. J. Med. Genet. 47, 211-216. doi: 10.1136/jmg.2009.068817

Ifergan, I., Kebir, H., Terouz, S., Alvarez, J. I., Lécuyer, M. A., Gendron, S., et al. (2011). Role of Ninjurin-1 in the migration of myeloid cells to central nervous system inflammatory lesions. Ann. Neurol. 70, 751-763. doi: 10.1002/ana. 22519

Inoki, K., Corradetti, M. N., and Guan, K.-L. (2005). Dysregulation of the TSC-mTOR pathway in human disease. Nat. Genet. 37, 19-24. doi: 10.1038/ng1494

Iossifov, I., Ronemus, M., Levy, D., Wang, Z., Hakker, I., Rosenbaum, J., et al. (2012). De novo gene disruptions in children on the autistic spectrum. Neuron 74, 285-299. doi: 10.1016/j.neuron.2012.04.009

Ishiguro, A., Inagaki, M., and Kaga, M. (2007). Stereotypic circling behavior in mice with vestibular dysfunction: asymmetrical effects of intrastriatal microinjection of a dopamine agonist. Int. J. Neurosci. 117, 1049-1064. doi: 10.1080/00207450600936874

Jamain, S., Quach, H., Betancur, C., Råstam, M., Colineaux, C., Gillberg, I. C., et al. (2003). Mutations of the X-linked genes encoding neuroligins NLGN3 and NLGN4 are associated with autism. Nat. Genet. 34, 27-29. doi: 10.1038/ ng1136

Jang, Y. S., Kang, J. H., Woo, J. K., Kim, H. M., Hwang, J. I., Lee, S. J., et al. (2016). Ninjurinl suppresses metastatic property of lung cancer cells through inhibition of interleukin 6 signaling pathway. Int. J. Cancer 139, 383-395. doi: 10.1002/ijc.30021

Jaramillo, T. C., Speed, H. E., Xuan, Z., Reimers, J. M., Liu, S., and Powell, C. M. (2016). Altered striatal synaptic function and abnormal behaviour in Shank3 exon4-9 deletion mouse model of autism. Autism Res. 9, 350-375. doi: 10.1002/aur.1529

Jardim, M. C., and Guimarães, F. S. (2001). GABAergic and glutamatergic modulation of exploratory behavior in the dorsomedial hypothalamus. Pharmacol. Biochem. Behav. 69, 579-584. doi: 10.1016/s0091-3057(01) 00560-3

Jia, Y. F., Wininger, K., Peyton, L., Ho, A. M., and Choi, D. S. (2021). Astrocytic glutamate transporter 1 (GLT1) deficient mice exhibit repetitive behaviors. Behav. Brain Res. 396:112906. doi: 10.1016/j.bbr.2020.112906

Jiang, Y.-H., Pan, Y., Zhu, L., Landa, L., Yoo, J., Spencer, C., et al. (2010). Altered ultrasonic vocalization and impaired learning and memory in Angelman syndrome mouse model with a large maternal deletion from Ube3a to Gabrb3. PLoS One 5:e12278. doi: 10.1371/journal.pone.0012278

Jiang, Y.-H., Yuen, R. K., Jin, X., Wang, M., Chen, N., Wu, X., et al. (2013). Detection of clinically relevant genetic variants in autism spectrum disorder by whole-genome sequencing. Am. J. Hum. Genet. 93, 249-263. doi: 10.1016/j. ajhg.2013.06.012

Jiujias, M., Kelley, E., and Hall, L. (2017). Restricted, repetitive behaviors in autism spectrum disorder and obsessive-compulsive disorder: a comparative review. Child Psychiatry Hum. Dev. 48, 944-959. doi: 10.1007/s10578-017-0717-0

Joyner, C. P., Myrick, L. C., Crossland, J. P., and Dawson, W. D. (1998). Deer mice as laboratory animals. ILAR J. 39, 322-330. doi: 10.1093/ilar.39.4.322

Jung, C. K., and Herms, J. (2014). Structural dynamics of dendritic spines are influenced by an environmental enrichment: an in vivo imaging study. Cereb. Cortex 24, 377-384. doi: 10.1093/cercor/bhs317
Jung, K.-M., Sepers, M., Henstridge, C. M., Lassalle, O., Neuhofer, D., Martin, H., et al. (2012). Uncoupling of the endocannabinoid signalling complex in a mouse model of fragile X syndrome. Nat. Commun. 3:1080. doi: $10.1038 /$ ncomms 2045

Kalueff, A. V., and Nutt, D. J. (2007). Role of GABA in anxiety and depression. Depress. Anxiety 24, 495-517. doi: 10.1002/da.20262

Kalueff, A. V., and Tuohimaa, P. (2004a). Contrasting grooming phenotypes in C57Bl/6 and 129S1/SvImJ mice. Brain Res. 1028, 75-82. doi: 10.1016/j.brainres. 2004.09.001

Kalueff, A. V., and Tuohimaa, P. (2004b). Grooming analysis algorithm for neurobehavioural stress research. Brain Res. Protoc. 13, 151-158. doi: 10.1016/j. brainresprot.2004.04.002

Kalueff, A. V., and Tuohimaa, P. (2005a). Contrasting grooming phenotypes in three mouse strains markedly different in anxiety and activity (129S1, BALB/c and NMRI). Behav. Brain Res. 160, 1-10. doi: 10.1016/j.bbr.2004.11.010

Kalueff, A. V., and Tuohimaa, P. (2005b). The grooming analysis algorithm discriminates between different levels of anxiety in rats: potential utility for neurobehavioural stress research. J. Neurosci. Methods 143, 169-177. doi: 10.1016/j.jneumeth.2004.10.001

Kalueff, A. V., and Tuohimaa, P. (2005c). Mouse grooming microstructure is a reliable anxiety marker bidirectionally sensitive to GABAergic drugs. Eur. J. Pharmacol. 508, 147-153. doi: 10.1016/j.ejphar.2004.11.054

Kalueff, A. V., Ren-Patterson, R. F., and Murphy, D. L. (2007). The developing use of heterozygous mutant mouse models in brain monoamine transporter research. Trends Pharmacol. Sci. 28, 122-127. doi: 10.1016/j.tips.2007.01.002

Kalueff, A. V., Ren-Patterson, R. F., LaPorte, J. L., and Murphy, D. L. (2008). Domain interplay concept in animal models of neuropsychiatric disorders: a new strategy for high-throughput neurophenotyping research. Behav. Brain Res. 188, 243-249. doi: 10.1016/j.bbr.2007.11.011

Kalueff, A. V., Stewart, A. M., Song, C., Berridge, K. C., Graybiel, A. M., and Fentress, J. C. (2016). Neurobiology of rodent self-grooming and its value for translational neuroscience. Nat. Rev. Neurosci. 17, 45-59. doi: 10.1038/nrn. 2015.8

Kametani, H. (1988). Analysis of age-related changes in stress-induced grooming in the rat. Differential behavioral profile of adaptation to stress. Ann. N. Y. Acad. Sci. 525, 101-113. doi: 10.1111/j.1749-6632.1988.tb38599.x

Kano, M., Ohno-Shosaku, T., Hashimotodani, Y., Uchigashima, M., and Watanabe, M. (2009). Endocannabinoid-mediated control of synaptic transmission. Physiol. Rev. 89, 309-380. doi: 10.1152/physrev.00019.2008

Karimi, P., Kamali, E., Mousavi, S. M., and Karahmadi, M. (2017). Environmental factors influencing the risk of autism. J. Res. Med. Sci. 22:27. doi: 10.4103/17351995.200272

Karler, R., Bedingfield, J. B., Thai, D. K., and Calder, L. D. (1997). The role of the frontal cortex in the mouse in behavioral sensitization to amphetamine. Brain Res. 757, 228-235. doi: 10.1016/s0006-8993(97)00221-7

Karler, R., Calder, L. D., Thai, D. K., and Bedingfield, J. B. (1998). The role of dopamine in the mouse frontal cortex: a new hypothesis of behavioral sensitization to amphetamine and cocaine. Pharmacol. Biochem. Behav. 61, 435-443. doi: 10.1016/s0091-3057(98)00133-6

Karvat, G., and Kimchi, T. (2014). Acetylcholine elevation relieves cognitive rigidity and social deficiency in a mouse model of autism. Neuropsychopharmacology 39, 831-840. doi: 10.1038/npp.2013.274

Kas, M. J., Fernandes, C., Schalkwyk, L. C., and Collier, D. A. (2007). Genetics of behavioural domains across the neuropsychiatric spectrum; of mice and men. Mol. Psychiatry 12, 324-330. doi: 10.1038/sj.mp.4001979

Kassim, A. B. B. M., and Mohamed, N. H. B. (2019). The global prevalence and diagnosis of autism spectrum disorder (ASD) among young children. Southeast Asia Psychol. J. 7, 26-45.

Katz, R. J., and Roth, K. A. (1979). Stress induced grooming in the rat-an endorphin mediated syndrome. Neurosci. Lett. 13, 209-212. doi: 10.1016/03043940(79)90043-0

Kaufman, J., Yang, B.-Z., Douglas-Palumberi, H., Grasso, D., Lipschitz, D., Houshyar, S., et al. (2006). Brain-derived neurotrophic factor-5-HTTLPR gene interactions and environmental modifiers of depression in children. Biol. Psychiatry 59, 673-680. doi: 10.1016/j.biopsych.2005.10.026

Kazdoba, T. M., Leach, P. T., and Crawley, J. N. (2016). Behavioral phenotypes of genetic mouse models of autism. Genes Brain Behav. 15, 7-26. doi: 10.1111/gbb. 12256 
Kent, J. M., Kushner, S., Ning, X., Karcher, K., Ness, S., Aman, M., et al. (2013). Risperidone dosing in children and adolescents with autistic disorder: a double-blind, placebo-controlled study. J. Autism Dev. Disord. 43, 1773-1783. doi: 10.1007/s10803-012-1723-5

Khakh, B. S., and Sofroniew, M. V. (2015). Diversity of astrocyte functions and phenotypes in neural circuits. Nat. Neurosci. 18, 942-952. doi: 10.1038/ nn. 4043

Kim, S., Burette, A., Chung, H. S., Kwon, S.-K., Woo, J., Lee, H. W., et al. (2006). NGL family PSD-95-interacting adhesion molecules regulate excitatory synapse formation. Nat. Neurosci. 9, 1294-1301. doi: 10.1038/nn1763

Kim, T. W., Kang, Y. K., Park, Z. Y., Kim, Y.-H., Hong, S. W., Oh, S. J., et al. (2014). SH3RF2 functions as an oncogene by mediating PAK4 protein stability. Carcinogenesis 35, 624-634. doi: 10.1093/carcin/bgt338

Kim, Y. S., and Leventhal, B. L. (2015). Genetic epidemiology and insights into interactive genetic and environmental effects in autism spectrum disorders. Biol. Psychiatry 77, 66-74. doi: 10.1016/j.biopsych.2014.11.001

Kim, H., Lim, C.-S., and Kaang, B.-K. (2016). Neuronal mechanisms and circuits underlying repetitive behaviors in mouse models of autism spectrum disorder. Behav. Brain Funct. 12:3. doi: 10.1186/s12993-016-0087-y

Kim, E. C., Patel, J., Zhang, J., Soh, H., Rhodes, J. S., Tzingounis, A. V., et al. (2020). Heterozygous loss of epilepsy gene KCNQ2 alters social, repetitive and exploratory behaviors. Genes Brain Behav. 19:e12599. doi: 10.1111/gbb.12599

Kim, I. H., Rossi, M. A., Aryal, D. K., Racz, B., Kim, N., Uezu, A., et al. (2015). Spine pruning drives antipsychotic-sensitive locomotion via circuit control of striatal dopamine. Nat. Neurosci. 18, 883-891. doi: 10.1038/nn.4015

Kim, J.-W., Seung, H., Kim, K. C., Gonzales, E. L. T., Oh, H. A., Yang, S. M., et al. (2017). Agmatine rescues autistic behaviors in the valproic acid-induced animal model of autism. Neuropharmacology 113, 71-81. doi: 10.1016/j.neuropharm. 2016.09.014

King, B. H., Hollander, E., Sikich, L., McCracken, J. T., Scahill, L., Bregman, J. D., et al. (2009). Lack of efficacy of citalopram in children with autism spectrum disorders and high levels of repetitive behavior: citalopram ineffective in children with autism. Arch. Gen. Psychiatry 66, 583-590. doi: 10.1001/archgenpsychiatry.2009.30

Kinsey, S. G., Bailey, M. T., Sheridan, J. F., Padgett, D. A., and Avitsur, R. (2007). Repeated social defeat causes increased anxiety-like behavior and alters splenocyte function in C57BL/6 and CD-1 mice. Brain Behav. Immun. 21, 458-466. doi: 10.1016/j.bbi.2006.11.001

Kiyatkin, E. A., and Rebec, G. V. (1999). Striatal neuronal activity and responsiveness to dopamine and glutamate after selective blockade of D1 and D2 dopamine receptors in freely moving rats. J. Neurosci. 19, 3594-3609. doi: 10.1523/JNEUROSCI.19-09-03594.1999

Klein, R. (2004). Eph/ephrin signaling in morphogenesis, neural development and plasticity. Curr. Opin. Cell Biol. 16, 580-589. doi: 10.1016/j.ceb.2004.07.002

Klein, R. (2009). Bidirectional modulation of synaptic functions by Eph/ephrin signaling. Nat. Neurosci. 12, 15-20. doi: 10.1038/nn.2231

Komorowska, J., and Pellis, S. M. (2004). Regulatory mechanisms underlying novelty-induced grooming in the laboratory rat. Behav. Processes 67, 287-293. doi: 10.1016/j.beproc.2004.05.001

Kouser, M., Speed, H. E., Dewey, C. M., Reimers, J. M., Widman, A. J., Gupta, N., et al. (2013). Loss of predominant Shank3 isoforms results in hippocampus-dependent impairments in behavior and synaptic transmission. J. Neurosci. 33, 18448-18468. doi: 10.1523/JNEUROSCI.301713.2013

Kreienkamp, H.-J. (2008). "Scaffolding proteins at the postsynaptic density: shank as the architectural framework," in Protein-Protein Interactions as New Drug Targets, eds E. Klussmann and J. Scott (Berlin: Springer), 365-380.

Krueger, D. D., Osterweil, E. K., Chen, S. P., Tye, L. D., and Bear, M. F. (2011). Cognitive dysfunction and prefrontal synaptic abnormalities in a mouse model of fragile X syndrome. Proc. Natl. Acad. Sci. U S A 108, 2587-2592. doi: $10.1073 /$ pnas. 1013855108

Kullander, K., and Klein, R. (2002). Mechanisms and functions of Eph and ephrin signalling. Nat. Rev. Mol. Cell Biol. 3, 475-486. doi: 10.1038/nrm856

Kumar, M., Duda, J. T., Hwang, W. T., Kenworthy, C., Ittyerah, R., Pickup, S., et al. (2014). High resolution magnetic resonance imaging for characterization of the neuroligin-3 knock-in mouse model associated with autism spectrum disorder. PLoS One 9:e109872. doi: 10.1371/journal.pone. 0109872
Kwon, C.-H., Luikart, B. W., Powell, C. M., Zhou, J., Matheny, S. A., Zhang, W., et al. (2006). Pten regulates neuronal arborization and social interaction in mice. Neuron 50, 377-388. doi: 10.1016/j.neuron.2006. 03.023

Lai, M.-C., Lombardo, M. V., and Baron-Cohen, S. (2014). Autism. Lancet 383, 896-910. doi: 10.1016/S0140-6736(13)61539-1

Langen, M., Leemans, A., Johnston, P., Ecker, C., Daly, E., Murphy, C. M., et al. (2012). Fronto-striatal circuitry and inhibitory control in autism: findings from diffusion tensor imaging tractography. Cortex 48, 183-193. doi: 10.1016/j. cortex.2011.05.018

LaSalle, J. M. (2013). Epigenomic strategies at the interface of genetic and environmental risk factors for autism. J. Hum. Genet. 58, 396-401. doi: 10.1038/jhg.2013.49

Lauber, E., Filice, F., and Schwaller, B. (2018). Dysregulation of parvalbumin expression in the Cntnap2 $2^{-/-}$mouse model of autism spectrum disorder. Front. Mol. Neurosci. 11:262. doi: 10.3389/fnmol.2018.00262

Lauterborn, J. C., Rex, C. S., Kramár, E., Chen, L. Y., Pandyarajan, V., Lynch, G., et al. (2007). Brain-derived neurotrophic factor rescues synaptic plasticity in a mouse model of fragile X syndrome. J. Neurosci. 27, 10685-10694. doi: 10.1523/JNEUROSCI.2624-07.2007

Le, H., Ahn, B. J., Lee, H. S., Shin, A., Chae, S., Lee, S. Y., et al. (2017). Disruption of Ninjurin1 leads to repetitive and anxiety-like behaviors in mice. Mol. Neurobiol. 54, 7353-7368. doi: 10.1007/s12035-016-0207-6

Lee, B., Lee, K., Panda, S., Gonzales-Rojas, R., Chong, A., Bugay, V., et al. (2018). Nanoparticle delivery of CRISPR into the brain rescues a mouse model of fragile X syndrome from exaggerated repetitive behaviours. Nat. Biomed. Eng. 2, 497-507. doi: 10.1038/s41551-018-0252-8

Lee, H. J., Macbeth, A. H., Pagani, J. H., and Young, W. S. III. (2009). Oxytocin: the great facilitator of life. Prog. Neurobiol. 88, 127-151. doi: 10.1016/j.pneurobio. 2009.04.001

Leonzino, M., Ponzoni, L., Braida, D., Gigliucci, V., Busnelli, M., Ceresini, I., et al. (2019). Impaired approach to novelty and striatal alterations in the oxytocin receptor deficient mouse model of autism. Horm. Behav. 114:104543. doi: 10.1016/j.yhbeh.2019.06.007

Lever, A. G., and Geurts, H. M. (2016). Psychiatric co-occurring symptoms and disorders in young, middle-aged, and older adults with autism spectrum disorder. J. Autism Dev. Disord. 46, 1916-1930. doi: 10.1007/s10803-016 $-2722-8$

Levitt, P., and Campbell, D. B. (2009). The genetic and neurobiologic compass points toward common signaling dysfunctions in autism spectrum disorders. J. Clin. Invest. 119, 747-754. doi: 10.1172/JCI37934

Levy, D., Ronemus, M., Yamrom, B., Lee, Y.-H., Leotta, A., Kendall, J., et al. (2011). Rare de novo and transmitted copy-number variation in autistic spectrum disorders. Neuron 70, 886-897. doi: 10.1016/j.neuron.2011.05.015

Lewis, M. H., and Bodfish, J. W. (1998). Repetitive behavior disorders in autism. Ment. Retardat. Dev. 4, 80-89.

Lewis, M., and Kim, S.-J. (2009). The pathophysiology of restricted repetitive behavior. J. Neurodev. Disord. 1, 114-132. doi: 10.1007/s11689-0099019-6

Lewis, M. H., Primiani, C. T., and Muehlmann, A. M. (2019). Targeting dopamine $\mathrm{D} 2$, adenosine $\mathrm{A} 2 \mathrm{~A}$, and glutamate mGlu5 receptors to reduce repetitive behaviors in deer mice. J. Pharmacol. Exp. Ther. 369, 88-97. doi: 10.1124/jpet. 118.256081

Lewis, M. H., Tanimura, Y., Lee, L. W., and Bodfish, J. W. (2007). Animal models of restricted repetitive behavior in autism. Behav. Brain Res. 176, 66-74. doi: 10.1016/j.bbr.2006.08.023

Li, Y.-C., Kellendonk, C., Simpson, E. H., Kandel, E. R., and Gao, W.-J. (2011). D2 receptor overexpression in the striatum leads to a deficit in inhibitory transmission and dopamine sensitivity in mouse prefrontal cortex. Proc. Natl. Acad. Sci. U S A 108, 12107-12112. doi: 10.1073/pnas.1109 718108

Li, W., and Pozzo-Miller, L. (2020). Dysfunction of the corticostriatal pathway in autism spectrum disorders. J. Neurosci. Res. 98, 2130-2147. doi: 10.1002/jnr. 24560

Lidstone, J., Uljarević, M., Sullivan, J., Rodgers, J., McConachie, H., Freeston, M., et al. (2014). Relations among restricted and repetitive behaviors, anxiety and sensory features in children with autism spectrum disorders. Res. Autism Spectr. Disord. 8, 82-92. doi: 10.1016/j.rasd.2013.10.001 
Lim, J., Ryu, J., Kang, S., Noh, H. J., and Kim, C. H. (2019). Autism-like behaviors in male mice with a Pcdh19 deletion. Mol. Brain 12:95. doi: 10.1186/s13041019-0519-3

Lin, J. C., Ho, W.-H., Gurney, A., and Rosenthal, A. (2003). The netrin-G1 ligand NGL-1 promotes the outgrowth of thalamocortical axons. Nat. Neurosci. 6, 1270-1276. doi: 10.1038/nn1148

Liu, J., and Moghaddam, B. (1995). Regulation of glutamate efflux by excitatory amino acid receptors: evidence for tonic inhibitory and phasic excitatory regulation. J. Pharmacol. Exp. Ther. 274, 1209-1215.

Lonetti, G., Angelucci, A., Morando, L., Boggio, E. M., Giustetto, M., and Pizzorusso, T. (2010). Early environmental enrichment moderates the behavioral and synaptic phenotype of MeCP2 null mice. Biol. Psychiatry 67, 657-665. doi: 10.1016/j.biopsych.2009.12.022

Lopez, B. R., Lincoln, A. J., Ozonoff, S., and Lai, Z. (2005). Examining the relationship between executive functions and restricted, repetitive symptoms of autistic disorder. J. Autism Dev. Disord. 35, 445-460. doi: 10.1007/s10803005-5035-x

Lord, C., Brugha, T. S., Charman, T., Cusack, J., Dumas, G., Frazier, T., et al. (2020). Autism spectrum disorder. Nat. Rev. Dis. Primers 6:5. doi: 10.1038/s41572-019-0138-4

Lord, C., Cook, E. H., Leventhal, B. L., and Amaral, D. G. (2000). Autism spectrum disorders. Neuron 28, 355-363. doi: 10.1016/s0896-6273(00)00115-x

Lu, H., Ash, R. T., He, L., Kee, S. E., Wang, W., Yu, D., et al. (2016). Loss and gain of MeCP2 cause similar hippocampal circuit dysfunction that is rescued by deep brain stimulation in a Rett syndrome mouse model. Neuron 91, 739-747. doi: 10.1016/j.neuron.2016.07.018

Lugo, J. N., Smith, G. D., Arbuckle, E. P., White, J., Holley, A. J., Floruta, C. M., et al. (2014). Deletion of PTEN produces autism-like behavioral deficits and alterations in synaptic proteins. Front. Mol. Neurosci. 7:27. doi: 10.3389/fnmol. 2014.00027

Maenner, M. J., Shaw, K. A., Baio, J., Washington, A., Patrick, M., DiRienzo, M., et al (2020). Prevalence of autism spectrum disorder among children aged 8 years-autism and developmental disabilities monitoring network, 11 sites, United States, 2016. MMWR Surveill. Summ. 69:1. doi: 10.15585/mmwr. ss6904a1

Mahmood, U., Ahn, S., Yang, E.-J., Choi, M., Kim, H., Regan, P., et al. (2018). Dendritic spine anomalies and PTEN alterations in a mouse model of VPA-induced autism spectrum disorder. Pharmacol. Res. 128, 110-121. doi: 10.1016/j.phrs.2017.08.006

Mahmoud, S., Gharagozloo, M., Simard, C., and Gris, D. (2019). Astrocytes maintain glutamate homeostasis in the CNS by controlling the balance between glutamate uptake and release. Cells 8:184. doi: 10.3390/cells80 20184

Malone, R. P., and Waheed, A. (2009). The role of antipsychotics in the management of behavioural symptoms in children and adolescents with autism. Drugs 69, 535-548. doi: 10.2165/00003495-200969050-00003

Maneeton, N., Maneeton, B., Putthisri, S., Woottiluk, P., Narkpongphun, A., and Srisurapanont, M. (2018). Risperidone for children and adolescents with autism spectrum disorder: a systematic review. Neuropsychiatr. Dis. Treat. 14, 1811-1820. doi: 10.2147/NDT.S151802

Mardirossian, S., Rampon, C., Salvert, D., Fort, P., and Sarda, N. (2009). Impaired hippocampal plasticity and altered neurogenesis in adult Ube3a maternal deficient mouse model for Angelman syndrome. Exp. neurol. 220, 341-348. doi: 10.1016/j.expneurol.2009.08.035

Martin, E. A., Muralidhar, S., Wang, Z., Cervantes, D. C., Basu, R., Taylor, M. R., et al. (2015). The intellectual disability gene Kirrel3 regulates target-specific mossy fiber synapse development in the hippocampus. elife 4:e09395. doi: 10.7554/eLife.09395

Martínez, A., and Soriano, E. (2005). Functions of ephrin/Eph interactions in the development of the nervous system: emphasis on the hippocampal system. Brain Res. Rev. 49, 211-226. doi: 10.1016/j.jenvman.2020.111781

Masi, A., DeMayo, M. M., Glozier, N., and Guastella, A. J. (2017). An overview of autism spectrum disorder, heterogeneity and treatment options. Neurosci. Bull. 33, 183-193. doi: 10.1007/s12264-017-0100-y

Matsukawa, H., Akiyoshi-Nishimura, S., Zhang, Q., Luján, R., Yamaguchi, K., Goto, H., et al. (2014). Netrin-G/NGL complexes encode functional synaptic diversification. J. Neurosci. 34, 15779-15792. doi: 10.1523/JNEUROSCI.114114.2014
Matsuki, M., Kabara, M., Saito, Y., Shimamura, K., Minoshima, A., Nishimura, M., et al. (2015). Ninjurin1 is a novel factor to regulate angiogenesis through the function of pericytes. Circ. J. 79, 1363-1371. doi: 10.1253/circj. CJ-14-1376

Matta, S. M., Moore, Z., Walker, F. R., Hill-Yardin, E. L., and Crack, P. J. (2020). An altered glial phenotype in the NL3 ${ }^{R 451 C}$ mouse model of autism. Sci. Rep. 10:14492. doi: 10.1038/s41598-020-71171-y

Mazurek, M. O., Vasa, R. A., Kalb, L. G., Kanne, S. M., Rosenberg, D., Keefer, A., et al. (2013). Anxiety, sensory over-responsivity and gastrointestinal problems in children with autism spectrum disorders. J. Abnorm. Child Psychol. 41, 165-176. doi: 10.1007/s10802-012-9668-x

Mazzocco, M. M., Pulsifer, M., Fiumara, A., Cocuzza, M., Nigro, F., Incorpora, G., et al. (1998). Brief report: autistic behaviors among children with fragile $\mathrm{X}$ or Rett syndrome: implications for the classification of pervasive developmental disorder. J. Autism and Dev. Disord. 28, 321-328. doi: 10.1023/a:1026012703449

McBride, P. A., Anderson, G. M., Hertzig, M. E., Sweeney, J. A., Kream, J., Cohen, D. J., et al. (1989). Serotonergic responsivity in male young adults with autistic disorder: results of a pilot study. Arch. Gen. Psychiatry 46, 213-221. doi: 10.1001/archpsyc.1989.01810030019003

McCracken, J. T., McGough, J., Shah, B., Cronin, P., Hong, D., Aman, M. G., et al. (2002). Risperidone in children with autism and serious behavioral problems. N. Engl. J. Med. 347, 314-321. doi: 10.1056/NEJMoa013171

McDougle, C., Naylor, S. T., Cohen, D. J., Aghajanian, G. K., Heninger, G. R., and Price, L. H. (1996). Effects of tryptophan depletion in drug-free adults with autistic disorder. Arch. Gen. Psychiatry 53, 993-1000. doi: 10.1001/archpsyc. 1996.01830110029004

McDougle, C. J., Scahill, L., Aman, M. G., McCracken, J. T., Tierney, E., Davies, M., et al. (2005). Risperidone for the core symptom domains of autism: results from the study by the autism network of the research units on pediatric psychopharmacology. Am. J. Psychiatry 162, 1142-1148. doi: 10.1176/appi.ajp. 162.6.1142

McDougle, C. J., Stigler, K. A., Erickson, C. A., and Posey, D. J. (2008). Atypical antipsychotics in children and adolescents with autistic and other pervasive developmental disorders. J. Clin. Psychiatry 69, 15-20.

McFarlane, H. G., Kusek, G., Yang, M., Phoenix, J., Bolivar, V., and Crawley, J. (2008). Autism-like behavioral phenotypes in BTBR T+tf/J mice. Genes Brain Behav. 7, 152-163. doi: 10.1111/j.1601-183X.2007.00330.x

McGrath, M. J., Campbell, K. M., Veldman, M. B., and Burton, F. H. (1999). Anxiety in a transgenic mouse model of cortical-limbic neuro-potentiated compulsive behavior. Behav. Pharmacol. 10, 435-443. doi: 10.1097/00008877199909000-00001

McNaughton, C. H., Moon, J., Strawderman, M. S., Maclean, K. N., Evans, J., and Strupp, B. J. (2008). Evidence for social anxiety and impaired social cognition in a mouse model of fragile X syndrome. Behav. Neurosci. 122, 293-300. doi: 10.1037/0735-7044.122.2.293

McPheeters, M. L., Warren, Z., Sathe, N., Bruzek, J. L., Krishnaswami, S., Jerome, R. N., et al. (2011). A systematic review of medical treatments for children with autism spectrum disorders. Pediatrics 127, e1312-e1321. doi: 10.1542/peds.2011-0427

Mehta, M. V., Gandal, M. J., and Siegel, S. J. (2011). mGluR5-antagonist mediated reversal of elevated stereotyped, repetitive behaviors in the VPA model of autism. PLoS One 6:e26077. doi: 10.1371/journal.pone.0026077

Mei, Y., Monteiro, P., Zhou, Y., Kim, J.-A., Gao, X., Fu, Z., et al. (2016). Adult restoration of Shank3 expression rescues selective autistic-like phenotypes. Nature 530, 481-484. doi: 10.1038/nature16971

Meikle, L., Pollizzi, K., Egnor, A., Kramvis, I., Lane, H., Sahin, M., et al. (2008). Response of a neuronal model of tuberous sclerosis to mammalian target of rapamycin (mTOR) inhibitors: effects on mTORC1 and Akt signaling lead to improved survival and function. J. Neurosci. 28, 5422-5432. doi: 10.1523/JNEUROSCI.0955-08.2008

Meikle, L., Talos, D. M., Onda, H., Pollizzi, K., Rotenberg, A., Sahin, M., et al. (2007). A mouse model of tuberous sclerosis: neuronal loss of Tscl causes dysplastic and ectopic neurons, reduced myelination, seizure activity and limited survival. J. Neurosci. 27, 5546-5558. doi: 10.1523/JNEUROSCI.5540 $-06.2007$

Mejias, R., Adamczyk, A., Anggono, V., Niranjan, T., Thomas, G. M., Sharma, K., et al. (2011). Gain-of-function glutamate receptor interacting protein 1 variants 
alter GluA2 recycling and surface distribution in patients with autism. Proc. Natl. Acad. Sci. U S A 108, 4920-4925. doi: 10.1073/pnas.1102 233108

Mejias, R., Chiu, S.-L., Han, M., Rose, R., Gil-Infante, A., Zhao, Y., et al. (2019). Purkinje cell-specific Grip $1 / 2$ knockout mice show increased repetitive self-grooming and enhanced mGluR5 signaling in cerebellum. Neurobiol. Dis. 132:104602. doi: 10.1016/j.nbd.2019.104602

Mercer, A. A., Palarz, K. J., Tabatadze, N., Woolley, C. S., and Raman, I. M. (2016). Sex differences in cerebellar synaptic transmission and sex-specific responses to autism-linked Gabrb3 mutations in mice. eLife 5:e07596. doi: 10.7554/eLife. 07596

Meyza, K., and Blanchard, D. (2017). The BTBR mouse model of idiopathic autism-current view on mechanisms. Neurosci. Biobehav. Rev. 76, 99-110. doi: 10.1016/j.neubiorev.2016.12.037

Miral, S., Gencer, O., Inal-Emiroglu, F. N., Baykara, B., Baykara, A., and Dirik, E. (2008). Risperidone versus haloperidol in children and adolescents with AD: a randomized, controlled, double-blind trial. Eur. Child Adolesc. Psychiatry 17, 1-8. doi: 10.1007/s00787-007-0620-5

Modabbernia, A., Velthorst, E., and Reichenberg, A. (2017). Environmental risk factors for autism: an evidence-based review of systematic reviews and metaanalyses. Mol. Autism 8:13. doi: 10.1186/s13229-017-0121-4

Modi, B., Pimpinella, D., Pazienti, A., Zacchi, P., Cherubini, E., and Griguoli, M. (2019). Possible implication of the CA2 hippocampal circuit in social cognition deficits observed in the neuroligin 3 knock-out mouse, a non-syndromic animal model of autism. Front. Psychiatry 10:513. doi: 10.3389/fpsyt.2019. 00513

Molofsky, A. V., Krenick, R., Ullian, E., Tsai, H.-H., Deneen, B., Richardson, W. D., et al. (2012). Astrocytes and disease: a neurodevelopmental perspective. Genes Dev. 26, 891-907. doi: 10.1101/gad.188326.112

Monteiro, P., and Feng, G. (2017). SHANK proteins: roles at the synapse and in autism spectrum disorder. Nat. Rev. Neurosci. 18, 147-157. doi: 10.1038/nrn. 2016.183

Moon, J.-S., Beaudin, A., Verosky, S., Driscoll, L., Weiskopf, M., Levitsky, D., et al. (2006). Attentional dysfunction, impulsivity, and resistance to change in a mouse model of fragile X syndrome. Behav. Neurosci. 120, 1367-1369. doi: 10.1037/0735-7044.120.6.1367

Morency, M. A., Stewart, R. J., and Beninger, R. J. (1985). Effects of unilateral microinjections of sulpiride into the medial prefrontal cortex on circling behavior of rats. Prog. Neuropsychopharmacol. Biol. Psychiatry 9, 735-738. doi: 10.1016/0278-5846(85)90051-x

Moretti, P., Bouwknecht, J. A., Teague, R., Paylor, R., and Zoghbi, H. Y. (2005). Abnormalities of social interactions and home-cage behavior in a mouse model of Rett syndrome. Hum. Mol. Genet. 14, 205-220. doi: 10.1093/hmg/ddi016

Morikawa, Y., Komori, T., Hisaoka, T., Ueno, H., Kitamura, T., and Senba, E. (2007). Expression of mKirre in the developing sensory pathways: its close apposition to nephrin-expressing cells. Neuroscience 150, 880-886. doi: 10.1016/j.neuroscience.2007.10.013

Moss, J., and Howlin, P. (2009). Autism spectrum disorders in genetic syndromes: implications for diagnosis, intervention and understanding the wider autism spectrum disorder population. J. Intellect. Disabil. Res. 53, 852-873. doi: 10.1111/j.1365-2788.2009.01197.x

Moy, S. S., and Nadler, J. J. (2008). Advances in behavioral genetics: mouse models of autism. Mol. Psychiatry 13, 4-26. doi: 10.1038/sj.mp.4002082

Moy, S. S., Nadler, J. J., Magnuson, T. R., and Crawley, J. N. (2006). Mouse models of autism spectrum disorders: the challenge for behavioral genetics. Am. J. Med. Genet. C Semin. Med. Genet. 142, 40-51. doi: 10.1002/ajmg.c.30081

Moy, S. S., Nadler, J. J., Poe, M. D., Nonneman, R. J., Young, N. B., Koller, B. H., et al. (2008a). Development of a mouse test for repetitive, restricted behaviors: relevance to autism. Behav. Brain Res. 188, 178-194. doi: 10.1016/j.bbr.2007. 10.029

Moy, S. S., Nadler, J. J., Young, N. B., Nonneman, R. J., Segall, S. K., Andrade, G. M., et al. (2008b). Social approach and repetitive behavior in eleven inbred mouse strains. Behav. Brain Res. 191, 118-129. doi: 10.1016/j.bbr.2008. 03.015

Moy, S. S., Nadler, J. J., Young, N. B., Perez, A., Holloway, L. P., Barbaro, R. P., et al. (2007). Mouse behavioral tasks relevant to autism: phenotypes of 10 inbred strains. Behav. Brain Res. 176, 4-20. doi: 10.1016/j.bbr.2006. 07.030
Muehlmann, A., Edington, G., Mihalik, A., Buchwald, Z., Koppuzha, D., Korah, M., et al. (2012). Further characterization of repetitive behavior in C58 mice: developmental trajectory and effects of environmental enrichment. Behav. Brain Res. 235, 143-149. doi: 10.1016/j.bbr.2012.07.041

Muhle, R., Trentacoste, S. V., and Rapin, I. (2004). The genetics of autism. Pediatrics 113, e472-e486. doi: 10.1542/peds.113.5.e472

Murai, K. K., Nguyen, L. N., Irie, F., Yamaguchi, Y., and Pasquale, E. B. (2003). Control of hippocampal dendritic spine morphology through ephrinA3/EphA4 signaling. Nat. Neurosci. 6, 153-160. doi: 10.1038/nn994

Nagarajan, N., Jones, B. W., West, P. J., Marc, R. E., and Capecchi, M. R. (2018). Corticostriatal circuit defects in Hoxb8 mutant mice. Mol. Psychiatry 23, 1868-1877. doi: 10.1038/mp.2017.180

Nardone, S., and Elliott, E. (2016). The interaction between the immune system and epigenetics in the etiology of autism spectrum disorders. Front. Neurosci. 10:329. doi: 10.3389/fnins.2016.00329

Naviaux, J. C., Wang, L., Li, K., Bright, A. T., Alaynick, W. A., Williams, K. R., et al. (2015). Antipurinergic therapy corrects the autism-like features in the Fragile X (fMRI knockout) mouse model. Mol. Autism 6:1. doi: 10.1186/20402392-6-1

Neumann-Haefelin, E., Kramer-Zucker, A., Slanchev, K., Hartleben, B., Noutsou, F., Martin, K., et al. (2010). A model organism approach: defining the role of Neph proteins as regulators of neuron and kidney morphogenesis. Hum. Mol. Genet. 19, 2347-2359. doi: 10.1093/hmg/ddq108

Nimmo-Smith, V., Heuvelman, H., Dalman, C., Lundberg, M., Idring, S., Carpenter, P., et al. (2020). Anxiety disorders in adults with autism spectrum disorder: a population-based study. J. Autism Dev. Disord. 50, 308-318. doi: 10.1007/s10803-019-04234-3

Nin, M. S., Ferri, M. K., Couto-Pereira, N. S., Souza, M. F., Azeredo, L. A., Agnes, G., et al. (2012). The effect of intra-nucleus accumbens administration of allopregnanolone on $\delta$ and $\gamma 2 \mathrm{GABA}_{\mathrm{A}}$ receptor subunit mRNA expression in the hippocampus and on depressive-like and grooming behaviors in rats. Pharmacol. Biochem. Behav. 103, 359-366. doi: 10.1016/j.pbb.2012.09.002

Nishida, K., Nakayama, K., Yoshimura, S., and Murakami, F. (2011). Role of Neph2 in pontine nuclei formation in the developing hindbrain. Mol. Cell. Neurosci. 46, 662-670. doi: 10.1016/j.mcn.2011.01.007

Niu, M., Han, Y., Dy, A. B. C., Du, J., Jin, H., Qin, J., et al. (2017). Autism symptoms in fragile X syndrome. J. Child Neurol. 32, 903-909. doi: $10.1177 / 0883073817712875$

Njung'e, K., and Handley, S. L. (1991). Evaluation of marble-burying behavior as a model of anxiety. Pharmacol. Biochem. Behav. 38, 63-67. doi: 10.1016/00913057(91)90590-x

Nolan, S. O., and Lugo, J. N. (2018). Reversal learning paradigm reveals deficits in cognitive flexibility in the fMR1 knockout male mouse. F1000Res. 7:711. doi: 10.12688/f1000research.14969.1

Nosyreva, E. D., and Huber, K. M. (2006). Metabotropic receptor-dependent long-term depression persists in the absence of protein synthesis in the mouse model of fragile X syndrome. J. Neurophysiol. 95, 3291-3295. doi: 10.1152/jn. 01316.2005

O’Leary, T. P., Gunn, R. K., and Brown, R. E. (2013). What are we measuring when we test strain differences in anxiety in mice? Behav. Genet. 43, 34-50. doi: 10.1007/s10519-012-9572-8

Obeso, J. A., and Lanciego, J. L. (2011). Past, present, and future of the pathophysiological model of the Basal Ganglia. Front. Neuroanat. 5:39. doi: 10.3389/fnana.2011.00039

Orefice, L. L., Zimmerman, A. L., Chirila, A. M., Sleboda, S. J., Head, J. P., and Ginty, D. D. (2016). Peripheral mechanosensory neuron dysfunction underlies tactile and behavioral deficits in mouse models of ASDs. Cell 166, 299-313. doi: 10.1016/j.cell.2016.05.033

Page, D. T., Kuti, O. J., Prestia, C., and Sur, M. (2009). Haploinsufficiency for Pten and serotonin transporter cooperatively influences brain size and social behavior. Proc. Natl. Acad. Sci. U S A 106, 1989-1994. doi: 10.1073/pnas. 0804428106

Palmen, S. J., and van Engeland, H. (2004). Review on structural neuroimaging findings in autism. J. Neural Transm. 111, 903-929. doi: 10.1007/s00702-0030068-9

Palmer, A., and Klein, R. (2003). Multiple roles of ephrins in morphogenesis, neuronal networking, and brain function. Genes Dev. 17, 1429-1450. doi: $10.1101 /$ gad. 1093703 
Panayotis, N., Pratte, M., Borges-Correia, A., Ghata, A., Villard, L., and Roux, J.-C. (2011). Morphological and functional alterations in the substantia nigra pars compacta of the Mecp2-null mouse. Neurobiol. Dis. 41, 385-397. doi: 10.1016/j. nbd.2010.10.006

Parr-Brownlie, L. C., and Hyland, B. I. (2005). Bradykinesia induced by dopamine D2 receptor blockade is associated with reduced motor cortex activity in the rat. J. Neurosci. 25, 5700-5709. doi: 10.1523/JNEUROSCI.0523-05.2005

Paylor, R., Yuva-Paylor, L. A., Nelson, D. L., and Spencer, C. M. (2008). Reversal of sensorimotor gating abnormalities in fMR1 knockout mice carrying a human Fmr1 transgene. Behav. Neurosci. 122, 1371-1371. doi: 10.1037/a00 13047

Peça, J., Feliciano, C., Ting, J. T., Wang, W., Wells, M. F., Venkatraman, T. N., et al. (2011). Shank3 mutant mice display autistic-like behaviours and striatal dysfunction. Nature 472, 437-442. doi: 10.1038/nature09965

Peier, A. M., McIlwain, K. L., Kenneson, A., Warren, S. T., Paylor, R., and Nelson, D. L. (2000). (Over)correction of fMR1 deficiency with YAC transgenics: behavioral and physical features. Hum. Mol. Genet. 9, 1145-1159. doi: $10.1093 / \mathrm{hmg} / 9.8 .1145$

Peixoto, R. T., Wang, W., Croney, D. M., Kozorovitskiy, Y., and Sabatini, B. L. (2016). Early hyperactivity and precocious maturation of corticostriatal circuits in Shank3B ${ }^{-/}-$mice. Nat. Neurosci. 19, 716-724. doi: 10.1038/nn.4260

Peñagarikano, O., Abrahams, B. S., Herman, E. I., Winden, K. D., Gdalyahu, A., Dong, H., et al. (2011). Absence of CNTNAP2 leads to epilepsy, neuronal migration abnormalities, and core autism-related deficits. Cell 147, 235-246. doi: 10.1016/j.cell.2011.08.040

Perry, W., Minassian, A., Lopez, B., Maron, L., and Lincoln, A. (2007). Sensorimotor gating deficits in adults with autism. Biol. Psychiatry 61, 482-486. doi: 10.1016/j.biopsych.2005.09.025

Persico, A. M., and Bourgeron, T. (2006). Searching for ways out of the autism maze: genetic, epigenetic and environmental clues. Trends Neurosci. 29, 349-358. doi: 10.1016/j.tins.2006.05.010

Petrenko, A., Gulyaev, M., Tischenko, D., Petuchov, V., and Abbasova, K. (2013). Effects of prenatal treatment with valproic acid (VPA) on offspring of epileptic adult rats: MRI investigation. J. Neurosci. Neuroengineering 2, 1-7. doi: 10.1166/jnsne.2013.1085

Pham, D. H., Tan, C. C., Homan, C. C., Kolc, K. L., Corbett, M. A., McAninch, D., et al. (2017). Protocadherin 19 (PCDH19) interacts with paraspeckle protein NONO to co-regulate gene expression with estrogen receptor alpha (ER $\alpha)$. Hum. Mol. Genet. 26, 2042-2052. doi: 10.1093/hmg/ddx094

Pierce, K., and Courchesne, E. (2001). Evidence for a cerebellar role in reduced exploration and stereotyped behavior in autism. Biol. Psychiatry 49, 655-664. doi: 10.1016/s0006-3223(00)01008-8

Pietropaolo, S., Guilleminot, A., Martin, B., d'Amato, F. R., and Crusio, W. E. (2011). Genetic-background modulation of core and variable autistic-like symptoms in Fmr1 knock-out mice. PLoS One 6:e17073. doi: 10.1371/journal. pone. 0017073

Pignatelli, M., Piccinin, S., Molinaro, G., Di Menna, L., Riozzi, B., Cannella, M., et al. (2014). Changes in mGlu5 receptor-dependent synaptic plasticity and coupling to homer proteins in the hippocampus of Ube3A hemizygous mice modeling angelman syndrome. J. Neurosci. 34, 4558-4566. doi: 10.1523/JNEUROSCI.1846-13.2014

Pobbe, R. L., Defensor, E. B., Pearson, B. L., Bolivar, V. J., Blanchard, D. C., and Blanchard, R. J. (2011). General and social anxiety in the BTBR $\mathrm{T}+\mathrm{tf} / \mathrm{J}$ mouse strain. Behav. Brain Res. 216, 446-451. doi: 10.1016/j.bbr.2010.08.039

Pobbe, R. L., Pearson, B. L., Defensor, E. B., Bolivar, V. J., Young, W. S. III., Lee, H. J., et al. (2012). Oxytocin receptor knockout mice display deficits in the expression of autism-related behaviors. Horm. Behav. 61, 436-444. doi: 10.1016/j.yhbeh.2011.10.010

Portmann, T., Yang, M., Mao, R., Panagiotakos, G., Ellegood, J., Dolen, G., et al. (2014). Behavioral abnormalities and circuit defects in the basal ganglia of a mouse model of 16p11. 2 deletion syndrome. Cell Rep. 7, 1077-1092. doi: 10.1016/j.celrep.2014.03.036

Postorino, V., Kerns, C. M., Vivanti, G., Bradshaw, J., Siracusano, M., and Mazzone, L. (2017). Anxiety disorders and obsessive-compulsive disorder in individuals with autism spectrum disorder. Curr. Psychiatry Rep. 19:92. doi: 10.1007/s11920-017-0846-y

Powell, S. B., Newman, H. A., McDonald, T. A., Bugenhagen, P., and Lewis, M. H. (2000). Development of spontaneous stereotyped behavior in deer mice: effects of early and late exposure to a more complex environment. Dev. Psychobiol. 37, 100-108. doi: 10.1002/1098-2302(200009)37:2<100::AID-DEV5>3.3.CO;2-Y

Presti, M. F., Gibney, B. C., and Lewis, M. H. (2004). Effects of intrastriatal administration of selective dopaminergic ligands on spontaneous stereotypy in mice. Physiol. Behav. 80, 433-439. doi: 10.1016/j.physbeh.2003. 09.008

Presti, M. F., Mikes, H. M., and Lewis, M. H. (2003). Selective blockade of spontaneous motor stereotypy via intrastriatal pharmacological manipulation. Pharmacol. Biochem. Behav. 74, 833-839. doi: 10.1016/s0091-3057(02)01081-x

Prince, J. E., Brignall, A. C., Cutforth, T., Shen, K., and Cloutier, J.-F. (2013). Kirrel3 is required for the coalescence of vomeronasal sensory neuron axons into glomeruli and for male-male aggression. Development 140, 2398-2408. doi: 10.1242/dev.087262

Qiu, S., Aldinger, K. A., and Levitt, P. (2012). Modeling of autism genetic variations in mice: focusing on synaptic and microcircuit dysfunctions. Dev. Neurosci. 34, 88-100. doi: 10.1159/000336644

Qualls-Creekmore, E., and Münzberg, H. (2018). Modulation of feeding and associated behaviors by lateral hypothalamic circuits. Endocrinology 159, 3631-3642. doi: 10.1210/en.2018-00449

Quintero-Rivera, F., Sharifi-Hannauer, P., and Martinez-Agosto, J. A. (2010). Autistic and psychiatric findings associated with the 3q29 microdeletion syndrome: case report and review. Am. J. Med. Genet. A 152, 2459-2467. doi: 10.1128/JCM.02955-20

Rademacher, S., and Eickholt, B. J. (2019). PTEN in autism and neurodevelopmental disorders. Cold Spring Harb. Perspect. Med. 9:a036780. doi: $10.1101 /$ cshperspect.a036780

Radyushkin, K., Hammerschmidt, K., Boretius, S., Varoqueaux, F., ElKordi, A., Ronnenberg, A., et al. (2009). Neuroligin-3-deficient mice: model of a monogenic heritable form of autism with an olfactory deficit. Genes Brain Behav. 8, 416-425. doi: 10.1111/j.1601-183X.2009. 00487.x

Ramaswami, G., and Geschwind, D. H. (2018). Genetics of autism spectrum disorder Handb. Clin. Neurol. 147, 321-329. doi: 10.1016/B978-0-444-632333.00021-X

Reiner, A., and Anderson, K. D. (1990). The patterns of neurotransmitter and neuropeptide co-occurrence among striatal projection neurons: conclusions based on recent findings. Brain Res. Rev. 15, 251-265. doi: 10.1016/01650173(90)90003-7

Reiss, A. L., Faruque, F., Naidu, S., Abrams, M., Beaty, T., Bryan, R. N., et al. (1993). Neuroanatomy of Rett syndrome: a volumetric imaging study. Ann. Neurol. 34, 227-234. doi: 10.1002/ana.410340220

Reis-Silva, T. M., Sandini, T. M., Calefi, A. S., Orlando, B. C. G., Moreira, N., Lima, A. P. N., et al. (2019). Stress resilience evidenced by grooming behaviour and dopamine levels in male mice selected for high and low immobility using the tail suspension test. Eur. J. Neurosci. 50, 2942-2954. doi: 10.1111/ ejn.14409

Reith, R. M., McKenna, J., Wu, H., Hashmi, S. S., Cho, S.-H., Dash, P. K., et al. (2013). Loss of Tsc2 in Purkinje cells is associated with autistic-like behavior in a mouse model of tuberous sclerosis complex. Neurobiol. Dis. 51, 93-103. doi: 10.1016/j.nbd.2012.10.014

Reynolds, S., Urruela, M., and Devine, D. P. (2013). Effects of environmental enrichment on repetitive behaviors in the BTBR T+tf/J mouse model of autism. Autism Res. 6, 337-343. doi: 10.1002/aur.1298

Richler, J., Bishop, S. L., Kleinke, J. R., and Lord, C. (2007). Restricted and repetitive behaviors in young children with autism spectrum disorders. J. Autism Dev. Disord. 37, 73-85. doi: 10.1007/s10803-006-0332-6

Rinaldi, T., Kulangara, K., Antoniello, K., and Markram, H. (2007). Elevated NMDA receptor levels and enhanced postsynaptic long-term potentiation induced by prenatal exposure to valproic acid. Proc. Natl. Acad. Sci. U S A 104, 13501-13506. doi: 10.1073/pnas.0704391104

Rodenas-Cuadrado, P., Ho, J., and Vernes, S. C. (2014). Shining a light on CNTNAP2: complex functions to complex disorders. Eur. J. Hum. Genet. 22, 171-178. doi: 10.1038/ejhg.2013.100

Roeling, T., Veening, J., Peters, J., Vermelis, M., and Nieuwenhuys, R. (1993). Efferent connections of the hypothalamic "grooming area" in the rat. Neuroscience 56, 199-225. doi: 10.1016/0306-4522(93)90574-y

Rojas, D. C., Peterson, E., Winterrowd, E., Reite, M. L., Rogers, S. J., and Tregellas, J. R. (2006). Regional gray matter volumetric changes in autism 
associated with social and repetitive behavior symptoms. BMC Psychiatry 6:56. doi: 10.1186/1471-244X-6-56

Ronemus, M., Iossifov, I., Levy, D., and Wigler, M. (2014). The role of de novo mutations in the genetics of autism spectrum disorders. Nat. Rev. Genet. 15, 133-141. doi: 10.1038/nrg3585

Rothwell, P. E., Fuccillo, M. V., Maxeiner, S., Hayton, S. J., Gokce, O., Lim, B. K., et al. (2014). Autism-associated neuroligin-3 mutations commonly impair striatal circuits to boost repetitive behaviors. Cell 158, 198-212. doi: 10.1016/j. cell.2014.04.045

Roullet, F. I., and Crawley, J. N. (2011). Mouse models of autism: testing hypotheses about molecular mechanisms. Curr. Top. Behav. Neurosci. 7, 187-212. doi: 10.1007/7854_2010_113

Rubenstein, J. L. (2010). Three hypotheses for developmental defects that may underlie some forms of autism spectrum disorder. Curr. Opin. Neurol. 23, 118-123. doi: 10.1097/WCO.0b013e328336eb13

Russell, K. M., Frost, K. M., and Ingersoll, B. (2019). The relationship between subtypes of repetitive behaviors and anxiety in children with autism spectrum disorder. Res. Autism Spectr. Disord. 62, 48-54. doi: 10.1007/s10803-016 $-2884-4$

Russell, A. J., Murphy, C. M., Wilson, E., Gillan, N., Brown, C., Robertson, D. M., et al. (2016). The mental health of individuals referred for assessment of autism spectrum disorder in adulthood: a clinic report. Autism 20, 623-627. doi: $10.1177 / 1362361315604271$

Ryan, S. G., Chance, P. F., Zou, C.-H., Spinner, N. B., Golden, J. A., and Smietana, S. (1997). Epilepsy and mental retardation limited to females: an X-linked dominant disorder with male sparing. Nat. Genet. 17, 92-95. doi: 10.1038/ng0997-92

Ryan, B. C., Young, N. B., Crawley, J. N., Bodfish, J. W., and Moy, S. S. (2010). Social deficits, stereotypy and early emergence of repetitive behavior in the C58/J inbred mouse strain. Behav. Brain Res. 208, 178-188. doi: 10.1016/j.bbr. 2009.11.031

Sagar, A., Bishop, J. R., Tessman, D. C., Guter, S., Martin, C. L., and Cook, E. H. (2013). Co-occurrence of autism, childhood psychosis and intellectual disability associated with a de novo 3q29 microdeletion. Am. J. Med. Genet. A 161, 845-849. doi: 10.1002/ajmg.a.35754

Sajdyk, T. J., and Shekhar, A. (2000). Sodium lactate elicits anxiety in rats after repeated GABA receptor blockade in the basolateral amygdala. Eur. J. Pharmacol. 394, 265-273. doi: 10.1016/s0014-2999(00) 00128-x

Sala, C., Vicidomini, C., Bigi, I., Mossa, A., and Verpelli, C. (2015). Shank synaptic scaffold proteins: keys to understanding the pathogenesis of autism and other synaptic disorders. J. Neurochem. 135, 849-858. doi: 10.1111/jnc. 13232

Sala, M., Braida, D., Lentini, D., Busnelli, M., Bulgheroni, E., Capurro, V., et al. (2011). Pharmacologic rescue of impaired cognitive flexibility, social deficits, increased aggression and seizure susceptibility in oxytocin receptor null mice: a neurobehavioral model of autism. Biol. Psychiatry 69, 875-882. doi: 10.1016/j. biopsych.2010.12.022

Samaco, R. C., Fryer, J. D., Ren, J., Fyffe, S., Chao, H.-T., Sun, Y., et al. (2008). A partial loss of function allele of methyl-CpG-binding protein 2 predicts a human neurodevelopmental syndrome. Hum. Mol. Genet. 17, 1718-1727. doi: $10.1093 / \mathrm{hmg} / \mathrm{ddn} 062$

Sangu, N., Shimojima, K., Takahashi, Y., Ohashi, T., Tohyama, J., and Yamamoto, T. (2017). A 7q31.33q32.1 microdeletion including LRRC4 and GRM8 is associated with severe intellectual disability and characteristics of autism. Hum. Genome Var. 4:17001. doi: 10.1038/hgv.2017.1

Sansal, I., and Sellers, W. R. (2004). The biology and clinical relevance of the PTEN tumor suppressor pathway. J. Clin. Oncol. 22, 2954-2963. doi: 10.1200/JCO. 2004.02.141

Satterstrom, F. K., Kosmicki, J. A., Wang, J., Breen, M. S., De Rubeis, S., An, J.-Y., et al. (2020). Large-scale exome sequencing study implicates both developmental and functional changes in the neurobiology of autism. Cell 180, 568.e23-584.e23. doi: 10.1016/j.cell.2019. 12.036

Scahill, L., and Challa, S. A. (2016). "Repetitive behavior in children with autism spectrum disorder: similarities and differences with obsessive-compulsive disorder," in Psychiatric Symptoms and Comorbidities in Autism Spectrum Disorder, eds L. Mazzone and B. Vitiello (Cham: Springer), 39-50.
Scahill, L., Koenig, K., Carroll, D. H., and Pachler, M. (2007). Risperidone approved for the treatment of serious behavioral problems in children with autism. J. Child Adolesc. Psychiatr. Nurs. 20, 188-190. doi: 10.1111/j.1744-6171. 2007.00112.x

Scahill, L., McDougle, C. J., Aman, M. G., Johnson, C., Handen, B., Bearss, K., et al. (2012). Effects of risperidone and parent training on adaptive functioning in children with pervasive developmental disorders and serious behavioral problems. J. Am. Acad. Child Adolesc. Psychiatry 51, 136-146. doi: 10.1016/j. jaac.2011.11.010

Schaefer, G. B., and Mendelsohn, N. J. (2013). Clinical genetics evaluation in identifying the etiology of autism spectrum disorders: 2013 guideline revisions. Genet. Med. 15, 399-407. doi: 10.1038/gim.2013.32

Schmeisser, M. J. (2015). Translational neurobiology in Shank mutant mice-model systems for neuropsychiatric disorders. Ann. Anat. 200, 115-117. doi: 10.1016/j.aanat.2015.03.006

Schmeisser, M. J., Ey, E., Wegener, S., Bockmann, J., Stempel, A. V., Kuebler, A., et al. (2012). Autistic-like behaviours and hyperactivity in mice lacking ProSAP1/Shank2. Nature 486, 256-260. doi: 10.1038/nature 11015

Schneider, T., and Przewocki, R. (2005). Behavioral alterations in rats prenatally exposed to valproic acid: animal model of autism. Neuropsychopharmacology 30, 80-89. doi: 10.1038/sj.npp.1300518

Schneider, T., Turczak, J., and Przewocki, R. (2006). Environmental enrichment reverses behavioral alterations in rats prenatally exposed to valproic acid: issues for a therapeutic approach in autism. Neuropsychopharmacology 31, 36-46. doi: 10.1038/sj.npp.1300767

Sealey, L., Hughes, B., Sriskanda, A., Guest, J., Gibson, A., JohnsonWilliams, L., et al. (2016). Environmental factors in the development of autism spectrum disorders. Environ. Int. 88, 288-298. doi: 10.1016/j.envint.2015. 12.021

Sears, L. L., Vest, C., Mohamed, S., Bailey, J., Ranson, B. J., and Piven, J. (1999). An MRI study of the basal ganglia in autism. Prog. Neuropsychopharmacol. Biol. Psychiatry 23, 613-624. doi: 10.1016/s0278-5846(99)00020-2

Sellin, L., Huber, T. B., Gerke, P., Quack, I., Pavenstädt, H., and Walz, G. (2003). NEPH1 defines a novel family of podocin interacting proteins. FASEB J. 17, 115-117. doi: 10.1096/fj.02-0242fje

Serizawa, S., Miyamichi, K., Takeuchi, H., Yamagishi, Y., Suzuki, M., and Sakano, H. (2006). A neuronal identity code for the odorant receptor-specific and activity-dependent axon sorting. Cell 127, 1057-1069. doi: 10.1016/j.cell. 2006.10.031

Sforazzini, F., Bertero, A., Dodero, L., David, G., Galbusera, A., Scattoni, M. L., et al. (2016). Altered functional connectivity networks in acallosal and socially impaired BTBR mice. Brain Struct. Funct. 221, 941-954. doi: 10.1007/s00429014-0948-9

Shafritz, K. M., Dichter, G. S., Baranek, G. T., and Belger, A. (2008). The neural circuitry mediating shifts in behavioral response and cognitive set in autism. Biol. Psychiatry 63, 974-980. doi: 10.1016/j.biopsych.2007.06.028

Shah, M. M., Migliore, M., Valencia, I., Cooper, E. C., and Brown, D. A. (2008). Functional significance of axonal Kv7 channels in hippocampal pyramidal neurons. Proc. Natl. Acad. Sci. U S A 105, 7869-7874. doi: 10.1073/pnas. 0802805105

Shah, A. A., Sjovold, T., and Treit, D. (2004). Inactivation of the medial prefrontal cortex with the $\mathrm{GABA}_{\mathrm{A}}$ receptor agonist muscimol increases open-arm activity in the elevated plus-maze and attenuates shock-probe burying in rats. Brain Res. 1028, 112-115. doi: 10.1016/j.brainres.2004.08.061

Shahbazian, M. D., Young, J. I., Yuva-Paylor, L. A., Spencer, C. M., Antalffy, B. A., Noebels, J. L., et al. (2002). Mice with truncated MeCP2 recapitulate many Rett syndrome features and display hyperacetylation of histone H3. Neuron 35, 243-254. doi: 10.1016/s0896-6273(02)00768-7

Sharma, A., and Shaw, S. R. (2012). Efficacy of risperidone in managing maladaptive behaviors for children with autistic spectrum disorder: a metaanalysis. J. Pediatr. Health Care 26, 291-299. doi: 10.1016/j.pedhc.2011. 02.008

Shavitt, R. G., Hounie, A. G., Rosário Campos, M. C., and Miguel, E. C. (2006). Tourette's syndrome. Psychiatr. Clin. North Am. 29, 471-486. doi: 10.1016/j. psc.2006.02.005

Shea, S., Turgay, A., Carroll, A., Schulz, M., Orlik, H., Smith, I., et al. (2004). Risperidone in the treatment of disruptive behavioral symptoms in children 
with autistic and other pervasive developmental disorders. Pediatrics 114, e634-e641. doi: 10.1542/peds.2003-0264-F

Sheng, M., and Kim, E. (2000). The Shank family of scaffold proteins. J. Cell Sci. $113,1851-1856$

Shi, R., Redman, P., Ghose, D., Hwang, H., Liu, Y., Ren, X., et al. (2017). Shank proteins differentially regulate synaptic transmission. eNeuro 4:ENEURO.0163-15.2017. doi: 10.1523/ENEURO.0163-15.2017

Shin, W., Kweon, H., Kang, R., Kim, D., Kim, K., Kang, M., et al. (2019). Scn2a haploinsufficiency in mice suppresses hippocampal neuronal excitability, excitatory synaptic drive and long-term potentiation and spatial learning and memory. Front. Mol. Neurosci. 12:145. doi: 10.3389/fnmol.2019.00145

Shonesy, B. C., Bluett, R. J., Ramikie, T. S., Báldi, R., Hermanson, D. J., Kingsley, P. J., et al. (2014). Genetic disruption of 2-arachidonoylglycerol synthesis reveals a key role for endocannabinoid signaling in anxiety modulation. Cell Rep. 9, 1644-1653. doi: 10.1016/j.celrep.2014.11.001

Shonesy, B. C., Parrish, W. P., Haddad, H. K., Stephenson, J. R., Báldi, R., Bluett, R. J., et al. (2018). Role of striatal direct pathway 2-arachidonoylglycerol signaling in sociability and repetitive behavior. Biol. Psychiatry 84, 304-315. doi: 10.1016/j.biopsych.2017.11.036

Shukla, T., de la Peña, J. B., Perish, J. M., Ploski, J. E., Stumpf, C. R., Webster, K. R., et al. (2020). A highly selective MNK inhibitor rescues deficits associated with fragile X syndrome in mice. Neurotherapeutics doi: 10.1007/s13311-020-009324 [Epub ahead of print].

Silverman, J. L., Pride, M., Hayes, J., Puhger, K., Butler-Struben, H., Baker, S., et al. (2015). GABA $A_{B}$ receptor agonist R-baclofen reverses social deficits and reduces repetitive behavior in two mouse models of autism. Neuropsychopharmacology 40, 2228-2239. doi: 10.1038/npp.2015.66

Silverman, J. L., Smith, D. G., Rizzo, S. J. S., Karras, M. N., Turner, S. M., Tolu, S. S., et al. (2012). Negative allosteric modulation of the mGluR5 receptor reduces repetitive behaviors and rescues social deficits in mouse models of autism. Sci. Transl. Med. 4:131ra151. doi: 10.1126/scitranslmed.3003501

Silverman, J. L., Tolu, S. S., Barkan, C. L., and Crawley, J. N. (2010). Repetitive self-grooming behavior in the BTBR mouse model of autism is blocked by the mGluR5 antagonist MPEP. Neuropsychopharmacology 35, 976-989. doi: 10.1038/npp.2009.201

Silverman, J. L., Turner, S. M., Barkan, C. L., Tolu, S. S., Saxena, R., Hung, A. Y., et al. (2011). Sociability and motor functions in Shankl mutant mice. Brain Res. 1380, 120-137. doi: 10.1016/j.brainres.2010.09.026

Sinclair, D., Featherstone, R., Naschek, M., Nam, J., Du, A., Wright, S., et al. (2017). GABA-B agonist baclofen normalizes auditory-evoked neural oscillations and behavioral deficits in the Fmr1 knockout mouse model of fragile X syndrome. Eneuro 4:ENEURO.0380-16.2017. doi: 10.1523/ENEURO.0380-16.2017

Singewald, N., Salchner, P., and Sharp, T. (2003). Induction of c-Fos expression in specific areas of the fear circuitry in rat forebrain by anxiogenic drugs. Biol. Psychiatry 53, 275-283. doi: 10.1016/s0006-3223(02)01574-3

Snow, W. M., Hartle, K., and Ivanco, T. L. (2008). Altered morphology of motor cortex neurons in the VPA rat model of autism. Dev. Psychobiol. 50, 633-639. doi: $10.1002 /$ dev.20337

Sosnoski, D., Emanuel, B., Hawkins, A., van Tuinen, P., Ledbetter, D., Nussbaum, R., et al. (1988). Chromosomal localization of the genes for the vitronectin and fibronectin receptors alpha subunits and for platelet glycoproteins IIb and IIIa. J. Clin. Invest. 81, 1993-1998. doi: 10.1172/JCI113548

Soto, F., Watkins, K. L., Johnson, R. E., Schottler, F., and Kerschensteiner, D. (2013). NGL-2 regulates pathway-specific neurite growth and lamination, synapse formation and signal transmission in the retina. J. Neurosci. 33, 11949-11959. doi: 10.1523/JNEUROSCI.152113.2013

Soto, F., Zhao, L., and Kerschensteiner, D. (2018). Synapse maintenance and restoration in the retina by NGL2. eLife 7:e30388. doi: 10.7554/eLife.30388

Specchio, N., Marini, C., Terracciano, A., Mei, D., Trivisano, M., Sicca, F., et al. (2011). Spectrum of phenotypes in female patients with epilepsy due to protocadherin 19 mutations. Epilepsia 52, 1251-1257. doi: 10.1111/j.1528-1167. 2011.03063.x

Spencer, C., Alekseyenko, O., Serysheva, E., Yuva-Paylor, L., and Paylor, R. (2005). Altered anxiety-related and social behaviors in the fMR1 knockout mouse model of fragile X syndrome. Genes Brain Behav. 4, 420-430. doi: 10.1111/j. 1601-183X.2005.00123.x
Spencer, C. M., Graham, D. F., Yuva-Paylor, L. A., Nelson, D. L., and Paylor, R. (2008). Social behavior in fMR1 knockout mice carrying a human FMR1 transgene. Behav. Neurosci. 122, 710-715. doi: 10.1037/0735-7044.122. 3.710

Spruijt, B. M., Cools, A. R., Ellenbroek, B. A., and Gispen, W. H. (1986). Dopaminergic modulation of ACTH-induced grooming. Eur. J. Pharmacol. 120, 249-256. doi: 10.1016/0014-2999(86)90465-6

Spruijt, B. M., van Hooff, J. A., and Gispen, W. H. (1992). Ethology and neurobiology of grooming behavior. Physiol. Rev. 72, 825-852. doi: 10.1152/physrev.1992.72.3.825

Squillace, M., Dodero, L., Federici, M., Migliarini, S., Errico, F., Napolitano, F., et al. (2014). Dysfunctional dopaminergic neurotransmission in asocial BTBR mice. Transl. Psychiatry 4:e427. doi: 10.1038/tp.2014.69

Stearns, N., Schaevitz, L., Bowling, H., Nag, N., Berger, U., and Berger-Sweeney, J. (2007). Behavioral and anatomical abnormalities in Mecp2 mutant mice: a model for Rett syndrome. Neuroscience 146, 907-921. doi: 10.1016/j. neuroscience.2007.02.009

Stratis, E. A., and Lecavalier, L. (2013). Restricted and repetitive behaviors and psychiatric symptoms in youth with autism spectrum disorders. Res. Autism Spectr. Disord. 7, 757-766. doi: 10.1016/j.rasd.2013. 02.017

Stubbs, G., Henley, K., and Green, J. (2016). Autism: will vitamin D supplementation during pregnancy and early childhood reduce the recurrence rate of autism in newborn siblings? Med. Hypotheses 88, 74-78. doi: 10.1016/j. mehy.2016.01.015

Subramaniam, B., Naidu, S., and Reiss, A. L. (1997). Neuroanatomy in Rett syndrome: cerebral cortex and posterior fossa. Neurology 48, 399-407. doi: $10.1212 /$ wnl.48.2.399

Südhof, T. C. (2008). Neuroligins and neurexins link synaptic function to cognitive disease. Nature 455, 903-911. doi: 10.1038/nature07456

Sultana, R., Ghandi, T., M. Davila, A., Lee, C. C., and Ogundele, O. M. (2018). Upregulated SK2 expression and impaired CaMKII phosphorylation are shared synaptic defects between 16p11. 2del and 129S: $\Delta$ disc1 mutant mice. ASN Neuro 11:1759091419847891. doi: 10.1177/1759091418817641

Sun, T., Song, Z., Tian, Y., Tian, W., Zhu, C., Ji, G., et al. (2019). Basolateral amygdala input to the medial prefrontal cortex controls obsessive-compulsive disorder-like checking behavior. Proc. Natl. Acad. Sci. U S A 116, 3799-3804. doi: $10.1073 /$ pnas. 1814292116

Sungur, A. Ö., Vörckel, K. J., Schwarting, R. K., and Wöhr, M. (2014). Repetitive behaviors in the Shank1 knockout mouse model for autism spectrum disorder: developmental aspects and effects of social context. J. Neurosci. Methods 234, 92-100. doi: 10.1016/j.jneumeth.2014.05.003

Sutcliffe, J. S., Delahanty, R. J., Prasad, H. C., McCauley, J. L., Han, Q., Jiang, L., et al. (2005). Allelic heterogeneity at the serotonin transporter locus (SLC6A4) confers susceptibility to autism and rigid-compulsive behaviors. Am. J. Hum. Genet. 77, 265-279. doi: 10.1086/432648

Suvrathan, A., Hoeffer, C. A., Wong, H., Klann, E., and Chattarji, S. (2010). Characterization and reversal of synaptic defects in the amygdala in a mouse model of fragile X syndrome. Proc. Natl. Acad. Sci. U S A 107, 11591-11596. doi: 10.1073/pnas.1002262107

Swanwick, C. C., Larsen, E. C., and Banerjee-Basu, S. (2011). "Genetic heterogeneity of autism spectrum disorders," in Autism Spectrum Disorders: The Role of Genetics in Diagnosis and Treatment, eds S. I. Deutsch and M. R. Urbano (Rikela: InTech), 65-82.

Szechtman, H., Ahmari, S. E., Beninger, R. J., Eilam, D., Harvey, B. H., EdemannCallesen, H., et al. (2017). Obsessive-compulsive disorder: insights from animal models. Neurosci. Biobehav. Rev. 76, 254-279. doi: 10.1016/j.neubiorev.2016. 04.019

Tabuchi, K., Blundell, J., Etherton, M. R., Hammer, R. E., Liu, X., Powell, C. M., et al. (2007). A neuroligin-3 mutation implicated in autism increases inhibitory synaptic transmission in mice. Science 318, 71-76. doi: 10.1126/science. 1146221

Takahata, R., and Moghaddam, B. (2003). Activation of glutamate neurotransmission in the prefrontal cortex sustains the motoric and dopaminergic effects of phencyclidine. Neuropsychopharmacology 28, 1117-1124. doi: 10.1038/sj.npp.1300127

Takamiya, K., Mao, L., Huganir, R. L., and Linden, D. J. (2008). The glutamate receptor-interacting protein family of GluR2-binding proteins 
is required for long-term synaptic depression expression in cerebellar Purkinje cells. J. Neurosci. 28, 5752-5755. doi: 10.1523/JNEUROSCI.0654 $-08.2008$

Tanaka, M., DeLorey, T. M., Delgado-Escueta, A., and Olsen, R. W. (2012). "GABRB3, epilepsy and neurodevelopment," in Jasper's Basic Mechanisms of the Epilepsies [Internet], 4th Edn. eds Jeffrey Noebels, Massimo Avoli, Michael Rogawski, Richard Olsen, and Antonio Delgado-Escueta (Bethesda, MD: National Center for Biotechnology Information US).

Tang, A.-H., and Alger, B. E. (2015). Homer protein-metabotropic glutamate receptor binding regulates endocannabinoid signaling and affects hyperexcitability in a mouse model of fragile $\mathrm{X}$ syndrome. J. Neurosci. 35, 3938-3945. doi: 10.1523/JNEUROSCI.4499-14.2015

Tanimura, Y., King, M. A., Williams, D. K., and Lewis, M. H. (2011). Development of repetitive behavior in a mouse model: roles of indirect and striosomal basal ganglia pathways. Int. J. Dev. Neurosci. 29, 461-467. doi: 10.1016/j.ijdevneu. 2011.02.004

Tanimura, Y., Vaziri, S., and Lewis, M. H. (2010). Indirect basal ganglia pathway mediation of repetitive behavior: attenuation by adenosine receptor agonists. Behav. Brain Res. 210, 116-122. doi: 10.1016/j.bbr.2010.02.030

Tanimura, A., Yamazaki, M., Hashimotodani, Y., Uchigashima, M., Kawata, S., Abe, M., et al. (2010). The endocannabinoid 2-arachidonoylglycerol produced by diacylglycerol lipase $\alpha$ mediates retrograde suppression of synaptic transmission. Neuron 65, 320-327. doi: 10.1016/j.neuron.2010.01.021

Tanimura, Y., Yang, M. C., and Lewis, M. H. (2008). Procedural learning and cognitive flexibility in a mouse model of restricted, repetitive behaviour. Behav. Brain Res. 189, 250-256. doi: 10.1016/j.bbr.2008.01.001

Tavazoie, S. F., Alvarez, V. A., Ridenour, D. A., Kwiatkowski, D. J., and Sabatini, B. L. (2005). Regulation of neuronal morphology and function by the tumor suppressors Tsc1 and Tsc2. Nat. Neurosci. 8, 1727-1734. doi: $10.1038 / \mathrm{nn} 1566$

Taylor, G. T., Lerch, S., and Chourbaji, S. (2017). Marble burying as compulsive behaviors in male and female mice. Acta Neurobiol. Exp. 77, 254-260.

Thakkar, K. N., Polli, F. E., Joseph, R. M., Tuch, D. S., Hadjikhani, N., Barton, J. J., et al. (2008). Response monitoring, repetitive behaviour and anterior cingulate abnormalities in autism spectrum disorders (ASD). Brain 131, 2464-2478. doi: 10.1093/brain/awn099

Thomas, A., Burant, A., Bui, N., Graham, D., Yuva-Paylor, L. A., and Paylor, R. (2009). Marble burying reflects a repetitive and perseverative behavior more than novelty-induced anxiety. Psychopharmacology 204, 361-373. doi: 10.1007/s00213-009-1466-y

Thomas, A. M., Bui, N., Perkins, J. R., Yuva-Paylor, L. A., and Paylor, R. (2012). Group I metabotropic glutamate receptor antagonists alter select behaviors in a mouse model for fragile X syndrome. Psychopharmacology 219, 47-58. doi: 10.1007/s00213-011-2375-4

Tordjman, S., Somogyi, E., Coulon, N., Kermarrec, S., Cohen, D., Bronsard, G., et al. (2014). Genex Environment interactions in autism spectrum disorders: role of epigenetic mechanisms. Front. Psychiatry 5:53. doi: 10.3389/fpsyt.2014. 00053

Triplett, J. W., and Feldheim, D. A. (2012). Eph and ephrin signaling in the formation of topographic maps. Semin. Cell Dev. Biol. 23, 7-15. doi: 10.1016/j. semcdb.2011.10.026

Tsujino, N., Nakatani, Y., Seki, Y., Nakasato, A., Nakamura, M., Sugawara, M., et al. (2007). Abnormality of circadian rhythm accompanied by an increase in frontal cortex serotonin in animal model of autism. Neurosci. Res. 57, 289-295. doi: 10.1016/j.neures.2006.10.018

Turner, K. C., Frost, L., Linsenbardt, D., Mcllroy, J. R., and Müller, R.-A. (2006). Atypically diffuse functional connectivity between caudate nuclei and cerebral cortex in autism. Behav. Brain Funct. 2:34. doi: 10.1186/1744-9081-2-34

Turner, G., Webb, T., Wake, S., and Robinson, H. (1996). Prevalence of fragile X syndrome. Am. J. Med. Genet. 64, 196-197. doi: 10.1002/(SICI)10968628(19960712)64:1<196::AID-AJMG35>3.0.CO;2-G

Ullrich, M., Weber, M., Post, A., Popp, S., Grein, J., Zechner, M., et al. (2018). OCD-like behavior is caused by dysfunction of thalamo-amygdala circuits and upregulated TrkB/ERK-MAPK signaling as a result of SPRED2 deficiency. Mol. Psychiatry 23, 444-458. doi: 10.1038/mp.2016.232

Um, S. M., Ha, S., Lee, H., Kim, J., Kim, K., Shin, W., et al. (2018). NGL-2 deletion leads to autistic-like behaviors responsive to NMDAR modulation. Cell Rep. 23, 3839-3851. doi: 10.1016/j.celrep.2018.05.087
Vaccarino, F. J., and Franklin, K. (1982). Dopamine mediates ipsi-and contraversive circling elicited from the substantia nigra. Pharmacol. Biochem. Behav. 17, 431-434. doi: 10.1016/0091-3057(82)90300-8

van Steensel, F. J., Bögels, S. M., and Perrin, S. (2011). Anxiety disorders in children and adolescents with autistic spectrum disorders: a meta-analysis. Clin. Child Fam. Psychol. Rev. 14, 302-317. doi: 10.1007/s10567-011-0097-0

Varea, O., Martin-de-Saavedra, M. D., Kopeikina, K. J., Schürmann, B., Fleming, H. J., Fawcett-Patel, J. M., et al. (2015). Synaptic abnormalities and cytoplasmic glutamate receptor aggregates in contactin associated protein-like 2/Caspr2 knockout neurons. Proc. Natl. Acad. Sci. U S A 112, 6176-6181. doi: 10.1073/pnas.1423205112

Varga, E. A., Pastore, M., Prior, T., Herman, G. E., and McBride, K. L. (2009). The prevalence of PTEN mutations in a clinical pediatric cohort with autism spectrum disorders, developmental delay and macrocephaly. Genet. Med. 11, 111-117. doi: 10.1097/GIM.0b013e31818fd762

Vasa, R. A., and Mazurek, M. O. (2015). An update on anxiety in youth with autism spectrum disorders. Curr. Opin. Psychiatry 28, 83-90. doi: 10.1097/YCO. 0000000000000133

Veenema, A. H., Meijer, O. C., de Kloet, E. R., Koolhaas, J. M., and Bohus, B. G. (2003). Differences in basal and stress-induced HPA regulation of wild house mice selected for high and low aggression. Horm. Behav. 43, 197-204. doi: 10.1016/s0018-506x(02)00013-2

Veenstra-VanderWeele, J., Muller, C. L., Iwamoto, H., Sauer, J. E., Owens, W. A., Shah, C. R., et al. (2012). Autism gene variant causes hyperserotonemia, serotonin receptor hypersensitivity, social impairment and repetitive behavior. Proc. Natl. Acad. Sci. U S A 109, 5469-5474. doi: 10.1073/pnas.1112345109

Velíšek, L., Velíšková, J., Ravizza, T., Giorgi, F. S., and Moshé, S. L. (2005). Circling behavior and $\left[{ }^{14} \mathrm{C}\right] 2$-deoxyglucose mapping in rats: possible implications for autistic repetitive behaviors. Neurobiol. Dis. 18, 346-355. doi: 10.1016/j.nbd. 2004.10.012

Verhoeven, J. S., De Cock, P., Lagae, L., and Sunaert, S. (2010). Neuroimaging of autism. Neuroradiology 52, 3-14. doi: 10.1007/s00234-009-0583-y

Wahlsten, D., Metten, P., and Crabbe, J. C. (2003). Survey of 21 inbred mouse strains in two laboratories reveals that BTBR T/ $+\mathrm{tf} / \mathrm{tf}$ has severely reduced hippocampal commissure and absent corpus callosum. Brain Res. 971, 47-54. doi: 10.1016/s0006-8993(03)02354-0

Walsh, T., McClellan, J. M., McCarthy, S. E., Addington, A. M., Pierce, S. B., Cooper, G. M., et al. (2008). Rare structural variants disrupt multiple genes in neurodevelopmental pathways in schizophrenia. Science 320, 539-543. doi: $10.1126 /$ science. 1155174

Wang, L., Almeida, L. E., Spornick, N. A., Kenyon, N., Kamimura, S., Khaibullina, A., et al. (2015). Modulation of social deficits and repetitive behaviors in a mouse model of autism: the role of the nicotinic cholinergic system. Psychopharmacology 232, 4303-4316. doi: 10.1007/s00213-015-4058-z

Wang, X., Bey, A. L., Katz, B. M., Badea, A., Kim, N., David, L. K., et al. (2016). Altered mGluR5-Homer scaffolds and corticostriatal connectivity in a Shank3 complete knockout model of autism. Nat. Commun. 7:11459. doi: $10.1038 /$ ncomms 11459

Wang, Y., Billon, C., Walker, J. K., and Burris, T. P. (2016). Therapeutic effect of a synthetic ROR $\alpha / \gamma$ agonist in an animal model of autism. ACS Chem. Neurosci. 7, 143-148

Wang, W., Li, C., Chen, Q., van der Goes, M.-S., Hawrot, J., Yao, A. Y., et al. (2017). Striatopallidal dysfunction underlies repetitive behavior in Shank3-deficient model of autism. J. Clin. Invest. 127, 1978-1990. doi: 10.1172/JCI87997

Wang, X., McCoy, P. A., Rodriguiz, R. M., Pan, Y., Je, H. S., Roberts, A. C., et al. (2011). Synaptic dysfunction and abnormal behaviors in mice lacking major isoforms of Shank3. Hum. Mol. Genet. 20, 3093-3108. doi: $10.1093 / \mathrm{hmg} / \mathrm{ddr} 212$

Wang, S., Tan, N., Zhu, X., Yao, M., Wang, Y., Zhang, X., et al. (2018). Sh3rf2 haploinsufficiency leads to unilateral neuronal development deficits and autistic-like behaviors in mice. Cell Rep. 25, 2963.e6-2971.e6. doi: 10.1016/j. celrep.2018.11.044

Wang, Y., Zeng, C., Li, J., Zhou, Z., Ju, X., Xia, S., et al. (2018), PAK2 haploinsufficiency results in synaptic cytoskeleton impairment and autism-related behavior. Cell Rep. 24, 2029-2041. doi: 10.1016/j.celrep.2018. 07.061

Way, S. W., McKenna, J. III., Mietzsch, U., Reith, R. M., Wu, H. C.-J., and Gambello, M. J. (2009). Loss of Tsc2 in radial glia models the brain pathology 
of tuberous sclerosis complex in the mouse. Hum. Mol. Genet. 18, 1252-1265. doi: 10.1093/hmg/ddp025

Weeber, E. J., Jiang, Y.-H., Elgersma, Y., Varga, A. W., Carrasquillo, Y., Brown, S. E., et al. (2003). Derangements of hippocampal calcium/calmodulindependent protein kinase II in a mouse model for Angelman mental retardation syndrome. J. Neurosci. 23, 2634-2644. doi: 10.1523/JNEUROSCI.23-07-02 634.2003

Welch, J. M., Lu, J., Rodriguiz, R. M., Trotta, N. C., Peca, J., Ding, J.-D., et al. (2007). Cortico-striatal synaptic defects and OCD-like behaviours in Sapap3mutant mice. Nature 448, 894-900. doi: 10.1038/nature06104

Whitehouse, C. M., and Lewis, M. H. (2015). Repetitive behavior in neurodevelopmental disorders: clinical and translational findings. Behav. Anal. 38, 163-178. doi: 10.1007/s40614-015-0029-2

Whitehouse, C. M., Curry-Pochy, L. S., Shafer, R., Rudy, J., and Lewis, M. H. (2017). Reversal learning in C58 mice: modeling higher order repetitive behavior. Behav. Brain Res. 332, 372-378. doi: 10.1016/j.bbr.2017.06.014

Whitney, E. R., Kemper, T. L., Bauman, M. L., Rosene, D. L., and Blatt, G. J. (2008). Cerebellar Purkinje cells are reduced in a subpopulation of autistic brains: a stereological experiment using calbindin-D28k. Cerebellum 7, 406-416. doi: 10.1007/s12311-008-0043-y

Wilhelm, M., Kukekov, N. V., Schmit, T. L., Biagas, K. V., Sproul, A. A., Gire, S., et al. (2012). Sh3rf2/POSHER protein promotes cell survival by ring-mediated proteasomal degradation of the c-Jun N-terminal kinase scaffold POSH (Plenty of SH3s) protein. J. Biol. Chem. 287, 2247-2256. doi: 10.1074/jbc.M111. 269431

Wilkes, B., and Lewis, M. (2018). The neural circuitry of restricted repetitive behavior: magnetic resonance imaging in neurodevelopmental disorders and animal models. Neurosci. Biobehav. Rev. 92, 152-171. doi: 10.1016/j.neubiorev. 2018.05.022

Willatt, L., Cox, J., Barber, J., Cabanas, E. D., Collins, A., Donnai, D., et al. (2005). 3q29 microdeletion syndrome: clinical and molecular characterization of a new syndrome. Am. J. Hum. Genet. 77, 154-160. doi: 10.1086/431653

Wöhr, M., Orduz, D., Gregory, P., Moreno, H., Khan, U., Vörckel, K. J., et al. (2015). Lack of parvalbumin in mice leads to behavioral deficits relevant to all human autism core symptoms and related neural morphofunctional abnormalities. Transl. Psychiatry 5:e525. doi: 10.1038/tp.2015.19

Wöhr, M., Roullet, F. I., and Crawley, J. N. (2011). Reduced scent marking and ultrasonic vocalizations in the BTBR $\mathrm{T}+\mathrm{tf} / \mathrm{J}$ mouse model of autism. Genes Brain Behav. 10, 35-43. doi: 10.1111/j.1601-183X.2010.00582.x

Wöhr, M., Silverman, J. L., Scattoni, M. L., Turner, S. M., Harris, M. J., Saxena, R., et al. (2013). Developmental delays and reduced pup ultrasonic vocalizations but normal sociability in mice lacking the postsynaptic cell adhesion protein neuroligin2. Behav. Brain Res. 251, 50-64. doi: 10.1016/j.bbr.2012.07.024

Wolmarans, D. W., Brand, L., Stein, D. J., and Harvey, B. H. (2013). Reappraisal of spontaneous stereotypy in the deer mouse as an animal model of obsessive-compulsive disorder (OCD): response to escitalopram treatment and basal serotonin transporter (SERT) density. Behav. Brain Res. 256, 545-553. doi: 10.1016/j.bbr.2013.08.049

Won, H., Lee, H.-R., Gee, H. Y., Mah, W., Kim, J.-I., Lee, J., et al. (2012). Autisticlike social behaviour in Shank2-mutant mice improved by restoring NMDA receptor function. Nature 486, 261-265. doi: 10.1038/nature11208

Wong, M., Ess, K. C., Uhlmann, E. J., Jansen, L. A., Li, W., Crino, P. B., et al. (2003). Impaired glial glutamate transport in a mouse tuberous sclerosis epilepsy model. Ann. Neurol. 54, 251-256. doi: 10.1002/ana.10648

Wong, D. F., Ricaurte, G., Gründer, G., Rothman, R., Naidu, S., Singer, H., et al. (1998). Dopamine transporter changes in neuropsychiatric disorders. Adv. Pharmacol. 42, 219-223. doi: 10.1016/s1054-3589(08)60732-2

Woo, J., Kwon, S.-K., Choi, S., Kim, S., Lee, J.-R., Dunah, A. W., et al. (2009). Trans-synaptic adhesion between NGL-3 and LAR regulates the formation of excitatory synapses. Nat. Neurosci. 12, 428-437. doi: 10.1038/nn.2279

Wu, K., Hanna, G. L., Rosenberg, D. R., and Arnold, P. D. (2012). The role of glutamate signaling in the pathogenesis and treatment of obsessive-compulsive disorder. Pharmacol. Biochem. Behav. 100, 726-735. doi: 10.1016/j.pbb.2011. 10.007

Wurzman, R., Forcelli, P. A., Griffey, C. J., and Kromer, L. F. (2015). Repetitive grooming and sensorimotor abnormalities in an Ephrin-A knockout model for autism spectrum disorders. Behav. Brain Res. 278, 115-128. doi: 10.1016/j.bbr. 2014.09.012
Xu, H.-Y., Liu, Y.-J., Xu, M.-Y., Zhang, Y.-H., Zhang, J.-X., and Wu, Y.-J. (2012). Inactivation of the bed nucleus of the stria terminalis suppresses the innate fear responses of rats induced by the odor of cat urine. Neuroscience 221, 21-27. doi: $10.1016 /$ j.neuroscience.2012.06.056

Xu, J., Marshall, J. J., Fernandes, H. B., Nomura, T., Copits, B. A., Procissi, D., et al. (2017). Complete disruption of the kainate receptor gene family results in corticostriatal dysfunction in mice. Cell Rep. 18, 1848-1857. doi: 10.1016/j. celrep.2017.01.073

$\mathrm{Xu}, \mathrm{T}$., and Pandey, S. C. (2000). Cellular localization of serotonin $2 \mathrm{~A}\left(5 \mathrm{HT}_{2 \mathrm{~A}}\right)$ receptors in the rat brain. Brain Res. Bull. 51, 499-505. doi: 10.1016/s03619230(99)00278-6

Yamaguchi, Y., and Pasquale, E. B. (2004). Eph receptors in the adult brain. Curr. Opin. Neurobiol. 14, 288-296. doi: 10.1016/j.conb.2004. 04.003

Yan, Q., Rammal, M., Tranfaglia, M., and Bauchwitz, R. (2005). Suppression of two major Fragile X syndrome mouse model phenotypes by the mGluR5 antagonist MPEP. Neuropharmacology 49, 1053-1066. doi: 10.1016/j.neuropharm.2005. 06.004

Yang, M., Bozdagi, O., Scattoni, M. L., Wöhr, M., Roullet, F. I., Katz, A. M., et al. (2012). Reduced excitatory neurotransmission and mild autism-relevant phenotypes in adolescent Shank3 null mutant mice. J. Neurosci. 32, 6525-6541. doi: 10.1523/JNEUROSCI.6107-11.2012

Yau, S., Bettio, L., Vetrici, M., Truesdell, A., Chiu, C., Chiu, J., et al. (2018). Chronic minocycline treatment improves hippocampal neuronal structure, NMDA receptor function and memory processing in fMRI knockout mice. Neurobiol. Dis. 113, 11-22. doi: 10.1016/j.nbd.2018.01.014

Yilmazer-Hanke, D. M., Roskoden, T., Zilles, K., and Schwegler, H. (2003). Anxiety-related behavior and densities of glutamate, $\mathrm{GABA}_{\mathrm{A}}$, acetylcholine and serotonin receptors in the amygdala of seven inbred mouse strains. Behav. Brain Res. 145, 145-159. doi: 10.1016/s0166-4328(03) 00107-4

Yu, Y., Chaulagain, A., Pedersen, S. A., Lydersen, S., Leventhal, B. L., Szatmari, P., et al. (2020). Pharmacotherapy of restricted/repetitive behavior in autism spectrum disorder:a systematic review and meta-analysis. BMC Psychiatry 20:121. doi: 10.1186/s12888-020-2477-9

Yu, X., Taylor, A. M., Nagai, J., Golshani, P., Evans, C. J., Coppola, G., et al. (2018). Reducing astrocyte calcium signaling in vivo alters striatal microcircuits and causes repetitive behavior. Neuron 99, 1170.e9-1187.e9. doi: 10.1016/j.neuron. 2018.08.015

Yu, X., Wang, G., Gilmore, A., Yee, A. X., Li, X., Xu, T., et al. (2013). Accelerated experience-dependent pruning of cortical synapses in ephrin-A2 knockout mice. Neuron 80, 64-71. doi: 10.1016/j.neuron.2013.07.014

Yue, C., and Yaari, Y. (2006). Axo-somatic and apical dendritic Kv7/M channels differentially regulate the intrinsic excitability of adult rat CA1 pyramidal cells. J. Neurophysiol. 95, 3480-3495. doi: 10.1152/jn.01333.2005

Yuen, R. K., Merico, D., Bookman, M., Howe, J. L., Thiruvahindrapuram, B., Patel, R. V., et al. (2017). Whole genome sequencing resource identifies 18 new candidate genes for autism spectrum disorder. Nat. Neurosci. 20, 602-611. doi: $10.1038 / \mathrm{nn} .4524$

Zablotsky, B., Black, L. I., Maenner, M. J., Schieve, L. A., Danielson, M. L., Bitsko, R. H., et al. (2019). Prevalence and trends of developmental disabilities among children in the United States: 2009-2017. Pediatrics 144:e20190811. doi: 10.1542/peds.2019-0811

Zamberletti, E., Gabaglio, M., Piscitelli, F., Brodie, J. S., Woolley-Roberts, M., Barbiero, I., et al. (2019). Cannabidivarin completely rescues cognitive deficits and delays neurological and motor defects in male Mecp2 mutant mice. J. Psychopharmacol. 33, 894-907. doi: 10.1177/02698811 19844184

Zandt, F., Prior, M., and Kyrios, M. (2007). Repetitive behaviour in children with high functioning autism and obsessive compulsive disorder. J. Autism Dev. Disord. 37, 251-259. doi: 10.1007/s10803-006-0158-2

Zeng, L.-H., Ouyang, Y., Gazit, V., Cirrito, J. R., Jansen, L. A., Ess, K. C., et al. (2007). Abnormal glutamate homeostasis and impaired synaptic plasticity and learning in a mouse model of tuberous sclerosis complex. Neurobiol. Dis. 28, 184-196. doi: 10.1016/j.nbd.2007.07.015

Zeng, L. H., Xu, L., Gutmann, D. H., and Wong, M. (2008). Rapamycin prevents epilepsy in a mouse model of tuberous sclerosis complex. Ann. Neurol. 63, 444-453. doi: 10.1002/ana.21331 
Zerbi, V., Ielacqua, G. D., Markicevic, M., Haberl, M. G., Ellisman, M. H., A-Bhaskaran, A., et al. (2018). Dysfunctional autism risk genes cause circuit-specific connectivity deficits with distinct developmental trajectories. Cereb. Cortex 28, 2495-2506. doi: 10.1093/cercor/ bhy046

Zhang, L., and Alger, B. E. (2010). Enhanced endocannabinoid signaling elevates neuronal excitability in fragile X syndrome. J. Neurosci. 30, 5724-5729. doi: 10.1523/JNEUROSCI.0795-10.2010

Zhang, W.-N., Bast, T., and Feldon, J. (2002). Effects of hippocampal N-methyl[D]-aspartate infusion on locomotor activity and prepulse inhibition: Differences between the dorsal and ventral hippocampus. Behav. Neurosci. 116, 72-84. doi: 10.1037/0735-7044.116.1.72

Zhang, C., Kalueff, A. V., and Song, C. (2019). Minocycline ameliorates anxietyrelated self-grooming behaviors and alters hippocampal neuroinflammation, GABA and serum cholesterol levels in female Sprague-Dawley rats subjected to chronic unpredictable mild stress. Behav. Brain Res. 363, 109-117. doi: 10.1016/j.bbr.2019.01.045

Zhang, Y. V., Ormerod, K. G., and Littleton, J. T. (2017). Astrocyte $\mathrm{Ca}^{2+}$ influx negatively regulates neuronal activity. eNeuro 4:ENEURO.0340-16.2017. doi: 10.1523/ENEURO.0340-16.2017

Zhou, M. S., Nasir, M., Farhat, L. C., Kook, M., Artukoglu, B. B., and Bloch, M. H. (2020). Meta-analysis: pharmacologic treatment of restricted and repetitive behaviors in autism spectrum disorders. J. Am. Acad. Child Adolesc. Psychiatry doi: 10.1016/j.jaac.2020.03.007 [Epub ahead of print].
Zhou, Y., Kaiser, T., Monteiro, P., Zhang, X., Van der Goes, M. S., Wang, D., et al. (2016). Mice with Shank3 mutations associated with ASD and schizophrenia display both shared and distinct defects. Neuron 89, 147-162. doi: 10.1016/j. neuron.2015.11.023

Zhou, L.-T., Ye, S.-H., Yang, H.-X., Zhou, Y.-T., Zhao, Q.-H., Sun, W.-W., et al. (2017). A novel role of fragile $\mathrm{X}$ mental retardation protein in pre-mRNA alternative splicing through RNA-binding protein 14. Neuroscience 349, 64-75. doi: 10.1016/j.neuroscience.2017.02.044

Zieba, J., Sinclair, D., Sebree, T., Bonn-Miller, M., Gutterman, D., Siegel, S., et al. (2019). Cannabidiol (CBD) reduces anxiety-related behavior in mice via an FMRP-independent mechanism. Pharmacol. Biochem. Behav. 181, 93-100. doi: 10.1016/j.pbb.2019.05.002

Conflict of Interest: The authors declare that the research was conducted in the absence of any commercial or financial relationships that could be construed as a potential conflict of interest.

Copyright (c) 2021 Gandhi and Lee. This is an open-access article distributed under the terms of the Creative Commons Attribution License (CC BY). The use, distribution or reproduction in other forums is permitted, provided the original author(s) and the copyright owner(s) are credited and that the original publication in this journal is cited, in accordance with accepted academic practice. No use, distribution or reproduction is permitted which does not comply with these terms. 